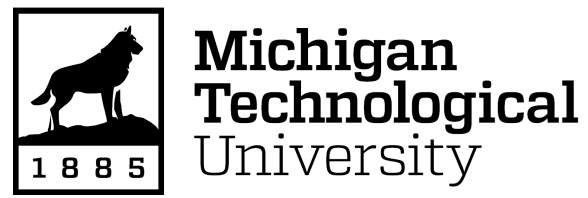

Michigan Technological University Digital Commons @ Michigan Tech

Dissertations, Master's Theses and Master's Reports

2021

Exploring Rapid Solidification and Equal Channel Angular Pressing in the Fabrication of Mg-Based Alloys for Medical Applications

Emily Tom

Michigan Technological University, eetom@mtu.edu

Copyright 2021 Emily Tom

Recommended Citation

Tom, Emily, "Exploring Rapid Solidification and Equal Channel Angular Pressing in the Fabrication of MgBased Alloys for Medical Applications", Open Access Master's Thesis, Michigan Technological University, 2021.

https://doi.org/10.37099/mtu.dc.etdr/1309

Follow this and additional works at: https://digitalcommons.mtu.edu/etdr

Part of the Biomedical Devices and Instrumentation Commons, and the Metallurgy Commons 


\title{
EXPLORING RAPID SOLIDIFICATION AND EQUAL CHANNEL ANGULAR PRESSING IN THE FABRICATION OF MG-BASED ALLOYS FOR MEDICAL APPLICATIONS
}

\author{
By \\ Emily Tom \\ A THESIS \\ Submitted in partial fulfillment of the requirements for the degree of \\ MASTER OF SCIENCE \\ In Materials Science and Engineering
}

MICHIGAN TECHNOLOGICAL UNIVERSITY

2021

(C) 2021 Emily Tom 
This thesis has been approved in partial fulfillment of the requirements for the Degree of MASTER OF SCIENCE in Materials Science and Engineering.

Department of Material Science and Engineering

Thesis Advisor: $\quad$ Dr. Jaroslaw Drelich

Committee Member: $\quad$ Dr. Stephen Kampe

Committee Member: Dr. Dan Seguin

Department Chair: $\quad$ Dr. Walter Milligan 


\section{Table of Contents}

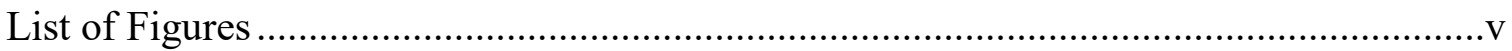

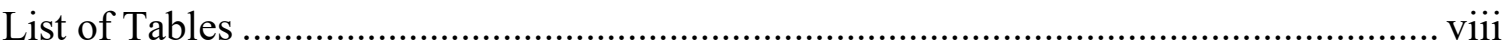

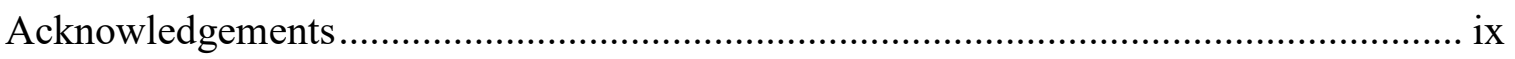

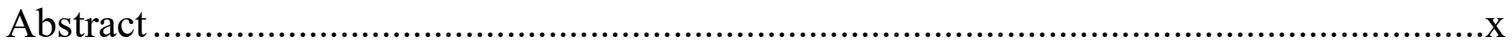

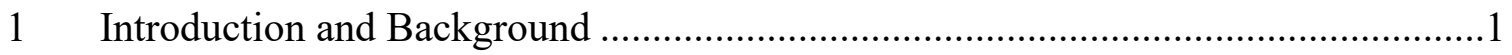

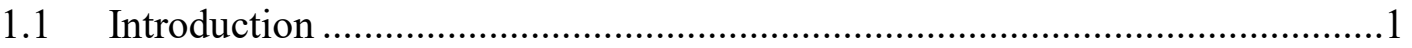

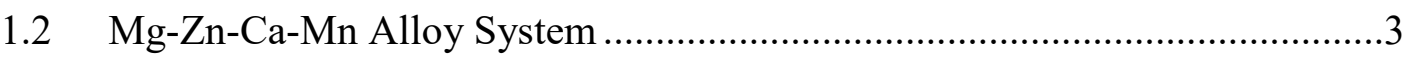

1.2.1 Magnesium as a Bioresorbable Metal.................................................

1.2.2 Effects of Alloy Elements on Magnesium ...........................................

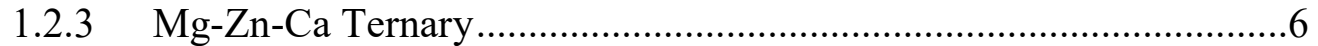

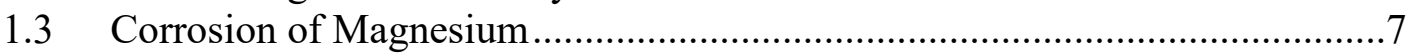

1.3.1 Corrosion in Mg-Zn-Ca Alloys........................................................ 9

1.4 Non-equilibrium Processing ......................................................................... 10

1.4.1 Rapid Solidification ..................................................................... 10

1.4.2 Equal Channel Angular Pressing ......................................................11

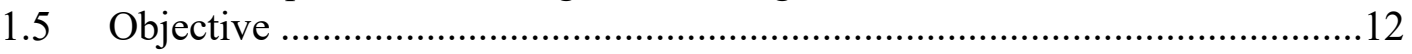

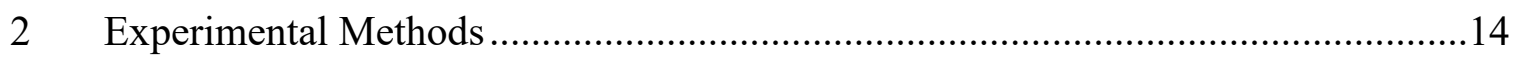

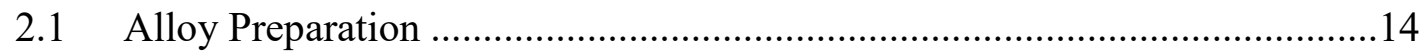

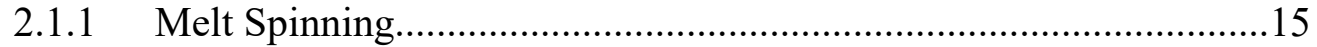

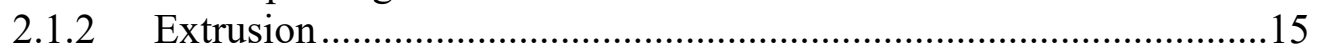

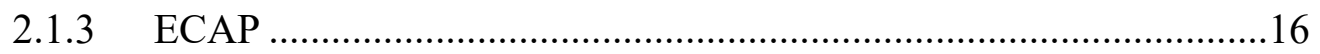

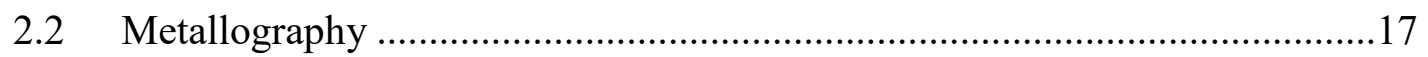

2.3 Corrosion Characterization......................................................................18

2.3.1 Electrochemical Corrosion Testing...................................................19

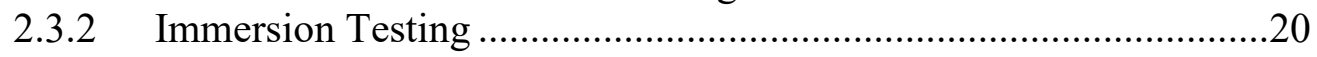

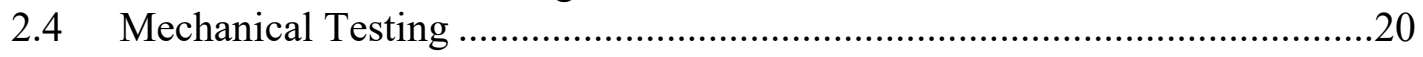

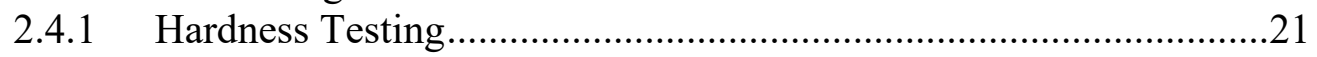

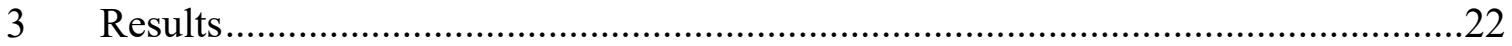

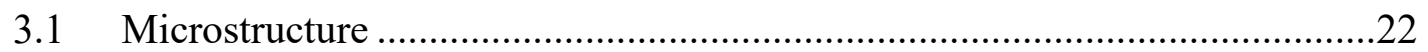

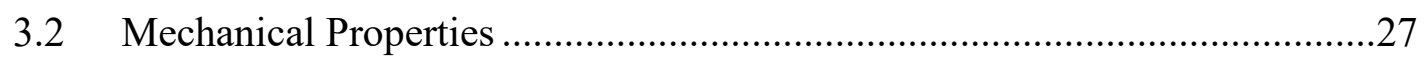

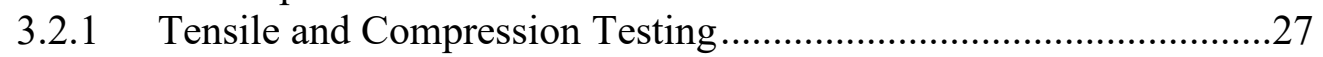

3.2.2 Hardness Testing...........................................................................

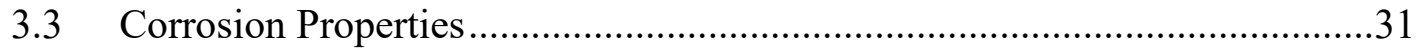

3.3.1 Electrochemical Testing................................................................. 31

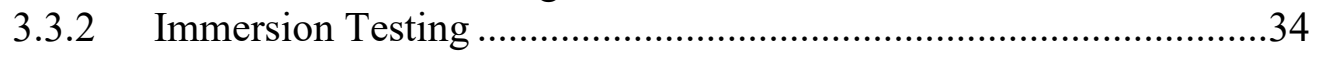

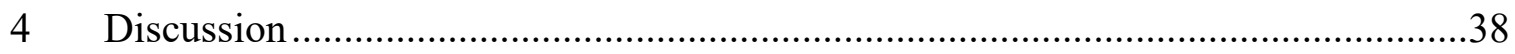

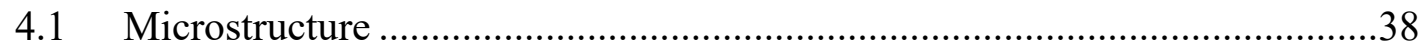




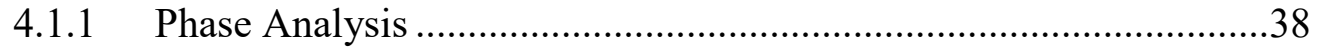

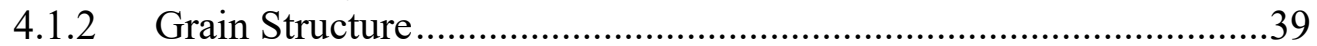

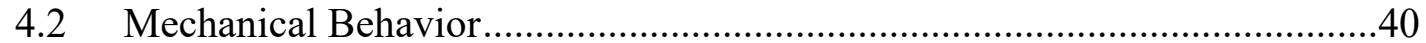

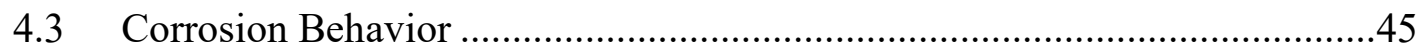

4.3.1 Potentiodynamic Tests ............................................................45

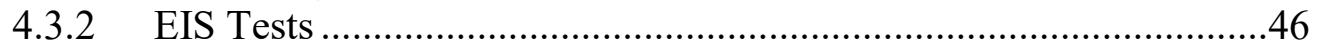

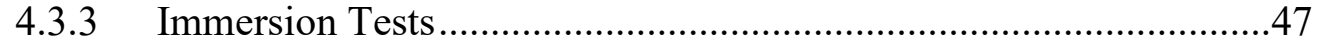

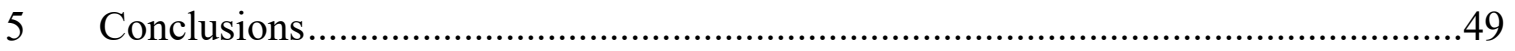

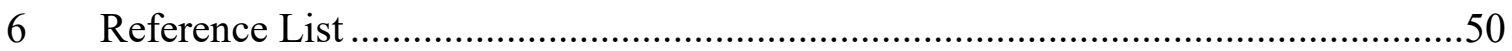

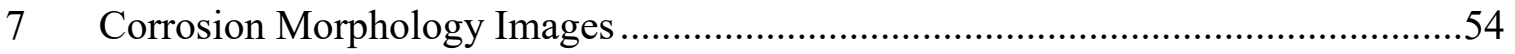

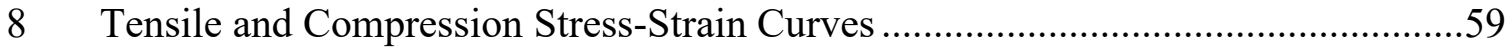

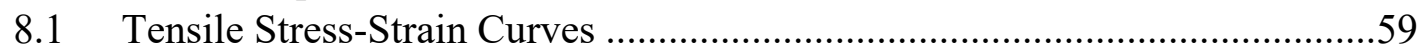

8.2 Compression Stress-Strain Curves ............................................................61

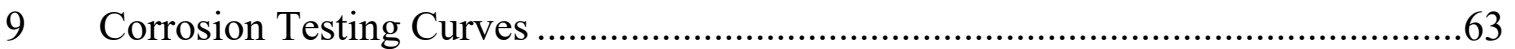

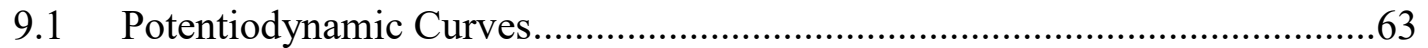

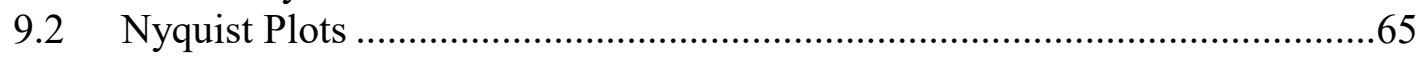

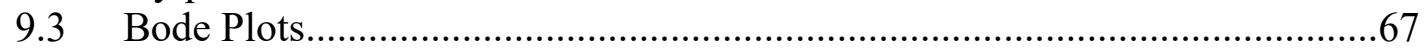

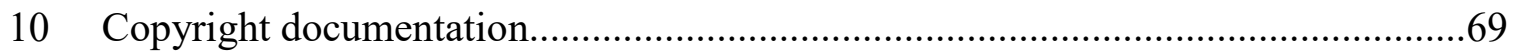




\section{List of Figures}

Figure 1.1. An ORIF implant used on a fractured humerus. From IStock, Tonpor Kasa [5]

Figure 1.2. Example timeline of bioresorbable implant degradation. Adapted from Zhao et al. [14].

Figure 1.3. Magnesium-zinc phase diagram generated in Thermo-Calc 2021a using the TCMG6 database.

Figure 1.4. Magnesium-calcium binary phase diagram generated in Thermo-Calc 2021a using the TCMG6 database.

Figure 1.5. Phase diagram of $\mathrm{Mg}-\mathrm{Zn}-\mathrm{Ca}$ alloys for $\mathrm{Mg}-1.2 \mathrm{Ca}$ vs zinc, generated through Thermo-Calc $2021 \mathrm{~b}$ using the TCMG6 database.

Figure 1.6. Schematic of biocorrosion of magnesium. Reproduced with permission from [18], 2014, Elsevier.

Figure 1.7. Schematic of a melt spinning process from a front view. 11

Figure 1.8. Schematic of an ECAP die viewed through the cross section. .12

Figure 2.1. (a) A whole view of the melt spinner set up, (b) close up of the graphite crucible and copper wheel, and (c) melt spun ribbons produced from melt spinning. Scale bars in inches.

Figure 2.2. (a) Extrusion die set up which the induction coil wraps around for heating, (b) magnesium cans which are packed with ribbons for consolidation through extrusion, and (c) produced extruded rod of consolidated ribbons..

Figure 2.3. (a) Front view of the ECAP die, (b) top view with heater cartridge placement, and (c) ECAP billets. Scale bars in inches

Figure 2.4. Conventional 3-electrode corrosion cell set up.

Figure 2.5. (a) Immersion test samples and (b) immersion samples inserted into HBSS..20

Figure 2.6. (a) Tensile test samples and (b) compression test samples.

Figure 3.1. BSE SEM images of Mg-1.2Zn-0.8Ca-0.2Mn (a) RS and (b) ECAP alloys, and $\mathrm{Mg}-1.8 \mathrm{Zn}-0.8 \mathrm{Ca}-0.2 \mathrm{Mn}$ (c) RS and (d) ECAP alloys along the extrusion and ECAP direction. Green arrows indicate $\mathrm{Ca}_{2} \mathrm{Mg}_{6} \mathrm{Zn}_{3}$ intermetallics and blue arrows indicate $\mathrm{Mg}_{2} \mathrm{Ca}$ intermetallics and the extrusion and ECAP direction runs from left to right.

Figure 3.2. SEM-EDS spectra for the precipitates pointed out by (a) the green arrows and (b) the blue arrows.

Figure 3.3. XRD patterns for Mg-1.2Zn-0.8Ca-0.2Mn (blue) and $\mathrm{Mg}-1.8 \mathrm{Zn}-0.8 \mathrm{Ca}-0.2 \mathrm{Mn}$ (red) alloys. Figure $3.3 \mathrm{~b}$ is the zoomed in pattern highlighted by the black box in figure 3.3a. 
Figure 3.4. Optical micrographs of the etched alloys with grain size distribution histograms.

Figure 3.5. Tensile stress-strain curves for RS and ECAP Mg-1.2Zn-0.8Ca-0.2Mn and $\mathrm{Mg}-1.8 \mathrm{Zn}-0.8 \mathrm{Ca}-0.2 \mathrm{Mn}$ alloys.

Figure 3.6. Fracture surfaces of (a) RS (SE SEM image) and (b) ECAP (BSE SEM image with EDS spectra) Mg-1.8Zn-0.8Ca-0.2Mn tensile samples.

Figure 3.7. Compressive stress-strain curves for RS and ECAP Mg-1.2Zn-0.8Ca-0.2Mn and $\mathrm{Mg}-1.8 \mathrm{Zn}-0.8 \mathrm{Ca}-0.2 \mathrm{Mn}$ alloys

Figure 3.8. Fracture surfaces of (a) RS (SE SEM image) and (b) ECAP (BSE SEM image) $\mathrm{Mg}-1.8 \mathrm{Zn}-0.8 \mathrm{Ca}-0.2 \mathrm{Mn}$ compression samples.

Figure 3.9. Potentiodynamic curves for RS and ECAP Mg-1.2Zn-0.8Ca- $0.2 \mathrm{Mn}$ and $\mathrm{Mg}-$ $1.8 \mathrm{Zn}-0.8 \mathrm{Ca}-0.2 \mathrm{Mn}$ alloys.

Figure 3.10. Nyquist plot from EIS testing of Mg-1.2Zn-0.8Ca-0.2Mn and Mg-1.8Zn0.8Ca-0.2Mn RS and ECAP alloys.

Figure 3.11. Bode plot from EIS testing of Mg-1.2Zn-0.8Ca- $0.2 \mathrm{Mn}$ and $\mathrm{Mg}-1.8 \mathrm{Zn}-$ $0.8 \mathrm{Ca}-0.2 \mathrm{Mn}$ RS and ECAP alloys.

Figure 3.12. Weight loss of Mg-1.2Zn-0.8Ca- $0.2 \mathrm{Mn}$ (blue) and $\mathrm{Mg}-1.8 \mathrm{Zn}-0.8 \mathrm{Ca}-0.2 \mathrm{Mn}$ (red) RS (triangles) and RS+ECAP (squares) alloys.

Figure 3.13. Surface morphology of cleaned samples immersed for 2 and 10 days of RS and ECAP Mg-1.5Zn-1.2Ca-0.4Mn and $\mathrm{Mg}-2.2 \mathrm{Zn}-1.2 \mathrm{Ca}-0.4 \mathrm{Mn}$ alloys.

Figure 3.14. BSE SEM images of cross sections of immersion samples immersed for 2 and 10 days showing the evolution of the $\mathrm{Mg}(\mathrm{OH})_{2}$ and $\mathrm{Ca}-\mathrm{P}$ hydroxyapatite layers.

Figure 4.1. Melt spun ribbon of $\mathrm{Mg}-1.8 \mathrm{Zn}-0.8 \mathrm{Ca}-0.2 \mathrm{Mn}$ showing columnar grain structure forming above the small grains formed along the wheel surface.

Figure 4.2.(a) RS and (b) ECAP Mg-1.8Zn-0.8Ca0.2Mn compression samples after testing.

Figure 7.1. BSE SEM images of the exposed surfaces of $\mathrm{Mg}-1.2 \mathrm{Zn}-0.8 \mathrm{Ca}-0.2 \mathrm{Mn}$ for 2, 5, 10 , and 15 day immersion times.

Figure 7.2. BSE SEM images of the exposed surfaces of Mg-1.8Zn-0.8Ca-0.2Mn for 2, 5, 10 , and 15 day immersion times.

Figure 7.3. BSE SEM images of the side profiles of $\mathrm{Mg}-1.2 \mathrm{Zn}-0.8 \mathrm{Ca}-0.2 \mathrm{Mn}$ for $2,5,10$, and 15 day immersion times.

Figure 7.4. BSE SEM images of the side profiles of Mg-1.8Zn-0.8Ca-0.2Mn for 2, 5, 10, and 15 day immersion times. .58

Figure 8.1. Tensile curves of the three RS Mg-1.2Zn-0.8Ca-0.2Mn samples. 59

Figure 8.2. Tensile curves of the three ECAP Mg-1.2Zn-0.8Ca-0.2Mn samples. .59 
Figure 8.3. Tensile curves for the three RS Mg-1.8Zn-0.8Ca-0.2Mn samples tested......60

Figure 8.4. Tensile curves for the three ECAP Mg-1.8Zn-0.8Ca-0.2Mn samples tested..60

Figure 8.5. Compression stress-strain curves of the three RS Mg-1.2Zn- $0.8 \mathrm{Ca}-0.2 \mathrm{Mn}$ samples tested.

Figure 8.6. Compression stress-strain curves of the three ECAP Mg-1.2Zn-0.8ca-0.2Mn samples tested.

Figure 8.7. Compression stress-strain curves of the three RS Mg-1.8Zn-0.8Ca- $0.2 \mathrm{Mn}$ samples tested.

Figure 8.8. Compression stress-strain curves of the three ECAP Mg-1.8Zn-0.8Ca-0.2Mn samples tested.

Figure 9.1. Potentiodynamic curves for three RS Mg-1.2Zn-0.8Ca-0.2Mn. .63

Figure 9.2. Potentiodynamic curves for three ECAP Mg-1.2Zn-0.8Ca-0.2Mn. .63

Figure 9.3. Potentiodynamic curves of the three RS Mg-1.8Zn-0.8Ca-0.2Mn alloys tested.

Figure 9.4. Potentiodynamic curves of the three ECAP Mg-1.8Zn-0.8Ca-0.2Mn alloys tested. .64

Figure 9.5. Nyquist Plot for RS Mg-1.2Zn-0.8Ca-0.2Mn. .......................................65

Figure 9.6. Nyquist plots for ECAP Mg-1.2Zn-0.8Ca-0.2Mn......................................65

Figure 9.7. Nyquist plots for RS Mg-1.8Zn-0.8Ca-0.2Mn. ........................................66

Figure 9.8. Nyquist plots for ECAP Mg-1.8Zn-0.8Ca-0.2Mn...................................66

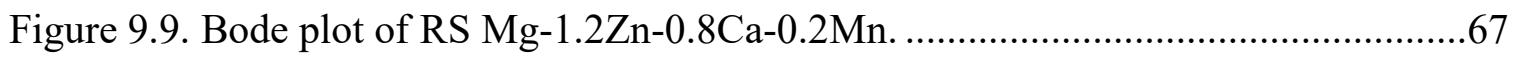

Figure 9.10. Bode plot of ECAP Mg-1.2Zn-0.8Ca-0.2Mn .........................................67

Figure 9.11. Bode plots of RS Mg-1.8Zn-0.8Ca-0.2Mn...........................................68

Figure 9.12. Bode plots of ECAP Mg-1.8Zn-0.8Ca-0.2Mn. .......................................68 


\section{List of Tables}

Table 1.1. Mechanical properties of bone tissue compared to various biomedical implant materials.

Table 1.2. Tensile Strengths and corrosion rates of pure magnesium compared to REEMg alloys.

Table 1.3.Tensile strengths and corrosion rates (calculated from potentiodynamic corrosion tests in Hank's solution) of bioresorbable magnesium alloys with $\mathrm{Ca}$, $\mathrm{Zn}$ and $\mathrm{Mn}$

Table 2.1. ICP results of four measured samples from the Mg-1.5Zn-1.2Ca- $0.4 \mathrm{Mn}$ and $\mathrm{Mg}-2.2 \mathrm{Zn}-1.2 \mathrm{Ca}-0.4 \mathrm{Mn}$ alloys. All compositions are in $\mathrm{wt} \%$.

Table 2.2. Abrasive steps and time used for metallography sample preparation. ..............18

Table 2.3. Composition of Hank's balanced salt solution. ..............................................19

Table 3.1. Average grain size of the Mg-1.2Zn- $0.8 \mathrm{Ca}-0.2 \mathrm{Mn}$ and $\mathrm{Mg}-1.8 \mathrm{Zn}-0.8 \mathrm{Ca}-$ $0.2 \mathrm{Mn}$ alloys after $\mathrm{RS}$ and ECAP processing.

Table 3.2. Tensile mechanical properties of RS and ECAP Mg-1.2Zn- $0.8 \mathrm{Ca}-0.2 \mathrm{Mn}$ and $\mathrm{Mg}-1.8 \mathrm{Zn}-0.8 \mathrm{Ca}-0.2 \mathrm{Mn}$.

Table 3.3. Compression mechanical properties of $\mathrm{Mg}-1.2 \mathrm{Zn}-0.8 \mathrm{Ca}-0.2 \mathrm{Mn}$ and $\mathrm{Mg}$ $1.8 \mathrm{Zn}-0.8 \mathrm{Ca}-0.2 \mathrm{Mn}$.

Table 3.4. Table of Vickers microhardness taken on the surfacess perpendicular (transverse) and parallel (longitudinal) to the extrusion and ECAP direction........31

Table 3.5. Electrochemical potential, current density, and corrosion rates calculated from Tafel extrapolation for $\mathrm{Mg}-1.2 \mathrm{Zn}-0.8 \mathrm{Ca}-0.2 \mathrm{Mn}$ and $\mathrm{Mg}-1.8 \mathrm{Zn}--0.8 \mathrm{Ca}-0.2 \mathrm{Mn} \mathrm{RS}$ and ECAP alloys. 32

Table 4.1. Properties of melt spun and ECAP processed Mg- $\mathrm{Zn}-\mathrm{Ca}$ alloys 


\section{Acknowledgements}

I would like to thank Dr. Jaroslaw Drelich for supporting me in my undergraduate research and into my master's degree. The guidance I have received from you during my master's degree has taught me invaluable skills that will follow me throughout my career as a scientist.

I am thankful to the various MTU MSE professors and staff whose assistance and expertise have played critical roles in the success of my project: Dr. Dan Seguin, Dr. Stephen Kampe, Paul Fraley, and Liz Miller.

Brendan Treanore, Matt Hasbrouck, Kyle Hrubecky, and Henry Summers, the countless hours spent in the lab and writing would not have been possible without your help and friendship.

Lastly, I would like to thank my family and partner, Jeremy Guinn, for being a constant support system to me over the years.

Research reported in this thesis was supported in part by funding provided by the National Aeronautics and Space Administration (NASA), under award number NNX15AJ20H, Michigan Space Grant Consortium (MSGC), and the National Heart, Lung, And Blood Institute of the National Institutes of Health (NIH) under Award Number R01HL144739. The content is solely the responsibility of the author and does not necessarily represent the official view of either MSGC or NIH. The support of the Materials Science and Engineering Department at Michigan Tech is also appreciated, as was the staff assistance and instrumentation expertise provided by the Applied Chemical and Morphological Analysis Laboratory at Michigan Tech. 


\section{Abstract}

The development of magnesium bioresorbable implants has become increasingly popular due to the increased need for temporary implants and magnesium's excellent biocompatibility and suitable elastic modulus. Even though magnesium is an excellent candidate, when alloyed with other metals magnesium's corrosion rate becomes too rapid for bioresorbable medical applications. The investigation into novel processing techniques to control the formation of precipitates to improve mechanical strength and ductility as well as corrosion rates has become of interest. This work investigates the combination of two nonequilibrium processing techniques, rapid solidification (RS) and equal channel angular pressing (ECAP), and the effects it has on the strength, ductility, and corrosion properties of two $\mathrm{Mg}-\mathrm{Zn}-\mathrm{Ca}-\mathrm{Mn}$ alloys: $\mathrm{Mg}-1.2 \mathrm{Zn}-0.8 \mathrm{Ca}-0.2 \mathrm{Mn}$ and $\mathrm{Mg}-$ $1.8 \mathrm{Zn}-0.8 \mathrm{Ca}-0.2 \mathrm{Mn}$. In the course of this study, it was found that the formulated alloys possessed flaws from processing responsible for a premature mechanical failure of samples. As the result, alloys' ductility improvements from processing could not be explored. Additionally, ECAP processing caused the dynamic precipitation of nano-size $\mathrm{Ca}_{2} \mathrm{Mg}_{6} \mathrm{Zn}_{3}$ precipitates which contributed to an increase in strength from the RS consolidated state after ECAP was performed. Corrosion testing also determined that ECAP caused an increase in corrosion rate of formulated alloys. 


\section{Introduction and Background}

\subsection{Introduction}

Bioresorbable implants are breaking the current paradigm of materials engineering as they are being designed to assimilate to a biological environment and degrade over time in the host body [1]. They have become increasingly popular as the need for temporary implants increases in the medical interventional world [2]. For example, open reduction with internal fixation (ORIF) of bone fractures (Figure 1.1) has been turning towards bioresorbable implants from the typical non-resorbable permanent alloys made of either titanium alloys, cobalt-chrome alloys, or stainless steels since these orthopedic implants are not needed once the healing process has completed [2,3]. Patients with permanent implants can suffer late onset pain, have the persistent risk of infection, and experience possible complications with future secondary surgeries, all of which could be eliminated by the use of bioresorbable materials [1]. If implants made of current permanent metals were to corrode, these alloys would present the risk of introducing potentially toxic elements such as chromium and aluminum into the body [4]. Bioresorbable metals have been sought after as a replacement for permanent load bearing implants since current biomedical polymers have too low of strength and ceramics are too brittle for load bearing applications $[2,4]$.

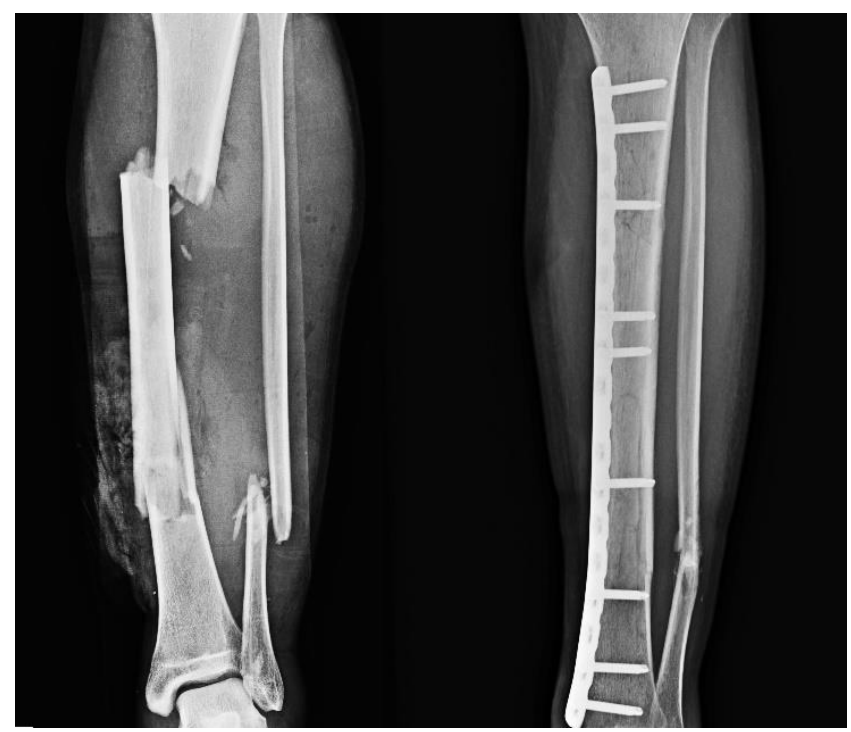

Figure 1.1. An ORIF implant used on a fractured humerus. From IStock, Tonpor Kasa [5].

Metals as bioresorbable materials have become highly popular for orthopedic load bearing applications since they have a tensile strength more suited to maintain the strength needed for the duration of the fractured bone healing process [1-3]. Specifically, magnesium has garnered much attention in the bioresorbable orthopedic materials field, as it is one of the most abundant nutrients in the body and has an elastic modulus close to that of bone $[4,6]$. Though pure magnesium is an attractive candidate for load bearing implants, its corrosion rate $(\sim 1-3 \mathrm{~mm} / \mathrm{y}$ [7]) is too high to maintain the 
mechanical strength of the implant until the bone is able to carry load again (Figure 1.2) [8]. Alloying magnesium with other elements has been a popular route to increase its strength and reduce the corrosion rate. Rare earth elements (REEs) including Nb, Gd, Y, $\mathrm{Dy}, \mathrm{La}, \mathrm{Ce}$ are the most extensively explored alloying elements in formulation of bioresorbable $\mathrm{Mg}$ alloys [9]. This is because REEs can improve mechanical strength, creep resistance and corrosion resistance of $\mathrm{Mg}$ [9]. However, their presence in bioresorbable implants and associated potential long-term toxicity effects on the human body is highly debated [10-12]. Alloying elements which are naturally found or essential in the body such as zinc, calcium, manganese, and strontium have become increasingly popular to avoid the use of REEs [6,12].The only downside in using these alloying elements is that these alloying additions do not have as drastic effects on the improvement of the corrosion rate and mechanical strength of magnesium compared to REEs, in low concentrations [13].

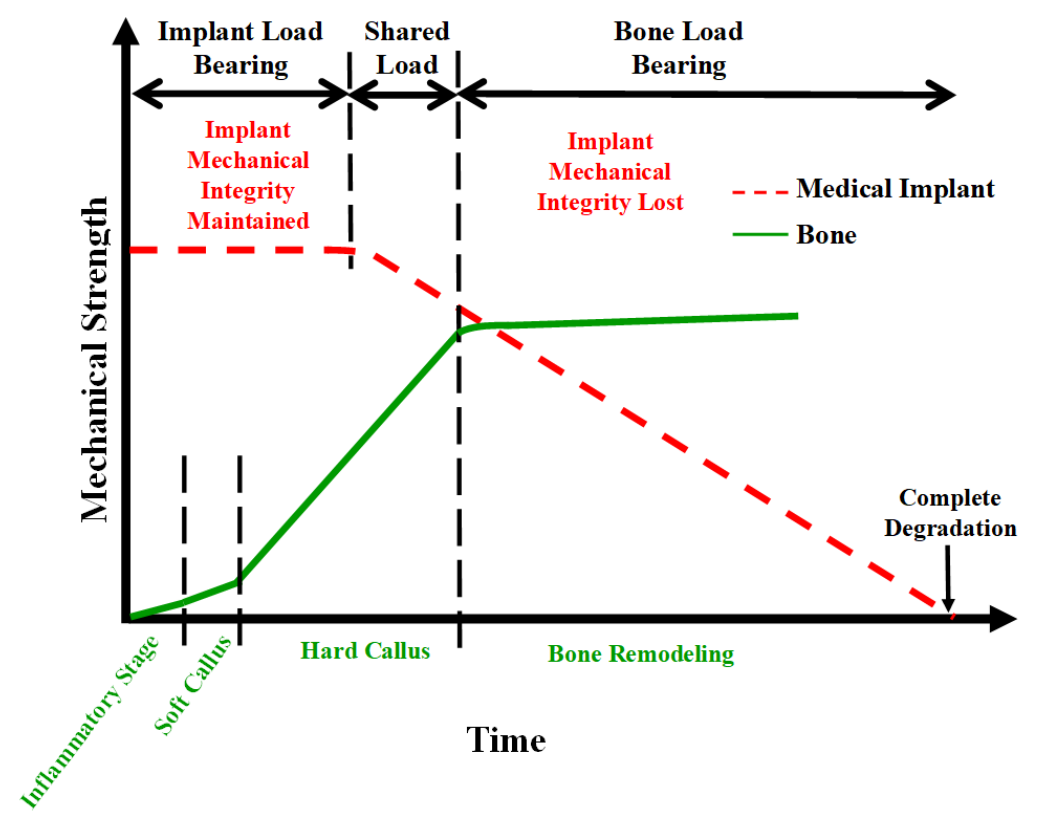

Figure 1.2. Example timeline of bioresorbable implant degradation. Adapted from Zhao et al. [14].

The use of novel non-equilibrium processing techniques is being investigated to further improve the mechanical strength and corrosion rate of magnesium alloys with essential nutrients as alloying elements. Rapid solidification (RS) via melt spinning has been shown to greatly improve the corrosion rate of magnesium alloys due to prevention of coarse precipitate formation and more homogeneous microstructure [15]. A severe plastic deformation technique (SPD), equal channel angular pressing (ECAP), has been proven to improve the ductility and corrosion rate of magnesium alloys through massive grain refinement $[8,16]$. Combining these two processing techniques has been poorly explored in the past despite the potential to produce alloys with superior corrosion resistance and mechanical strength and ductility compared to alloys processed using one of these individual processes. 


\subsection{Mg-Zn-Ca-Mn Alloy System}

\subsubsection{Magnesium as a Bioresorbable Metal}

Magnesium is considered an essential element for the human body to function as it plays a role in many enzymatic reactions ranging from muscle contraction to neuronal control [14]. This makes it an attractive metal for bioresorbable implants. Magnesium has a standard electrochemical potential of about $-2.37 \mathrm{~V}$, meaning it readily releases $\mathrm{Mg}^{2+}$ ions, or degrades, when exposed to a corrosive environment [4]. Using a metal that readily releases a by-product that is a vital nutrient to the body can help lower the risk of long term effects caused by the implant and potentially speed up the healing process [4]. Additionally, magnesium's elastic modulus closely matches the elastic modulus of bone (Table 1.1), which eliminates stress shielding effects caused by a mismatch of elastic moduli between the implant and bone [2,3]. As shown in Table 1.1, a significant mismatch exists between load bearing permanent implant materials such as stainless steel, titanium alloys, and cobalt-chrome alloys used today [2,4]. Eliminating stress shielding is especially important for load bearing medical implants as stress shielding can reduce the remodeling of bone leading to a longer healing time [17]. Even though pure magnesium has an elastic modulus suitable for a medical implant, the strength of magnesium is too weak to maintain the mechanical strength (Table 1.1) for the duration of the healing period even after subjection to processing (extrusion, forging, cold working) such that alloying additions have been turned to, to address this shortcoming $[3,18,19]$.

Table 1.1. Mechanical properties of bone tissue compared to various biomedical implant materials.

\begin{tabular}{ccccc}
\hline Material & $\begin{array}{c}\text { Elastic } \\
\text { Modulus } \\
(\mathbf{G P a})\end{array}$ & $\begin{array}{c}\text { Tensile } \\
\text { Strength } \\
\text { (MPa) }\end{array}$ & $\begin{array}{c}\text { Compressive } \\
\text { Strength } \\
(\text { MPa) }\end{array}$ & Reference \\
\hline $\begin{array}{c}\text { Cortical Bone } \\
\text { Pure Magnesium } \\
\quad \text { (as-cast) }\end{array}$ & $7-30$ & $164-240$ & $100-230$ & {$[14]$} \\
$\begin{array}{c}\text { Stainless Steel } \\
\text { 316L }\end{array}$ & 41 & 87 & 40 & {$[14]$} \\
$\quad 193$ & $540-1000$ & $480-620$ & {$[14]$} \\
$\begin{array}{c}\text { Ti6Al4V } \\
\text { (wrought) }\end{array}$ & 114 & $860-965$ & $896-1172$ & {$[14]$} \\
Co-Cr Alloys & 240 & $900-1540$ & $450-1000$ & {$[14]$} \\
\hline
\end{tabular}

\subsubsection{Effects of Alloy Elements on Magnesium}

The biocompatibility and the effects possible alloying elements have on the physical properties of magnesium needs to be considered when selecting alloying elements. Rare earth elements (REEs) have been a popular alloying option for increasing the strength of magnesium and maintaining a relatively low corrosion rate compared to more common alloying elements $[12,18]$. In general, both binary and more complex Mg alloys with 
REEs have typically reduced corrosion resistance (WE43 and JDBM in Table 1.2) [9]; the REEs retard the galvanic corrosion when added to other Mg binary alloys [9]. However, the long-term effects of REEs within the human body have not been studied extensively and there is a lack of consensus about the safe dosage of REEs [11]. Due to these biocompatibility concerns, alloying magnesium with elements that are present in the body such as zinc and calcium have become the target of research [6].

Table 1.2. Tensile Strengths and corrosion rates of pure magnesium compared to REEMg alloys.

\begin{tabular}{cccc}
\hline Material & $\begin{array}{c}\text { Tensile } \\
\text { Strength } \\
(\mathbf{M P a})\end{array}$ & $\begin{array}{c}\text { Corrosion Rate } \\
(\mathbf{m m} / \mathbf{y r})\end{array}$ & Reference \\
\hline Pure magnesium & 87 & 0.8 & {$[14,20]$} \\
Mg- 10Gd & 131 & 1.0 & {$[21]$} \\
Mg-2Y & 189 & 6.6 & {$[22]$} \\
Mg-10Dy & 130 & 3.0 & {$[23]$} \\
WE43* & 295 & 0.3 & {$[24]$} \\
JDBM** & 307 & 0.1 & {$[24]$} \\
\hline
\end{tabular}

*Mg-3.94Y-2.29Nd-0.88Gd-0.32Zr

** Mg-3.09Nd-0.22Zn-0.44Zr

Zinc is an essential element in the human body and participates in numerous enzymatic processes [18]. It is also one of the most popular alloying elements in structural magnesium alloys due to its strengthening mainly through solid solution strengthening [1]. With small (1-4 wt\%) additions of zinc, magnesium's strength and ductility increases without a large decrease in corrosion resistance (Table 1.3) [18]. Small additions of zinc are most effective because the corrosion resistance of magnesium is maintained by preventing zinc-rich intermetallic precipitates from forming which are detrimental to the galvanic corrosion (Figure 1.3) [18].

Table 1.3.Tensile strengths and corrosion rates (calculated from potentiodynamic corrosion tests in Hank's solution) of bioresorbable magnesium alloys with $\mathrm{Ca}, \mathrm{Zn}$ and $\mathrm{Mn}$.

\begin{tabular}{cccc}
\hline Alloy & $\begin{array}{c}\text { Ultimate Tensile } \\
\text { Strength } \\
(\mathbf{M P a})\end{array}$ & $\begin{array}{c}\text { Corrosion } \\
\text { Rate } \\
(\mathbf{m m} / \mathbf{y r})\end{array}$ & Reference \\
\hline $\mathrm{Mg}-1 \mathrm{Ca}$ & $105 \pm 4$ & $3.2 \pm 0.5$ & {$[25]$} \\
$\mathrm{Mg}-1 \mathrm{Zn}$ & 188 & 2.0 & {$[26]$} \\
$\mathrm{Mg}-2 \mathrm{Zn}-1 \mathrm{Ca}$ & $143 \pm 5$ & $2.4 \pm 0.3$ & {$[25]$} \\
$\mathrm{Mg}-2 \mathrm{Zn}-2 \mathrm{Ca}-0.5 \mathrm{Mn}$ & 169 & 1.8 & {$[27]$} \\
\hline
\end{tabular}




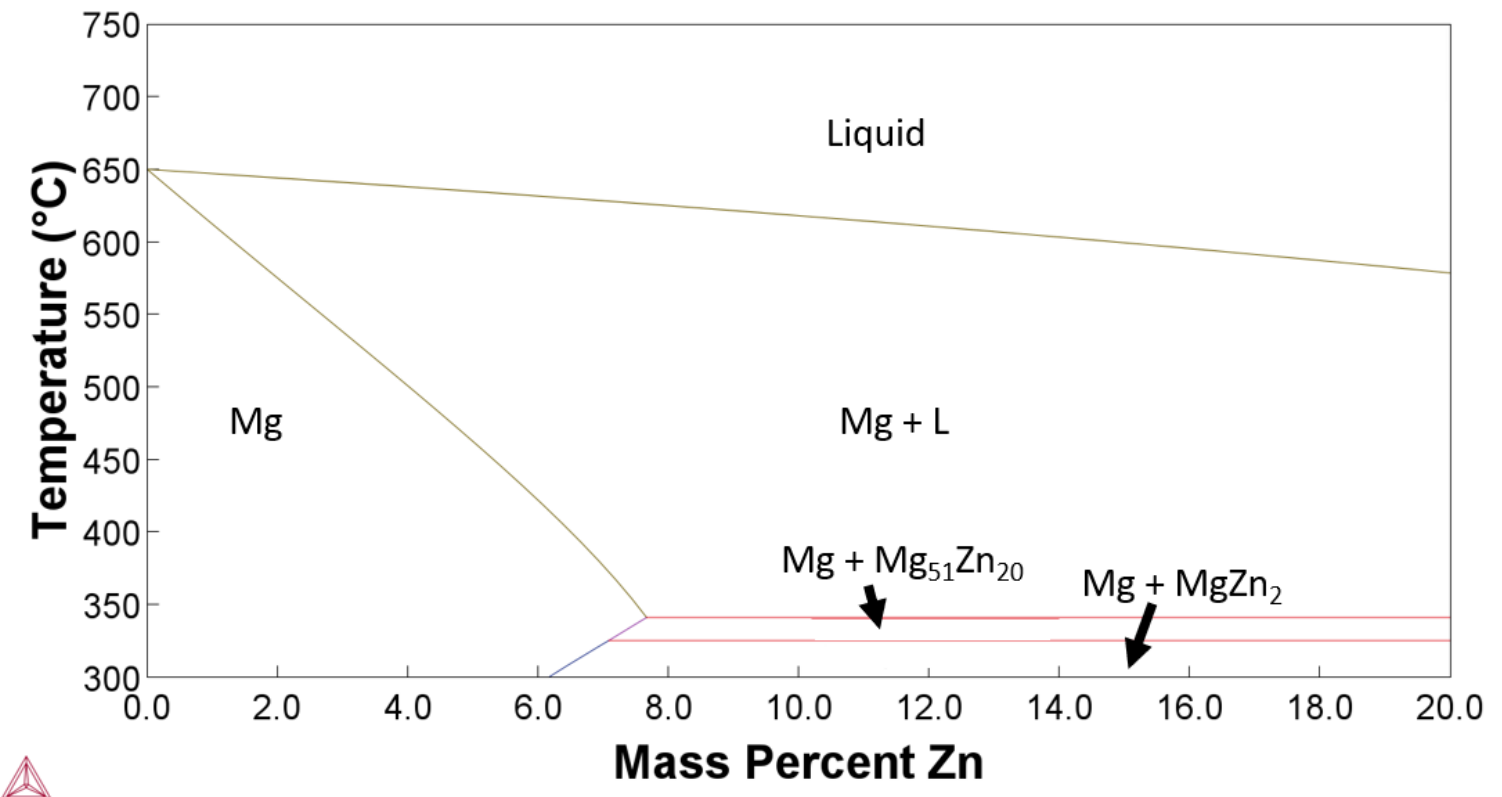

Figure 1.3. Magnesium-zinc phase diagram generated in Thermo-Calc 2021a using the TCMG6 database.

Calcium is another essential element in the body that can be alloyed with magnesium. Calcium's main function in the body is structural, as it is the main element that makes up bones $[18,28]$. As an alloying element in magnesium, calcium has a relatively low (1.34 $\mathrm{wt} \%)$ solubility so secondary intermetallic precipitates form $[1,4,28]$. The $\mathrm{Mg}_{2} \mathrm{Ca}$ intermetallics in $\mathrm{Mg}-\mathrm{Ca}$ binary alloys precipitate along grain boundaries serving as a strengthener and grain refiner (Figure 1.4) [18]. In Mg-Ca binary alloys, calcium content is kept low $(\sim 1 \mathrm{wt} \%)$ since more calcium leads to a higher amount of $\mathrm{Mg}_{2} \mathrm{Ca}$ which decreases the corrosion resistance of the alloy drastically through microgalvanic coupling (Table 1.3) [18]. 


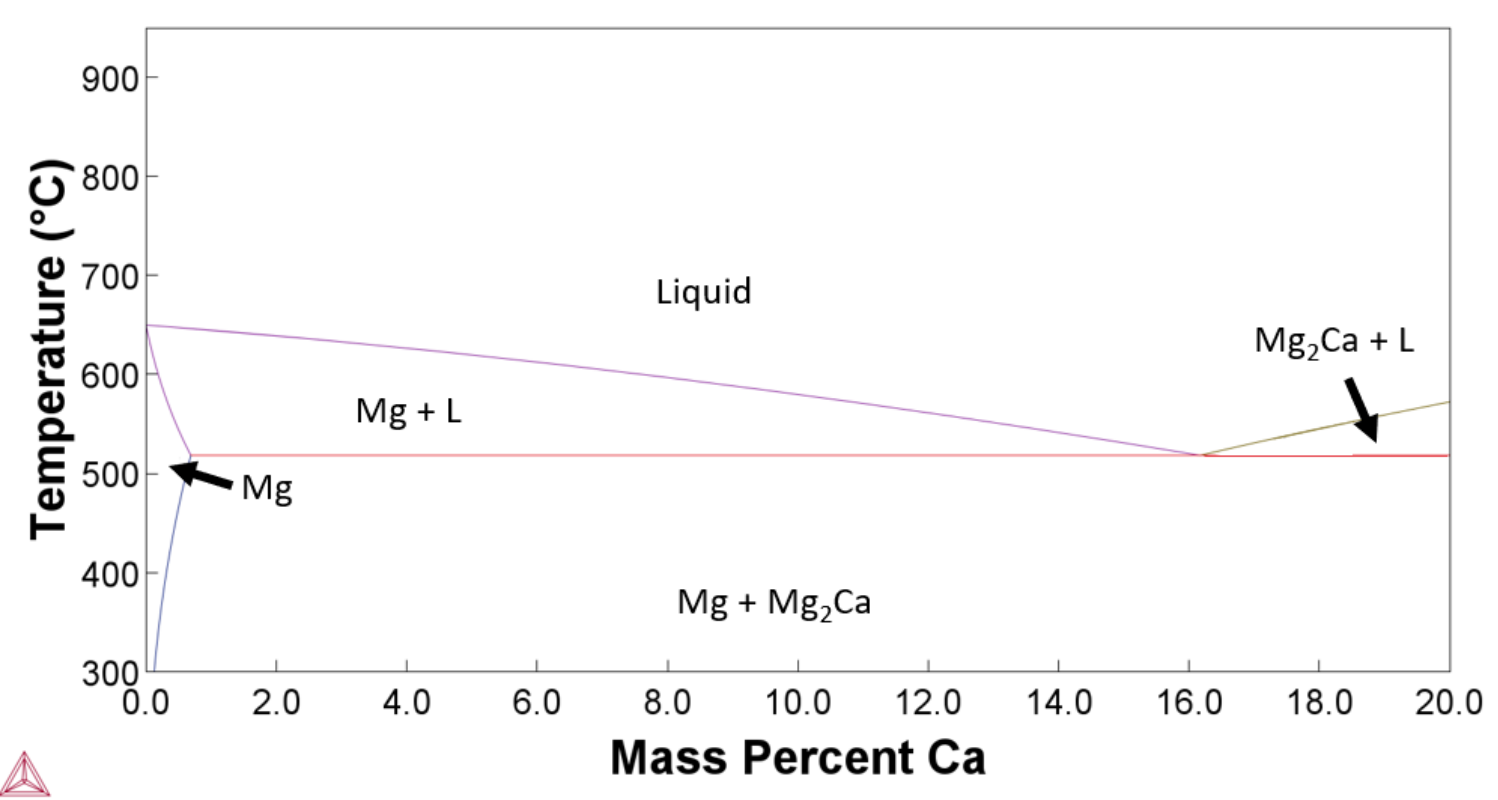

Figure 1.4. Magnesium-calcium binary phase diagram generated in Thermo-Calc 2021a using the TCMG6 database.

Manganese is a powerful grain refiner in magnesium alloys [1]. It is typically used when thermomechanical processing is employed to improve the strength and ductility of magnesium alloys through grain refinement [1]. It is considered biocompatible because a trace amount is found within the body that acts as an enzyme activator $[1,29]$.

\subsubsection{Mg-Zn-Ca Ternary}

Additions of zinc and calcium improve the mechanical strength (UTS) of magnesium (Table 1.3) [25]. Increasing the amount of each of these alloying additions can cause a decrease in the corrosion resistance of magnesium. By combining these two elements in one alloy, the improvement in mechanical and corrosion properties is achieved while keeping their concentrations relatively low (Table 1.3) $[18,28,30]$. The improvements in mechanical strength and ductility are due to the formation of $\mathrm{Mg}_{2} \mathrm{Ca}$ and $\mathrm{Ca}_{2} \mathrm{Mg}_{6} \mathrm{Zn}_{3}$ intermetallics when zinc and calcium additions are kept at concentrations below $3 \mathrm{wt} \%$ (Figure 1.5) [19,25]. The $\mathrm{Ca}_{2} \mathrm{Mg}_{6} \mathrm{Zn}_{3}$ intermetallic forms a eutectic phase, $\left(\mathrm{Ca}_{2} \mathrm{Mg}_{6} \mathrm{Zn}_{3}+\right.$ $\alpha-\mathrm{Mg}$ ), if the $\mathrm{Zn} / \mathrm{Ca}$ ratio is above 1.2 while $\mathrm{Ca}_{2} \mathrm{Mg}_{6} \mathrm{Zn}_{3}$ forms the eutectic $\left(\mathrm{Ca}_{2} \mathrm{Mg}_{6} \mathrm{Zn}_{3}+\mathrm{Mg}_{2} \mathrm{Ca}+\alpha-\mathrm{Mg}\right)$ if the $\mathrm{Zn} / \mathrm{Ca}$ ratio is below 1.2 [31]. Whether the $\mathrm{Zn} / \mathrm{Ca}$ ratio is above or below 1.2, both intermetallics contribute to improved strength of magnesium alloys. This ratio matters when considering the corrosion properties of the alloy due to the differences in electrochemical potentials between the intermetallics and magnesium matrix [19]. 


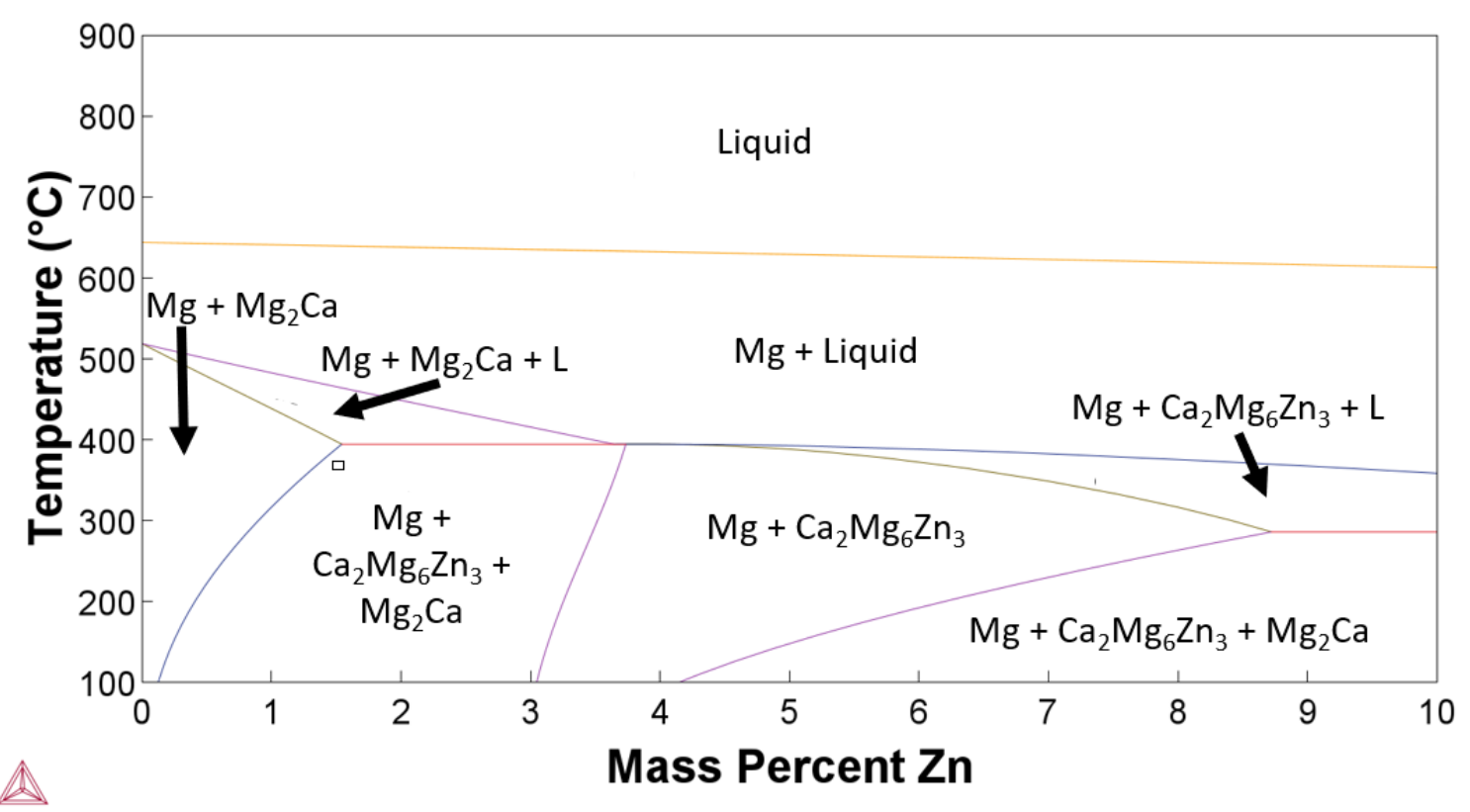

Figure 1.5. Phase diagram of $\mathrm{Mg}-\mathrm{Zn}-\mathrm{Ca}$ alloys for $\mathrm{Mg}-1.2 \mathrm{Ca}$ vs zinc, generated through Thermo-Calc 2021b using the TCMG6 database.

\subsection{Corrosion of Magnesium}

Magnesium has one of the most negative electrochemical potentials $(-2.37 \mathrm{~V})$, which makes using magnesium more difficult in structural applications because it is so prone to corrosion. Magnesium's large, negative electrochemical potential indicates that magnesium readily corrodes (Equation 1.1). In aqueous solutions, including physiological fluids, magnesium reduces water (Equation 1.2) to form magnesium hydroxide $\left(\mathrm{Mg}(\mathrm{OH})_{2}\right)$ and hydrogen gas (Equation 1.3).

$\mathrm{Mg} \rightarrow \mathrm{Mg}^{2+}+2 \mathrm{e}^{-}$(anodic reaction)

Equation 1.1

$2 \mathrm{H}_{2} \mathrm{O}+2 \mathrm{e}^{-} \rightarrow \mathrm{H}_{2}+2 \mathrm{OH}^{-}$(cathodic reaction)

Equation 1.2

$\mathrm{Mg}(\mathrm{s})+2 \mathrm{H}_{2} \mathrm{O}(\mathrm{l}) \rightarrow \mathrm{Mg}(\mathrm{OH})_{2}(\mathrm{~s})+\mathrm{H}_{2}(\mathrm{~g})$

Equation 1.3

The magnesium hydroxide that forms combines with magnesium oxide on the exposed magnesium surface and acts as a corrosion barrier, decreasing the electrochemical potential between magnesium and the corrosive environment, and thus, slowing down the corrosion rate of magnesium (Figure 1.6b) [20,30]. Over the $\mathrm{Mg}(\mathrm{OH})_{2}$ layer, a calciumphosphate (Ca-P) hydroxyapatite layer forms from the $\mathrm{Ca}^{2+}$ and $\mathrm{PO}_{4}{ }^{3+}$ ions from the physiological fluid that further retards the corrosion rate of the $\mathrm{Mg}$ alloy (Figure 1.6c) $[18,20,30]$. These protective layer is so effective that ultra-high purity magnesium has an intrinsic corrosion rate of $0.3 \mathrm{~mm} / \mathrm{yr}$ [20]. Though ultra-high purity magnesium has a relatively slow corrosion rate, if any impurities are present in magnesium, the corrosion rate can rise by two orders of magnitude [20]. Trace impurities in magnesium such as Fe, 
$\mathrm{Ni}$, or $\mathrm{Cu}$ can increase the corrosion rate to higher than $15 \mathrm{~mm} / \mathrm{yr}$ in concentrations less than $0.02 \mathrm{wt} \%[20,30]$. This increase in corrosion rate is due to microgalvanic couples forming between magnesium and the impurities. These microgalvanic couples form due to the electrochemical potentials mismatch between magnesium and the impurities $[29,30]$. These microgalvanic couples center around these impurities which become cathodic sites that act as catalysts for electrochemical attacks [30]. These sites are centers of localized corrosion that accelerate the corrosion rate of the alloy by exposing a greater surface area to the corrosive environment $[29,30]$. The pits that form can also compromise the mechanical integrity of the alloy as they grow deeper into the surface [29]. As the amount of impurities, intentional or not, increases, the number of sites where localized corrosion occurs increases, leading to larger corrosion rates. The pits created from microgalvanic corrosion also start spreading laterally along the surface of the alloy. This lateral spread is due to the unique corrosion mechanisms of magnesium and as they spread laterally across the surface, the pits can connect with other site of corrosion which can undermine secondary phases and solute atoms on the surface [30]. Undermining the secondary phases or solute atoms creates larger pitting as they fall out of the surface (Figure 1.6d). This effect is more profound with secondary phases within the matrix because the removal of the secondary phase creates larger pits since they occupy a larger localized volume compared to a few grouped solute atoms within the matrix [30].
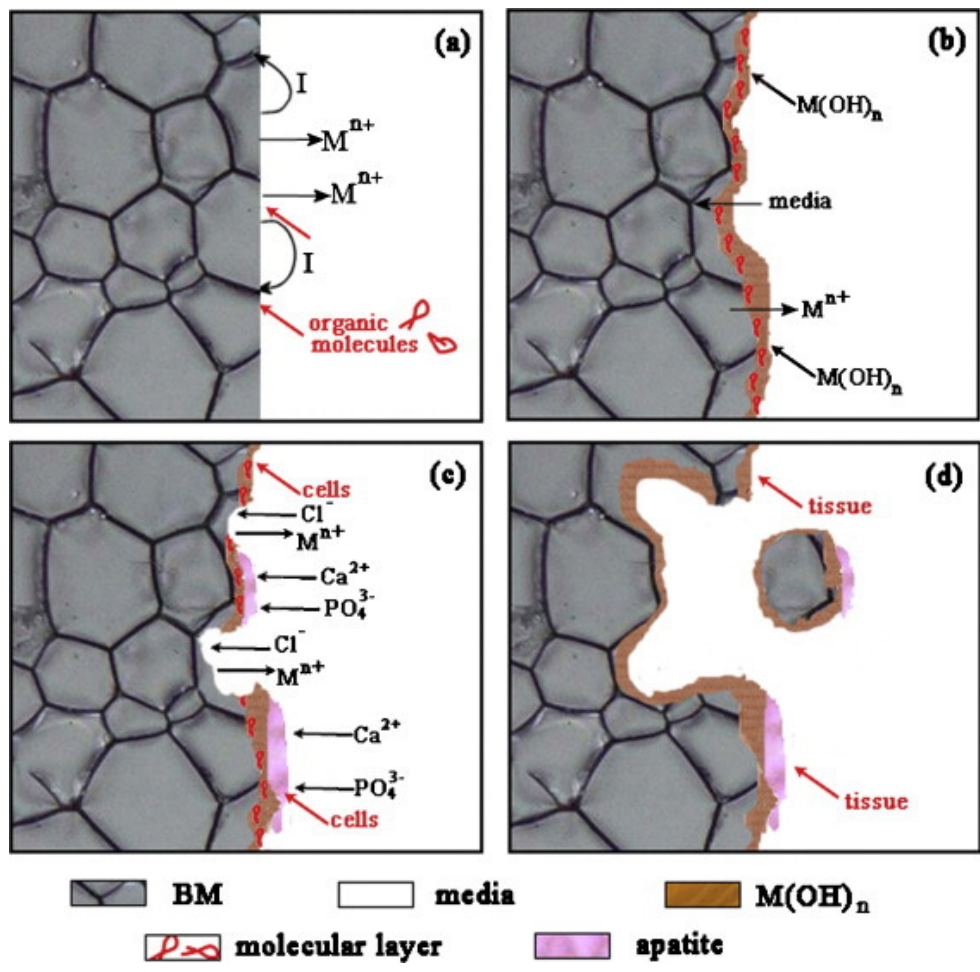

Figure 1.6. Schematic of biocorrosion of magnesium. Reproduced with permission from [18], 2014, Elsevier.

For bioresorbable applications, magnesium's large, negative electrochemical potential makes it an attractive candidate as it easily corrodes in vivo [29]. In physiological 
environments, the large concentration of $\mathrm{Cl}^{-}$ions reacts with the $\mathrm{Mg}(\mathrm{OH})_{2}$ protective layer that forms dissolving into $\mathrm{MgCl}_{2}$ and $\mathrm{OH}^{-}$ions (Equation 1.4) $[4,18,29]$. This leads to continuous corrosion of magnesium in vivo through localized corrosion where the protective layer becomes compromised [29].

$$
\mathrm{Mg}(\mathrm{OH})_{2}(\mathrm{~s})+2 \mathrm{Cl}^{-}(\mathrm{aq}) \rightarrow \mathrm{MgCl}_{2}(\mathrm{aq})+2 \mathrm{OH}^{-}(\mathrm{aq})
$$

Equation 1.4

Even though the $\mathrm{Mg}(\mathrm{OH})_{2}$ layer degrades in the presence of $\mathrm{Cl}^{-}$ions, the Ca-P hydroxyapatite layer forms on the remaining $\mathrm{Mg}(\mathrm{OH})_{2}$ layer which helps improve the corrosion resistance of the remaining magnesium and help make a bioresorbable implant more osteoconductive during healing $[4,18]$. Improving the corrosion resistance of magnesium for bioresorbable applications is imperative as high corrosion rates, not only compromise the mechanical integrity of the implant but also release hydrogen gas too fast for the body to reabsorb in the initial implantation stage until the protective layers form. The hydrogen gas bubbles that form can cause delays in tissue healing and possibly result in gas embolisms [6].

Corrosion resistance of magnesium can decrease with the addition of alloying elements, especially, when secondary precipitates are formed [30]. Minimizing the size and volume fraction of secondary precipitates can help further improve the corrosion resistance of magnesium alloys $[18,30]$. To achieve this, alloying additions can be kept close to or below their respective solubility limits within magnesium and the microstructure can be refined [18]. Keeping alloying additions lean minimizes the formation of secondary precipitates within the magnesium matrix reducing the size and number of cathodic sites forming microgalvanic couples. Refining the microstructure of magnesium and its alloys also improves the corrosion resistance through formation of a more homogeneous microstructure with finer secondary precipitates that are distributed more uniformly throughout the matrix $[8,15,18]$.

\subsubsection{Corrosion in Mg-Zn-Ca Alloys}

In the $\mathrm{Mg}-\mathrm{Zn}-\mathrm{Ca}$ alloy system, the ratio of zinc and calcium added affects the corrosion behavior of the alloy as this ratio determines the type of intermetallics formed. As stated in section 1.2.2, if the $\mathrm{Zn} / \mathrm{Ca}$ ratio is above 1.2 the eutectic $\left(\mathrm{Ca}_{2} \mathrm{Mg}_{6} \mathrm{Zn}_{3}+\alpha-\mathrm{Mg}\right)$ forms, but if the $\mathrm{Zn} / \mathrm{Ca}$ ratio is below 1.2 the eutectic $\left(\mathrm{Ca}_{2} \mathrm{Mg}_{6} \mathrm{Zn}_{3}+\mathrm{Mg}_{2} \mathrm{Ca}+\alpha-\mathrm{Mg}\right)$ forms [31]. It has been observed from corrosion analyses that $\mathrm{Mg}_{2} \mathrm{Ca}$ preferentially corrodes to the $\alpha$ $\mathrm{Mg}$ matrix and both $\mathrm{Mg}_{2} \mathrm{Ca}$ and $\alpha-\mathrm{Mg}$ preferentially corrode to $\mathrm{Ca}_{2} \mathrm{Mg}_{6} \mathrm{Zn}_{3}$ indicating that $\mathrm{Mg}_{2} \mathrm{Ca}$ has the lowest electrochemical potential and $\mathrm{Mg}_{2} \mathrm{Ca}_{6} \mathrm{Zn}_{3}$ has the highest [19]. Noting this, $\mathrm{Mg}_{2} \mathrm{Ca}$ dissolves before the magnesium matrix does, creating pits along the surface primed for localized corrosion but delaying the degradation of the matrix as it dissolves. Meanwhile, $\mathrm{Ca}_{2} \mathrm{Mg}_{6} \mathrm{Zn}_{3}$ temporarily blocks corrosion due to its lower electrochemical potential but still forms microgalvanic couples within the matrix that lead to undermining as corrosion progresses creating more pits along the surface of the alloy as precipitates fall out $[19,30]$. Since the additions of zinc and calcium offer magnesium bioresorbable alloys improved mechanical strength but need an improved corrosion resistance in physiological environments, different processing techniques are 
being explored to lower the corrosion rates without changing the chemistry of the alloy $[15,16,32]$.

\subsection{Non-equilibrium Processing}

Pure magnesium is not strong enough to be used in load bearing applications, even after processing. Alloying magnesium is necessary for the development of a viable bioresorbable magnesium implant at the possible cost of a decrease in corrosion resistance [18]. The microstructure of the alloys can be refined without changing the composition of magnesium alloys to help improve the corrosion resistance of the alloy $[8,15,18]$. Research has shown that in magnesium alloys, ultrafine-grained structures (UFG) enhance corrosion resistance compared to alloys processed conventionally that have coarser microstructures $[8,16]$. To achieve UFG, different processing techniques have been explored, from non-equilibrium casting to severe plastic deformation (SPD) $[15,16,33]$

\subsubsection{Rapid Solidification}

Rapid solidification (RS) is a group of techniques that utilize cooling rates above $10^{4} \mathrm{~K} / \mathrm{s}$ to cast alloys with a nonequilibrium microstructure [34]. The high cooling rates effectively increases the solubility of alloying elements within the magnesium matrix [34]. This also prevents coarse secondary phases and grains from growing so a refined microstructure can be achieved. In the Mg-Zn-Ca alloy system, RS processed alloys exhibited improved corrosion resistance and its uniformity compared to conventionally processed alloys [32]. This improved corrosion resistance was attributed to the more homogeneous microstructure produced from rapid solidification that had evenly dispersed, fine precipitates and a fine grain structure (grain size $=\sim 4 \mu \mathrm{m}$ ) [15].

One technique to achieve rapid solidification of an alloy, is melt spinning. Melt spinning is a process that uses a rotating copper wheel to rapidly cool metal that is ejected from a crucible on to it (Figure 1.7). The high heat transfer of copper allows the metal to cool rapidly when ejected which forms thin ribbons of metal that feature a nonequilibrium, supersaturated microstructure [34]. As discussed, this microstructure consists of fine grains and smaller precipitate size compared to that of a conventionally cast microstructure which produces $\mathrm{Mg}-\mathrm{Zn}-\mathrm{Ca}$ alloys with an increased corrosion resistance. 


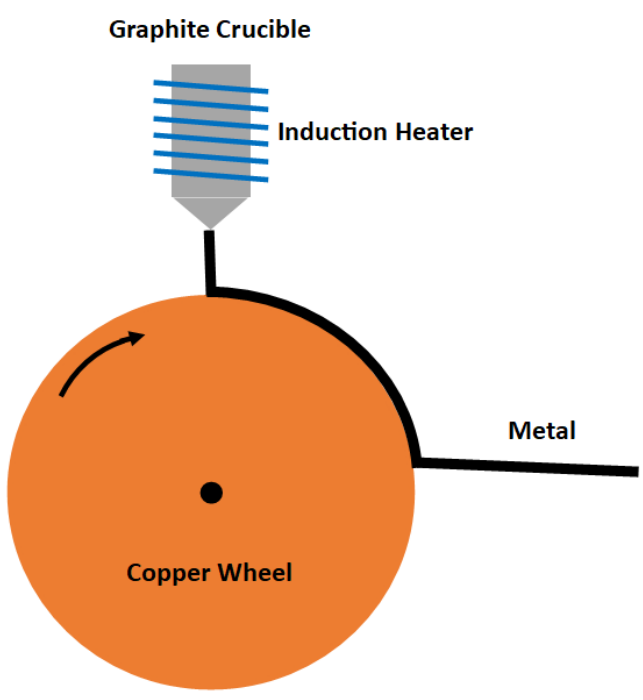

Figure 1.7. Schematic of a melt spinning process from a front view.

\subsubsection{Equal Channel Angular Pressing}

Severe plastic deformation (SPD) is a set of techniques which induce a large amount of mechanical strain to refine a microstructure through an extensive hydrostatic pressure without an extensive change in shape of the alloy [35]. The main staple of severe plastic deformation is that there is no significant change to the geometry of the sample such that subsequent passes can be performed to further refine the microstructure [35].

The most popular SPD technique is equal channel angular pressing (ECAP). ECAP consists of pushing a billet through two channels of identical cross-sectional areas that intersect at an angle (Figure 1.8). This change in direction introduces a large simple shear to the billet without changing the geometry of the billet allowing for multiple ECAP passes. The massive grain refinement that occurs during ECAP affects the corrosion and mechanical properties in magnesium alloys [8,33]. 


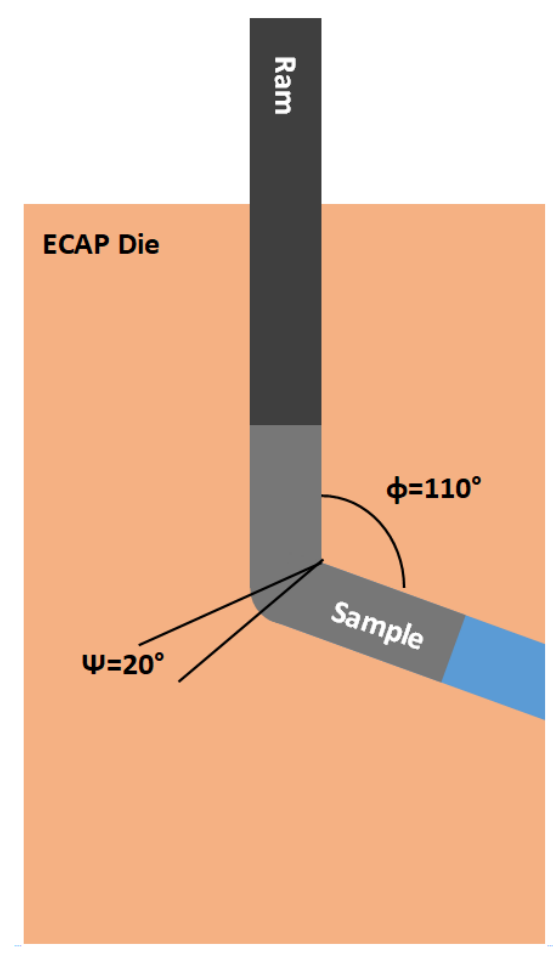

Figure 1.8. Schematic of an ECAP die viewed through the cross section.

In magnesium, since it has a hexagonal close packed (HCP) structure, the simple shear introduced during ECAP can cause dynamic recrystallization (DRX) to occur [35]. The massive grain refinement observed after multiple passes through ECAP is due to grain refinement through DRX mechanisms. As observed with rapid solidification, the refinement in microstructure improves corrosion resistance of magnesium alloys $[8,16]$. With ECAP though, the ductility of magnesium alloys are also improved. The texture of $\mathrm{Mg}$ alloys after ECAP processing weakens the strong basal texture of the $\{0001\}\langle 11 \overline{2} 0\rangle$ slip system parallel to the extrusion direction) that typically develops during extrusion [36]. This weakened texture and grain refinement allows a higher number of slip systems to activate upon loading, allowing yielding to occur before fracture and increasing the ductility of ECAP processed magnesium alloys $[8,35]$. Introducing more available slip systems in magnesium alloys is vital for improving the ductility since the magnesium HCP crystal structure only slips along the basal slip system at non-elevated temperatures [36]. This improvement in ductility is worth noting due to magnesium's reputation as a brittle metal, and by improving the ductility of the alloy, the chance of catastrophic failure during its lifetime decreases. This change in texture does also marginally compromises the strength of the alloy compared to conventionally extruded alloys [16].

\subsection{Objective}

Though the $\mathrm{Mg}-\mathrm{Zn}-\mathrm{Ca}$ has received an increasing amount of attention as a possible alloy for bioresorbable implants, alloys produced through conventional casting and processing methods still need improvement in mechanical and corrosion properties to be suitable for bioresorbable implants. This has led to the investigation of using nonequilibrium 
processing techniques to further improve the behavior of $\mathrm{Mg}-\mathrm{Zn}-\mathrm{Ca}$ alloys without changing the overall chemistry of the alloys. Rapid solidification and ECAP individually have shown promising results in improving the corrosion and mechanical behavior, respectively, but still need further improvement for use as bioresorbable implants [15,33]. To improve upon the results obtained through the two different processing techniques, the effects of combining rapid solidification and ECAP processing on $\mathrm{Mg}-\mathrm{Zn}-\mathrm{Ca}$ alloys have been explored.

Through this work the following hypothesis was also tested.

If $\mathrm{Mg}-\mathrm{Zn}$-Ca alloys are subjected to rapid solidification and then ECAP, then the mechanical ductility will be improved while maintaining the corrosion resistance produced through rapid solidification because ECAP processing introduces a homogenous ultrafine grain structure (UFG) that introduces more grains in a variety of orientations that makes more slip systems available to activate when loaded to allow a larger amount of yielding to occur while keeping precipitate size low to maintain the improved corrosion resistance from rapid solidification. 


\section{Experimental Methods}

\subsection{Alloy Preparation}

Two Mg-Zn-Ca alloys with trace amounts of Mn were prepared through two processing conditions: rapid solidification via melt spinning (designated RS for labeling) and rapid solidification via melt spinning followed by ECAP (designated ECAP for labeling). For alloy formulation commercially pure $\mathrm{Mg}(99.95 \%), \mathrm{Ca}(99.99 \%)$ (Alfa-Aesar, Inc), Zn (99.99\%) (Sigma-Alrich, Inc), and Mn (99.99\%) were used. A Mg-10Ca master alloy was prepared for the alloying process. The elemental compositions of the two alloys were measured through inductively coupled plasma-optical emission spectroscopy (ICP-OES) using a Perkin Elmer Optima 7000DV ICP-OES (Table 2.1). For this analysis, about 0.25 $\mathrm{g}$ of each alloy was dissolved in a 1:1:1 solution of water, nitric acid, and $\mathrm{HCl}$. The dissolved solution was then diluted with water.

Table 2.1. ICP results of four measured samples from the $\mathrm{Mg}-1.5 \mathrm{Zn}-1.2 \mathrm{Ca}-0.4 \mathrm{Mn}$ and $\mathrm{Mg}-2.2 \mathrm{Zn}-1.2 \mathrm{Ca}-0.4 \mathrm{Mn}$ alloys. All compositions are in $\mathrm{wt} \%$.

\begin{tabular}{ccc}
$\begin{array}{c}\text { Alloy } \\
\text { Target }\end{array}$ & Mg-1.5Zn-1.2Ca-0.4Mn & Mg-2.2Zn-1.2Ca-0.4Mn \\
\hline Zn & $1.25 \pm 0.04$ & $1.85 \pm 0.06$ \\
Ca & $0.82 \pm 0.06$ & $0.74 \pm 0.12$ \\
Mn & $0.18 \pm 0.07$ & $0.24 \pm 0.06$ \\
Fe & $0.023 \pm 0.001$ & $0.023 \pm 0.001$ \\
Ni & $0.0002 \pm 0.0003$ & $0.0002 \pm 0.0003$ \\
Cu & $0.002 \pm 0.0001$ & $0.004 \pm 0.003$ \\
Al & $0.037 \pm 0.001$ & $0.021 \pm 0.001$ \\
\hline
\end{tabular}




\subsubsection{Melt Spinning}

Alloys were remelted in a graphite crucible with a $1 \mathrm{~mm}$ orifice at $750^{\circ} \mathrm{C}$ under an argon atmosphere for melt spinning. The melt was then ejected onto a copper-beryllium wheel spinning at $1600 \mathrm{rpm}$ to create rapidly solidified ribbons (Figure 2.1a-b). The ribbons produced were about $50 \mu \mathrm{m}$ thick and $2 \mathrm{~mm}$ wide (Figure 2.1c).

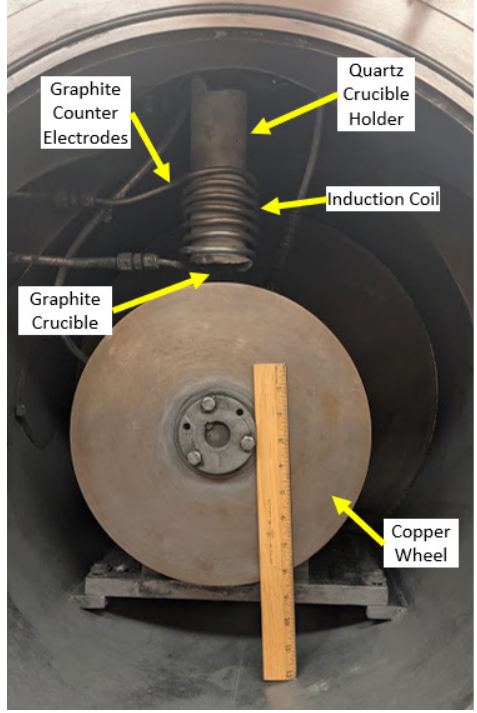

(a)

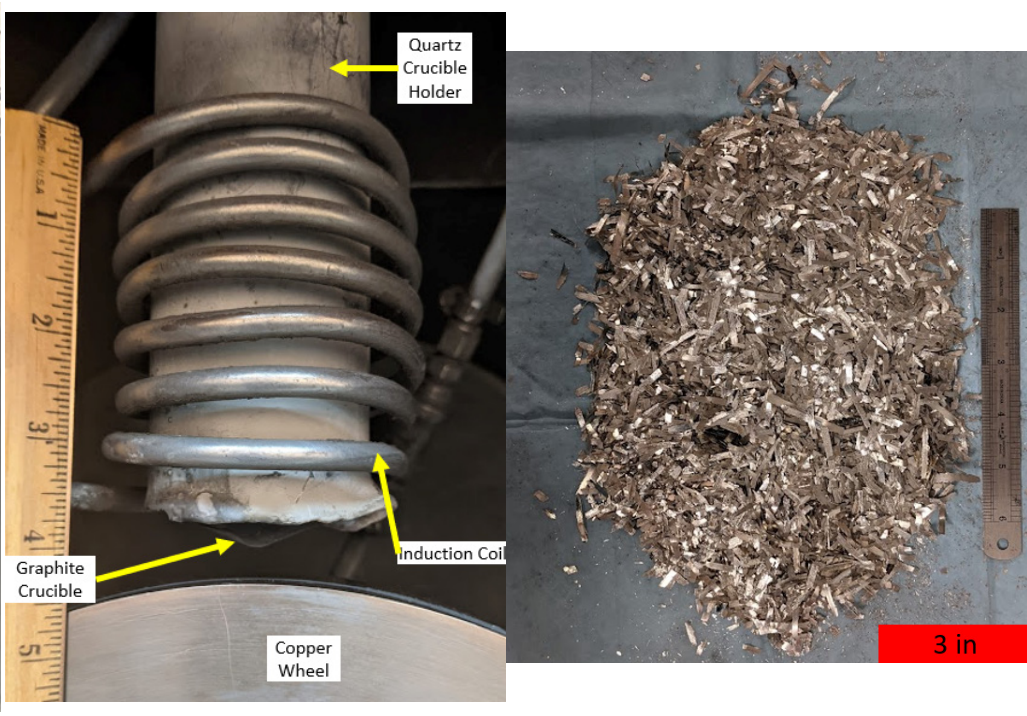

(b) (c)

Figure 2.1. (a) A whole view of the melt spinner set up, (b) close up of the graphite crucible and copper wheel, and (c) melt spun ribbons produced from melt spinning. Scale bars in inches.

\subsubsection{Extrusion}

To consolidate the melt spun ribbons, hot extrusion was performed with an extrusion ratio of 8:1. The ribbons were compacted into pure $\mathrm{Mg}$ cans with an outer diameter of 31 $\mathrm{mm}$, inner diameter of $28 \mathrm{~mm}$, and walls $45 \mathrm{~mm}$ tall (Figure $2.2 \mathrm{~b}$ ). These cans were then extruded at $390^{\circ} \mathrm{C}$ with a ram speed of $5 \mathrm{~mm} / \mathrm{min}$ using boron nitride spray as a lubricant. The die was heated using an induction heating coil and temperature was monitored through an inserted thermocouple within the die (Figure 2.2a). The first $3 \mathrm{~cm}$ of the extruded rod (Figure 2.2c) were then cut off before processing for ECAP since this material was 


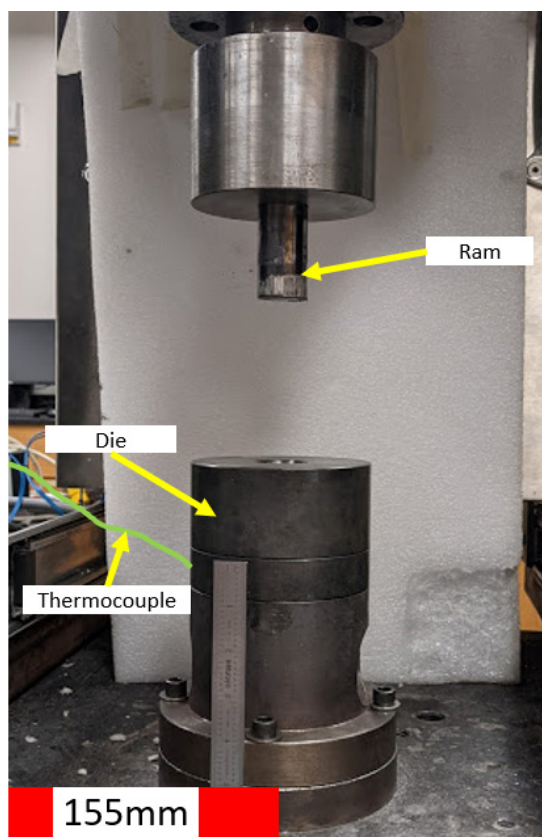

(a)

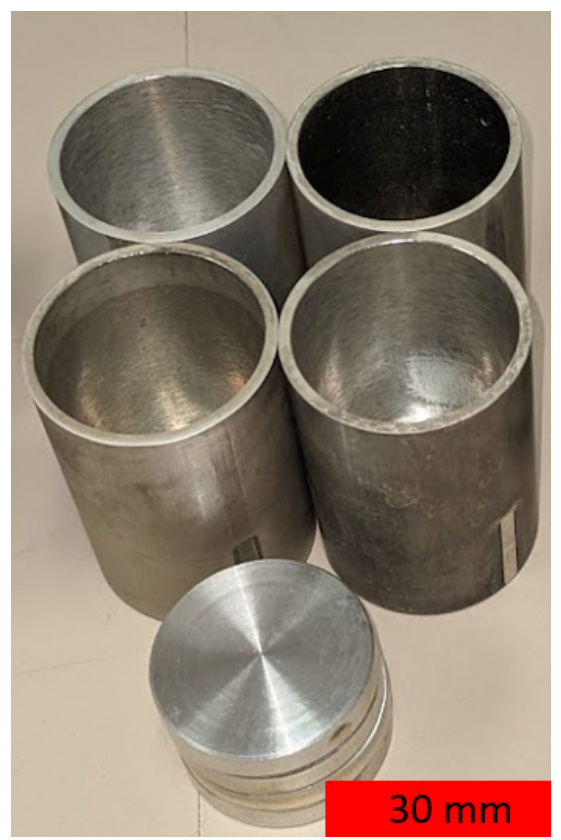

(b)

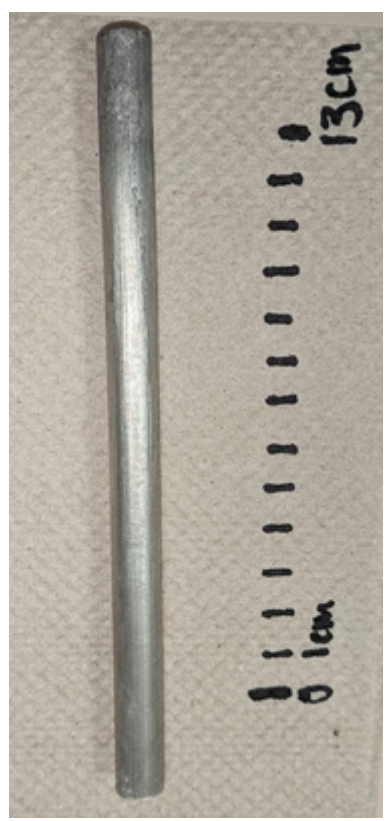

(c)

Figure 2.2. (a) Extrusion die set up which the induction coil wraps around for heating, (b) magnesium cans which are packed with ribbons for consolidation through extrusion, and (c) produced extruded rod of consolidated ribbons.

\subsubsection{ECAP}

ECAP was performed on billets $11 \mathrm{~mm}$ in diameter and $90 \mathrm{~mm}$ in height with the extrusion direction parallel to the ECAP direction. The ECAP die consisted of two channels intersecting at an angle of $110^{\circ}$ with an outer arc curvature of $20^{\circ}$ (Figure 1.8) which produced an equivalent strain of $\sim 0.76$ per pass [37]. ECAP was carried out at $200^{\circ} \mathrm{C}$ at a speed of $30.5 \mathrm{~mm} / \mathrm{min}$ using molybdenum disulfide $\left(\mathrm{MoS}_{2}\right)$ as a lubricant (Figure 2.3a-b). Two passes were performed rotating the billet $90^{\circ}$ clockwise between passes [38]. To heat the die, four resistance heaters placed parallel to the ECAP channel homogeneously heated the die which was monitored through an inserted thermocouple (Figure 2.3b). The ends of the produced billets (Figure 2.3c) do no undergo SPD so the ends are cut off $(\sim 1 \mathrm{~cm})$ prior to characterization. 


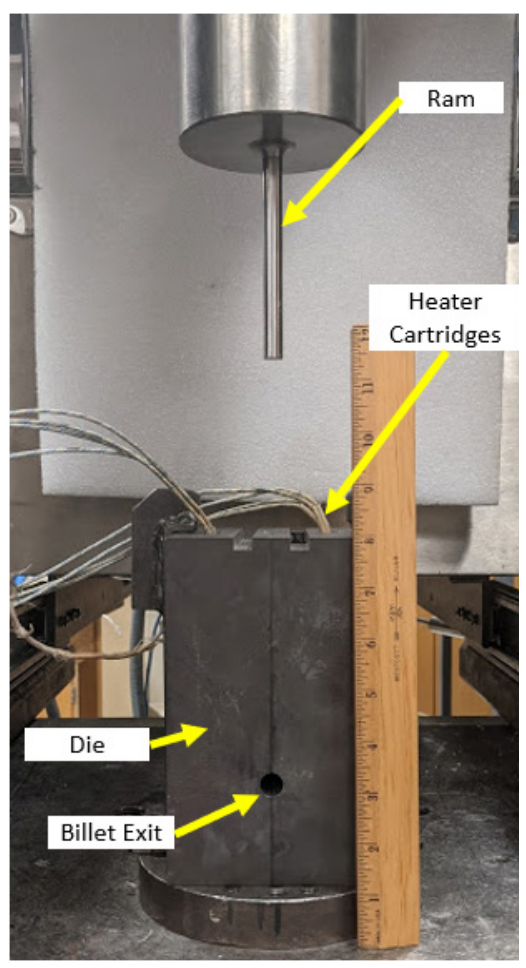

(a)

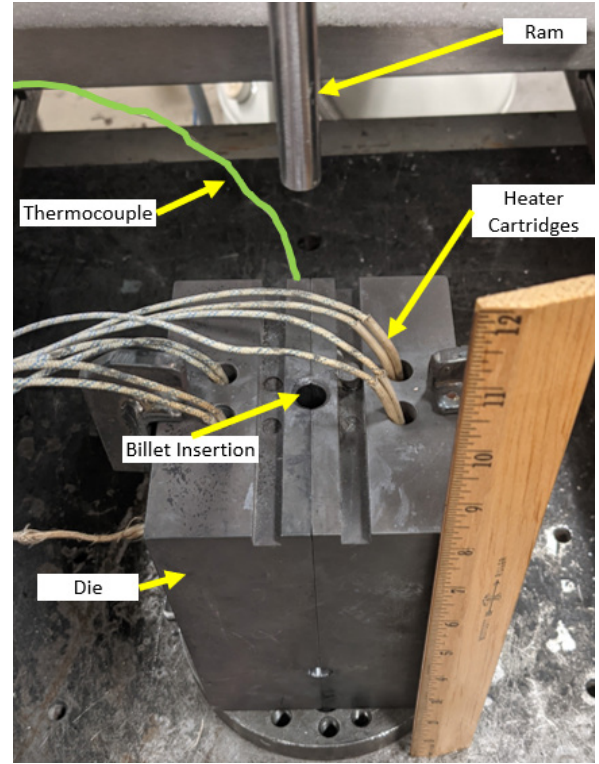

(b)

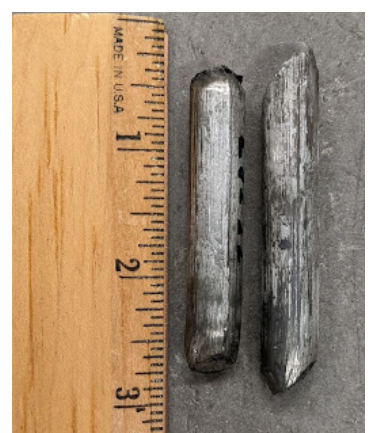

(c)

Figure 2.3. (a) Front view of the ECAP die, (b) top view with heater cartridge placement, and (c) ECAP billets. Scale bars in inches.

\subsection{Metallography}

Microstructural characterization was done using optical microscopy and scanning electron microscopy (SEM). Optical microscopy was performed using a Nikon Eclipse MA100 microscope with an Olympus SC50 camera. Image analysis was performed with the Olympus Stream software. SEM was performed using a Philips XL40 ESEM with energy dispersive spectroscopy (EDS) and a Hitachi S-4700 FE-SEM. RS and ECAP samples were examined parallel to the extrusion and ECAP direction. Metallographic samples were prepared following the steps in Table 2.2. SiC abrasive paper (Hudson Supply) was used for all grinding steps using water as a lubricant. After the 1200 grit step, samples were polished using a combination of rotational and vibratory polishing using waterless lubrications and polycrystalline diamond pastes. Between all polishing steps samples were sonicated for 5 minutes in ethanol. A nylon pad (Allied High Tech Products, Inc) and a polypropylene glycol-based lubricant (RedLube, Allied High Tech Products, Inc) was used for the rotational $3 \mu \mathrm{m}$ polishing step. For the $1 \mu \mathrm{m}$ and $0.25 \mu \mathrm{m}$ polishing steps, vibratory polishing was used using plain cloth pads (Hudson Supply) and kerosene as a lubricant. The final polishing step of $0.05 \mu \mathrm{m}$, used a low-napped, synthetic rayon flock pad (Imperial Pad, Allied High Tech Products, Inc) and MasterPolish ${ }^{\mathrm{TM}}$ final polishing suspension (Buehler, Ltd). For the final polishing step deionized (DI) water was briefly ( $\sim 3$ sec contact) used to wash off the MasterPolish suspension. Samples were then 
immediately rinsed with ethanol to prevent etching caused by contact with DI water. FESEM samples did not undergo the final polishing step because the brief contact with water etched away the nanoscale precipitates.

Samples were etched using a solution of $6 \mathrm{~g}$ picric, $5 \mathrm{~mL}$ acetic, $10 \mathrm{~mL}$ water and 100 $\mathrm{mL}$ ethanol for optical microscopy. Grain size analysis was performed using the Olympus Stream software using image thresholding and edge detection filters to measure the mean grain size and distribution of grain sizes. Three images were taken of each alloy for analysis. The average grain size was calculated by fitting a distribution function to the grain size data and then determining the average and standard deviation from the function.

Table 2.2. Abrasive steps and time used for metallography sample preparation.

\begin{tabular}{cc}
\hline Step & Time \\
\hline 320 grit & Until planar \\
400 grit & 45 seconds \\
600 grit & 45 seconds \\
800 grit & 45 seconds \\
1200 grit & 1 minute \\
$3 \mu \mathrm{m}$ & 2 minutes \\
$1 \mu \mathrm{m}$ & 30 minutes \\
$0.25 \mu \mathrm{m}$ & 45 minutes \\
$0.05 \mu \mathrm{m}$ & 8 seconds \\
\hline
\end{tabular}

SEM images taken with the Philips ESEM used an accelerating voltage of $15 \mathrm{kV}$ in conjunction with the AzTec software. Images taken on the FE-SEM used an accelerating voltage of $11 \mathrm{kV}$.

For phase identification, $\mathrm{x}$-ray diffraction was performed using the Scintag XDS2000 Powder Diffractometer equipped with copper K $\alpha$ x-rays set at $45 \mathrm{kV}$ and $35 \mathrm{~mA}$. A step scan from $20^{\circ}$ to $88^{\circ}$ was performed with a step size of $0.02^{\circ}$ and 16 second count time.

\subsection{Corrosion Characterization}

All corrosion tests were carried out in Hank's balanced salt solution (Sigma-Aldrich, Inc) (HBSS) modified with $0.35 \mathrm{~g} / \mathrm{L}$ of $\mathrm{NaHCO}_{3}$ (Table 2.3). The solution was balanced to a $\mathrm{pH}$ of 7.4 using $0.1 \mathrm{M} \mathrm{HCl}$ and $0.1 \mathrm{M} \mathrm{NaOH}$ solutions. All tests were held at $37 \pm 1^{\circ} \mathrm{C}$. Prior to testing all exposed surfaces were polished to $3 \mu \mathrm{m}$ following the metallography practices discussed in section 2.2 and then degreased via sonication in ethanol for 5 minutes followed by 5 minutes in acetone. 
Table 2.3. Composition of Hank's balanced salt solution.

\begin{tabular}{cc} 
Component & $\begin{array}{c}\text { Concentration } \\
(\mathbf{g} / \mathbf{L})\end{array}$ \\
\hline $\mathrm{CaCl}_{2} \cdot 2 \mathrm{H}_{2} \mathrm{O}$ & 0.19 \\
$\mathrm{MgSO}_{4}$ (anhydrous) & 0.10 \\
$\mathrm{KCl}$ & 0.40 \\
$\mathrm{KH}_{2} \mathrm{PO}_{4}$ (anhydrous) & 0.06 \\
$\mathrm{NaHCO}_{3}$ & 0.35 \\
$\mathrm{NaCl}$ & 8.00 \\
$\mathrm{Na}_{2} \mathrm{HPO}_{4}$ & 0.05 \\
(anhydrous) & 1.0 \\
D-Glucose &
\end{tabular}

\subsubsection{Electrochemical Corrosion Testing}

Potentiodynamic polarization and electrochemical inductance spectroscopy (EIS) tests were performed using a Princeton Applied Research PARSTAT 4000 with the VersaStudio ${ }^{\circledR}$ software. All tests used a conventional three-electrode corrosion cell with a saturated calomel electrode (SCE) reference electrode with graphite counter electrodes (Figure 2.4). The exposed surface area of the samples was about $0.6 \mathrm{~cm}^{2}$. For each test, the open circuit potential (OCP) was measured for 1 hour before potentiodynamic or EIS tests were performed. Potentiodynamic tests were carried out over a range of $-0.25 \mathrm{~V}$ vs $\mathrm{OCP}$ to $0.75 \mathrm{~V}$ vs OCP with a scan rate of $0.166 \mathrm{mV} / \mathrm{s}$. For EIS testing, a frequency range of $100 \mathrm{kHz}$ to $0.01 \mathrm{~Hz}$ with an oscillation amplitude of $10 \mathrm{mV}$ was used. The corrosion rate was estimated following ASTM G102 following the Tafel extrapolation method using the potentiodynamic curves [39]. Three repetitions of each test were completed for the two alloys and the two different processing conditions.

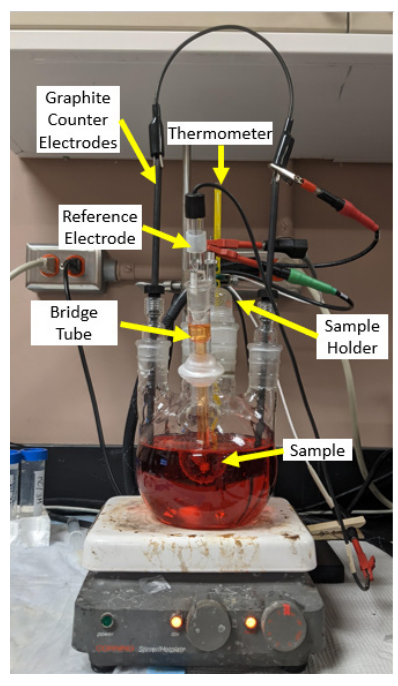

Figure 2.4. Conventional 3-electrode corrosion cell set up. 


\subsubsection{Immersion Testing}

For immersion testing, ASTM guide G31 was followed [40]. Round samples $8.3 \mathrm{~mm}$ in diameter and $1 \mathrm{~mm}$ thick were immersed for durations of 2, 5, 10, and 15 days (Figure 2.5a). Samples were cut from a turned down billet using wire electrical discharge machining (wire-EDM). Three samples in each of the four conditions were suspended in HBSS by fishing line in a $50 \mathrm{~mL}$ test tube. The volume of HBSS to surface area ratio was $0.2 \mathrm{~mL} / \mathrm{mm}^{2}$ and the solution was changed every 2 days to keep the $\mathrm{pH}$ of the solution consistent (Figure 2.5b). The mass of samples pre- and post-immersion was measured using a scale accurate to $0.0001 \mathrm{~g}$. Corrosion products were removed using a chromic acid aqueous solution of $200 \mathrm{~g} / \mathrm{L} \mathrm{CrO}_{3}$ and $10 \mathrm{~g} / \mathrm{L} \mathrm{AgNO}_{3}$ and then sonicated for 5 minutes in ethanol followed by 5 minutes in acetone. Cross sections of pre-cleaned immersion samples were examined using backscatter SEM to observe corrosion uniformity and corrosion product morphology. Secondary SEM was used to examine the surface morphology of the magnesium alloys once the corrosion products were removed.

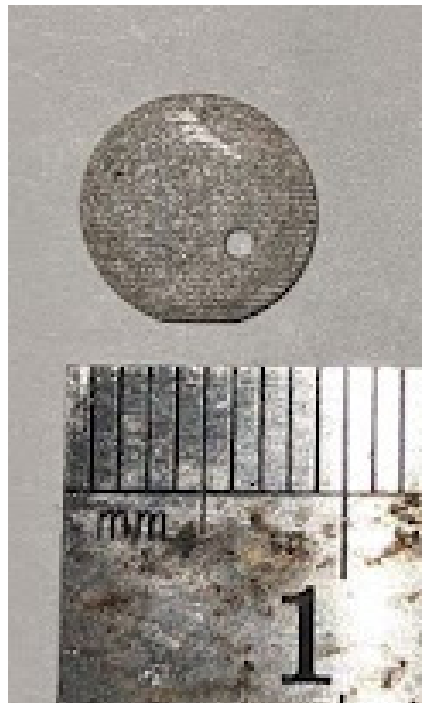

(a)

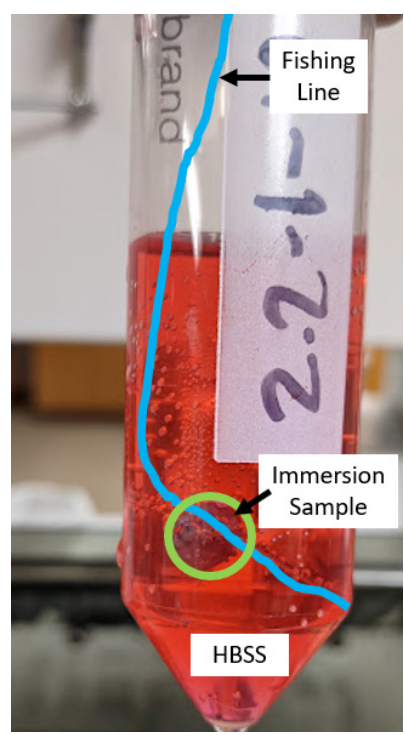

(b)

Figure 2.5. (a) Immersion test samples and (b) immersion samples inserted into HBSS.

\subsection{Mechanical Testing}

All mechanical testing was performed using an Instron 4210 tensile frame with the Test Works Elite software. For tensile testing, ASTM E8 was followed using type 4 round tensile bars [41]. Three round tensile bars in each condition were machined with a diameter of $4 \mathrm{~mm}$ and gage length of $16 \mathrm{~mm}$ (Figure 2.6a) with the gage length parallel to the extrusion and ECAP direction. For compression testing, ASTM E9 was followed [42]. Three samples in each condition of $6 \mathrm{~mm}$ in diameter and $12 \mathrm{~mm}$ in height (Figure 2.6b) were machined parallel to the extrusion and ECAP direction. An initial strain rate of $1.8 \times 10^{-3} \mathrm{~mm} / \mathrm{mm} / \mathrm{s}$ was used for tensile and compression testing. A $10 \mathrm{kN}$ load cell 
with a $10 \mathrm{~mm}$ extensometer (for tensile) and deflectometer (for compression) were used to monitor load and displacement for each test.

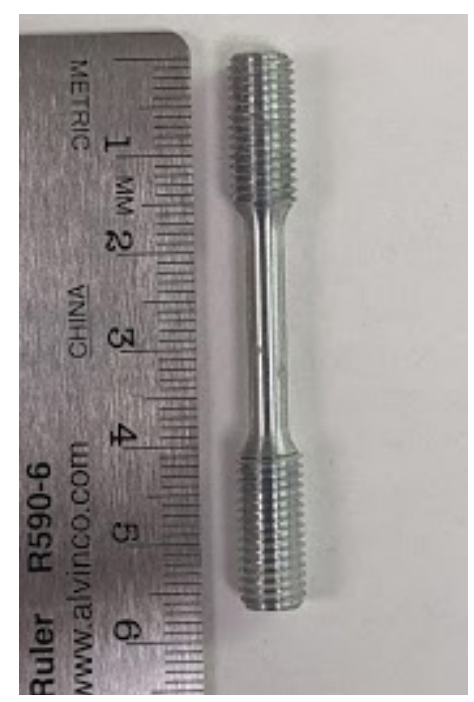

(a)

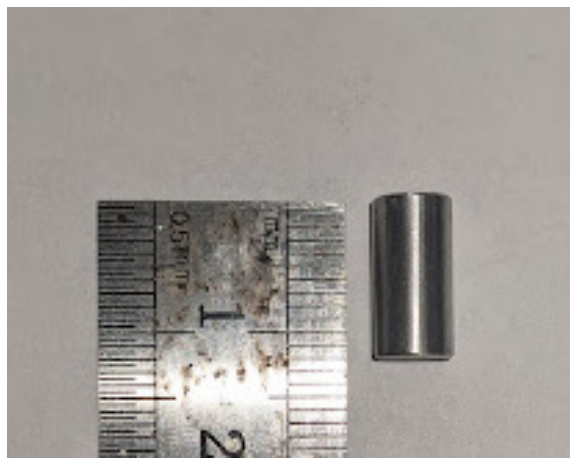

(b)

Figure 2.6. (a) Tensile test samples and (b) compression test samples.

\subsubsection{Hardness Testing}

Vickers microhardness testing was performed on the parallel (longitudinal) and perpendicular (transverse) surfaces to the extrusion and ECAP direction with a load of $200 \mathrm{~g}$ and dwell time of 15 seconds using a Leco M-400-G1 hardness tester. Measurements were repeated 10 times on each surface. 


\section{Results}

\subsection{Microstructure}

ICP-OES of four samples of each alloy determined that the concentration of $\mathrm{Zn}, \mathrm{Ca}$, and $\mathrm{Mn}$ in the two alloys prepared were below the target compositions (Table 2.1). Though, the concentrations were below the target composition, the compositions were consistent between multiple samples melt spun and extruded. The concentrations of $\mathrm{Fe}, \mathrm{Cu}$, and $\mathrm{Ni}$ in the alloys were below the threshold concentrations for causing the corrosion rate of magnesium to deteriorate rapidly [30]. The two different alloys are now referred to as $\mathrm{Mg}-1.2 \mathrm{Zn}-0.8 \mathrm{Ca}-0.2 \mathrm{Mn}$ and $\mathrm{Mg}-1.8 \mathrm{Zn}-0.8 \mathrm{Ca}-0.2 \mathrm{Mn}$ to better match their measured compositions.

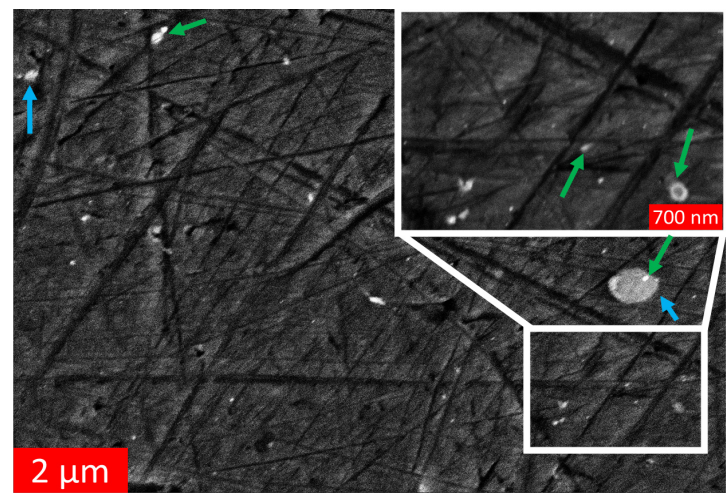

(a)

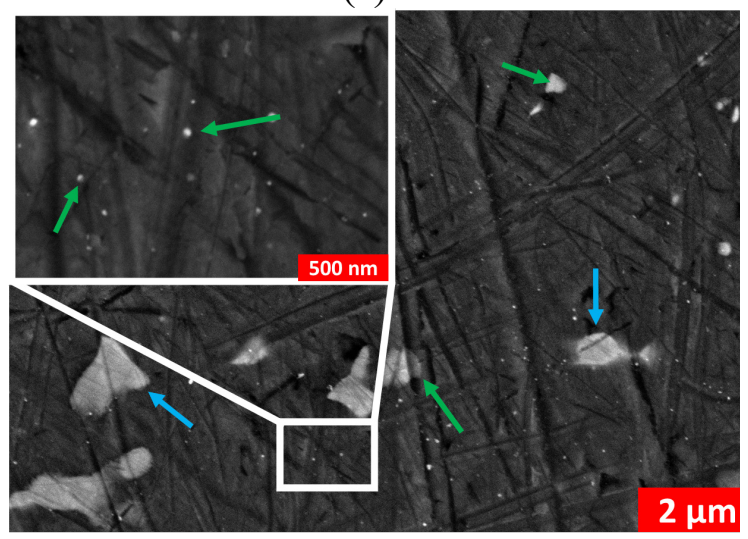

(c)

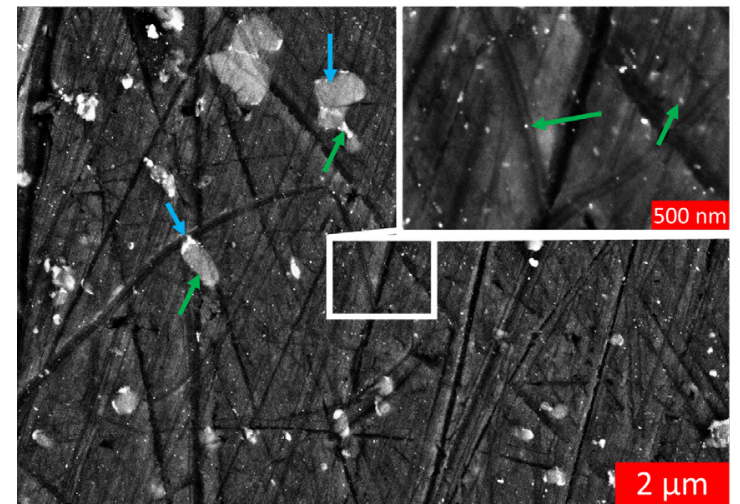

(b)

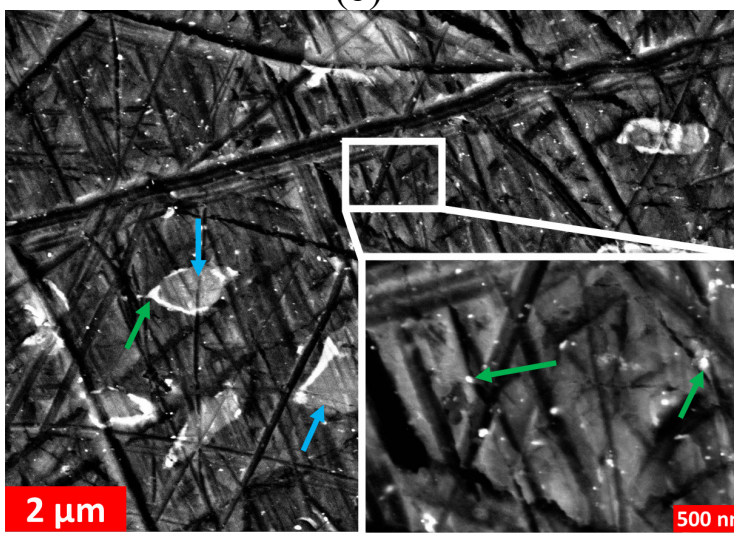

(d)

Figure 3.1. BSE SEM images of Mg-1.2Zn-0.8Ca-0.2Mn (a) RS and (b) ECAP alloys, and $\mathrm{Mg}-1.8 \mathrm{Zn}-0.8 \mathrm{Ca}-0.2 \mathrm{Mn}$ (c) RS and (d) ECAP alloys along the extrusion and ECAP direction. Green arrows indicate $\mathrm{Ca}_{2} \mathrm{Mg}_{6} \mathrm{Zn}_{3}$ intermetallics and blue arrows indicate $\mathrm{Mg}_{2} \mathrm{Ca}$ intermetallics and the extrusion and ECAP direction runs from left to right.

Secondary precipitates $(\sim 1 \mu \mathrm{m})$ were uniformly dispersed throughout the magnesium matrix in both the RS and ECAP conditions as indicated by the backscatter electron (BSE) FE-SEM images of each alloy (Figure 3.1). Two precipitates were present, one brighter than the other, indicating one is more Zn-rich than the other. Energy dispersive spectroscopy (SEM-EDS) using the ESEM confirmed that the bright precipitate (green 
arrows (Figure 3.1)) contained $\mathrm{Mg}, \mathrm{Zn}$ and $\mathrm{Ca}$ whereas the dark precipitates (blue arrows (Figure 3.1)) only contained $\mathrm{Mg}$ and $\mathrm{Ca}$ (Figure 3.2). In the magnesium matrix, manganese was not detected because the additions of Mn were below the detection limit of SEM-EDS. The identification of these two precipitates was attempted using $\mathrm{X}$-ray diffraction (XRD) but the volume fraction of these two precipitates was too low to be detected among the background of the diffraction pattern (Figure 3.3a). There were a few low intensity peaks (circles) that did show up in the pattern that could not be matched to the diffraction patterns of $\mathrm{Mg}$ (diamonds), any expected precipitate $\left(\mathrm{Mg}_{2} \mathrm{Ca}, \mathrm{Ca}_{2} \mathrm{Mg}_{6} \mathrm{Zn}_{3}\right)$, nor any other compound that could form between the present alloying elements (Figure $3.3 b$ ). These peaks were suspected to be from $\mathrm{Ca}_{2} \mathrm{Mg}_{6} \mathrm{Zn}_{3}$ and $\mathrm{Mg}_{2} \mathrm{Ca}$ phases and the lack in matching peaks is caused by the low concentration of alloying elements and nonequilibrium processing these alloys underwent. After ECAP processing, the $\mathrm{Ca}_{2} \mathrm{Mg}_{6} \mathrm{Zn}_{3}$ precipitates are more abundant and formed on the edges of larger $\mathrm{Mg}_{2} \mathrm{Ca}$ precipitates (Figure 3.1).

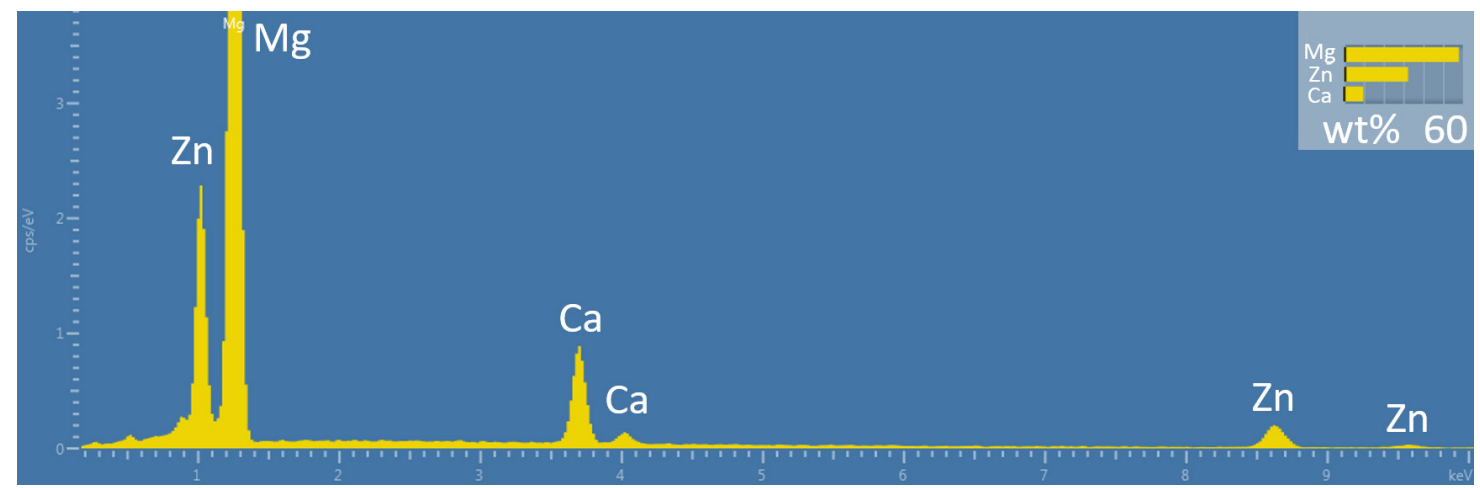

(a)

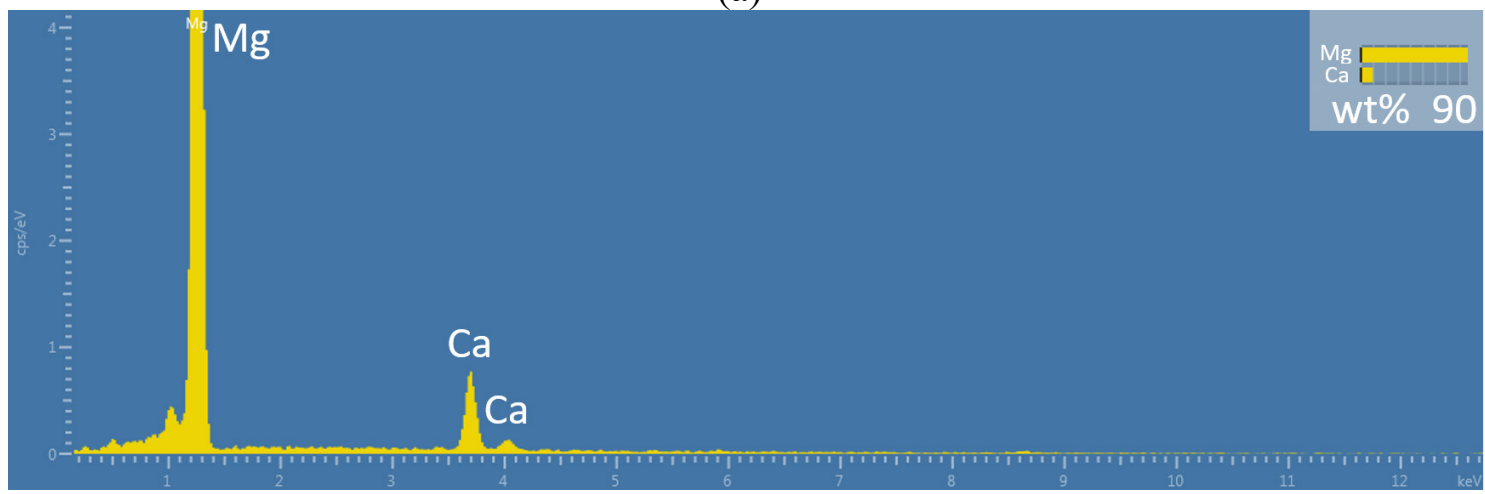

(b)

Figure 3.2. SEM-EDS spectra for the precipitates pointed out by (a) the green arrows and (b) the blue arrows.

Between the secondary precipitates in each alloy, nanoprecipitates $(\sim 50 \mathrm{~nm})$ were also uniformly dispersed throughout the magnesium matrix. These precipitates were assumed to be $\mathrm{Ca}_{2} \mathrm{Mg}_{6} \mathrm{Zn}_{3}$ based on the contrast and prior literature since these precipitates were too fine to be analyzed through SEM-EDS. In the Mg-1.8Zn-0.8Ca-0.2Mn alloy (Figure $3.1 \mathrm{c}-\mathrm{d}$ ), $\mathrm{Ca}_{2} \mathrm{Mg}_{6} \mathrm{Zn}_{3}$ nanoprecipitates and secondary precipitates (green arrows) are more abundant than in the Mg-1.2Zn-0.8Ca-0.4Mn alloys (Figure 3.1a-b) due to the higher 
concentration of zinc added to the alloy. This difference is especially evident between the RS processed alloys. The ECAP processed alloys (Figure 3.1b, d) exhibited a higher volume density of these nano-precipitates than the RS processed alloys (Figure 3.1a, c) demonstrating the dynamic recrystallization occurring during ECAP processing.

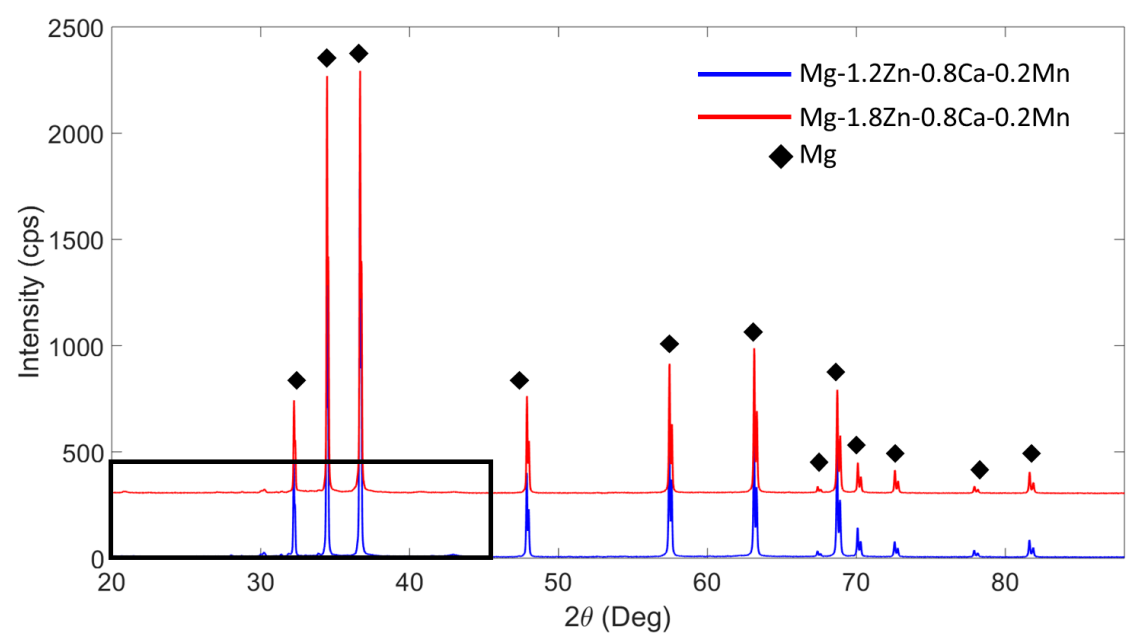

(a)

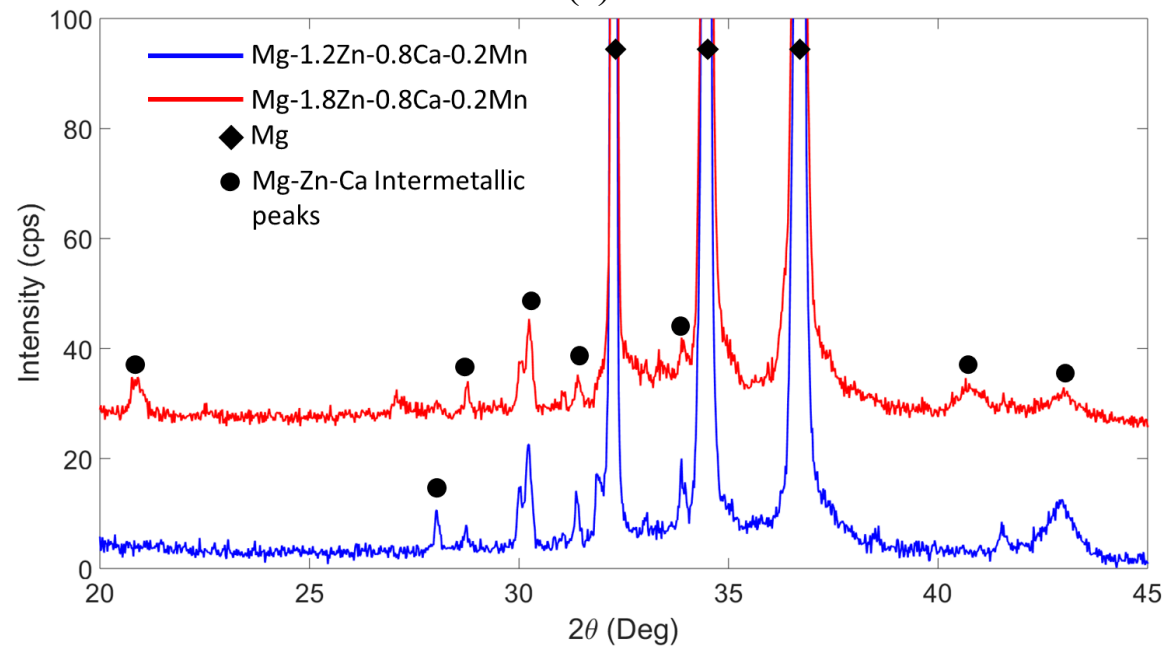

(b)

Figure 3.3. XRD patterns for $\mathrm{Mg}-1.2 \mathrm{Zn}-0.8 \mathrm{Ca}-0.2 \mathrm{Mn}$ (blue) and $\mathrm{Mg}-1.8 \mathrm{Zn}-0.8 \mathrm{Ca}-0.2 \mathrm{Mn}$ (red) alloys. Figure $3.3 \mathrm{~b}$ is the zoomed in pattern highlighted by the black box in figure 3.3a.

The grain size and morphology of the RS and ECAP processed alloys were examined through optical microscopy to assess the microstructural refinement induced through ECAP. The average grain size is smaller in the ECAP processed $\mathrm{Mg}-1.2 \mathrm{Zn}-0.8 \mathrm{Ca}-0.2 \mathrm{Mn}$ alloy than the RS processed alloy but the grain size remained about the same between the $\mathrm{Mg}-1.8 \mathrm{Zn}-0.8 \mathrm{Ca}-0.2 \mathrm{Mn}$ ECAP and RS processed alloys (Table 3.1). Though the grain sizes are not significantly different between the two $\mathrm{Mg}-1.2 \mathrm{Zn}-0.8 \mathrm{Ca}-0.2 \mathrm{Mn}$ alloys, the average for the ECAP processed alloy is about one-half that of the RS processed alloy. Grain size distributions were larger in the RS processed alloys than in the ECAP 
processed alloys. The two RS processed alloys possessed a relatively higher number of larger size grains $(>4 \mu \mathrm{m})$ indicated by the shallower slope in the distribution towards higher grain sizes (Figure 3.4b, f). The narrower distributions in the two ECAP'ed alloys indicates grain refinement (Figure $3.4 \mathrm{~d}, \mathrm{~h}$ ).

The ECAP processed alloys exhibited grains elongated along the ECAP direction (Figure $3.4 \mathrm{c}, \mathrm{g}$ ), an indicator of deformation processing compared to the RS processed alloys that possessed an equiaxed grain structure after extrusion (Figure 3.4a, e). The Mg-1.2Zn0.8Ca-0.2Mn ECAP processed alloy (Figure 3.4c) exhibited a higher degree of grain elongation compared to the $\mathrm{Mg}-1.8 \mathrm{Zn}-0.8 \mathrm{Ca}-0.2 \mathrm{Mn}$ ECAP processed alloy which still possessed some equiaxed grains (Figure $3.4 \mathrm{~g}$ ).

Table 3.1. Average grain size of the $\mathrm{Mg}-1.2 \mathrm{Zn}-0.8 \mathrm{Ca}-0.2 \mathrm{Mn}$ and $\mathrm{Mg}-1.8 \mathrm{Zn}-0.8 \mathrm{Ca}-$ $0.2 \mathrm{Mn}$ alloys after RS and ECAP processing.

\begin{tabular}{|c|c|}
\hline Alloy & $\begin{array}{c}\text { Grain Size } \\
(\mu \mathrm{m})\end{array}$ \\
\hline $\begin{array}{c}\mathrm{RS} \\
\mathrm{Mg}-1.2 \mathrm{Zn}-0.8 \mathrm{Ca}-0.2 \mathrm{Mn}\end{array}$ & $1.1 \pm 0.5$ \\
\hline $\begin{array}{c}\text { ECAP } \\
\mathrm{Mg}-1.2 \mathrm{Zn}-0.8 \mathrm{Ca}-0.2 \mathrm{Mn}\end{array}$ & $0.6 \pm 0.7$ \\
\hline $\begin{array}{c}\mathrm{RS} \\
\mathrm{Mg}-1.8 \mathrm{Zn}-0.8 \mathrm{Ca}-0.2 \mathrm{Mn}\end{array}$ & $1.2 \pm 0.6$ \\
\hline $\begin{array}{c}\text { ECAP } \\
\mathrm{Mg}-1.8 \mathrm{Zn}-0.8 \mathrm{Ca}-0.2 \mathrm{Mn}\end{array}$ & $1.1 \pm 0.5$ \\
\hline
\end{tabular}




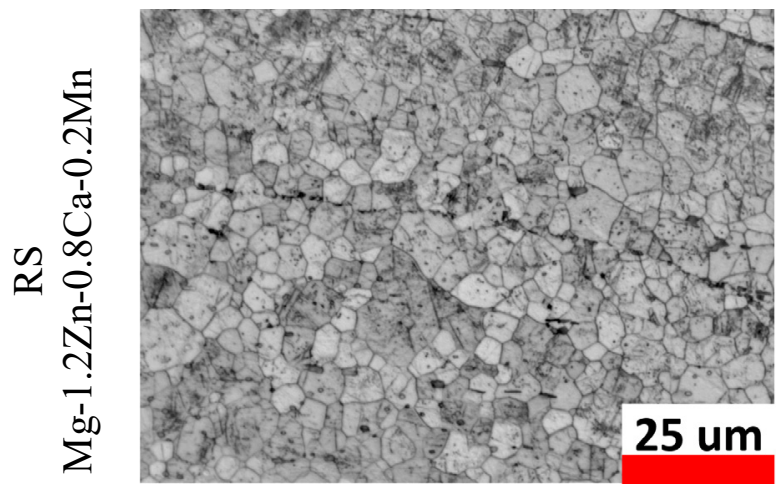

(a)

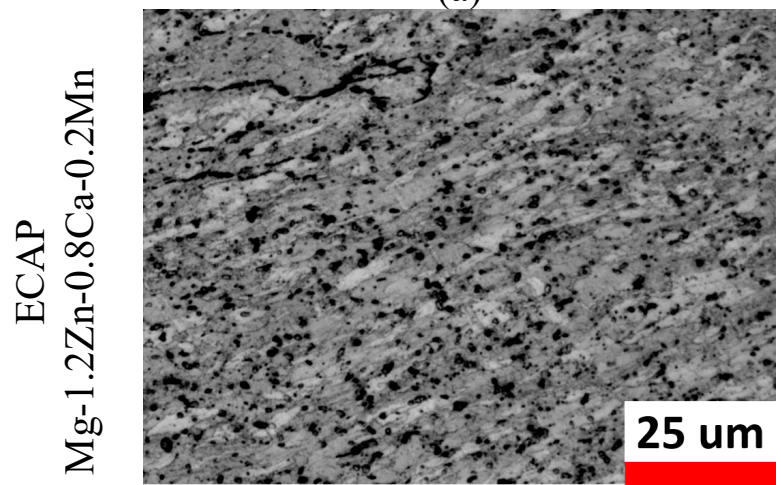

(c)

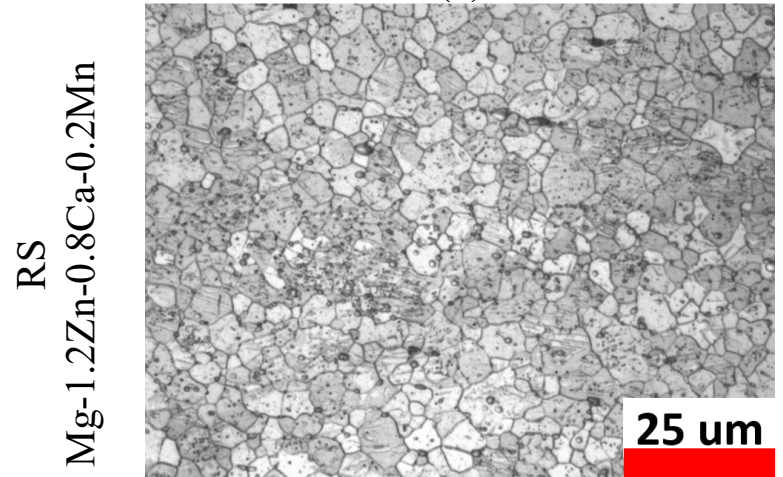

(e)

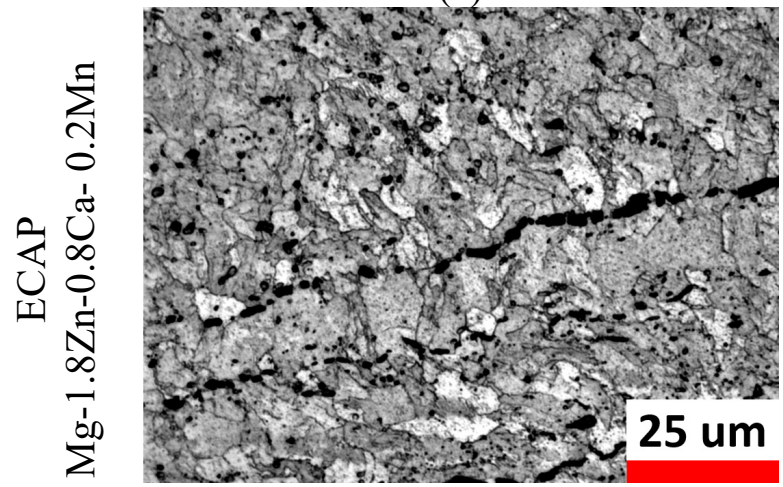

(g)

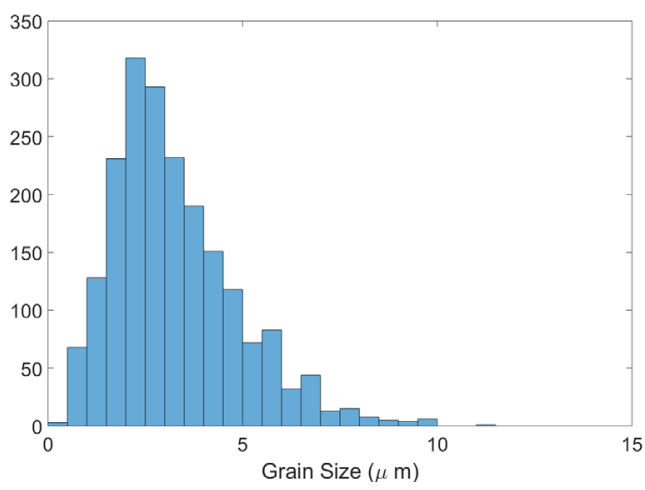

(b)

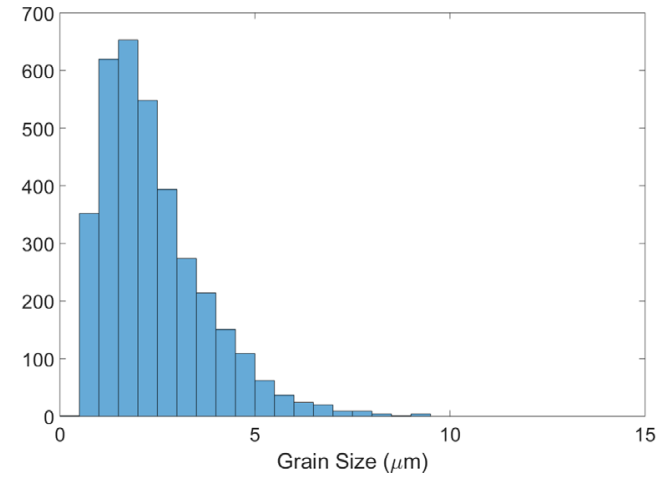

(d)

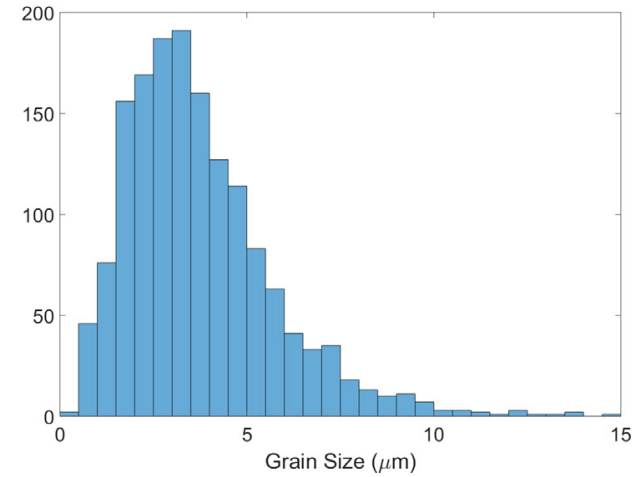

(f)

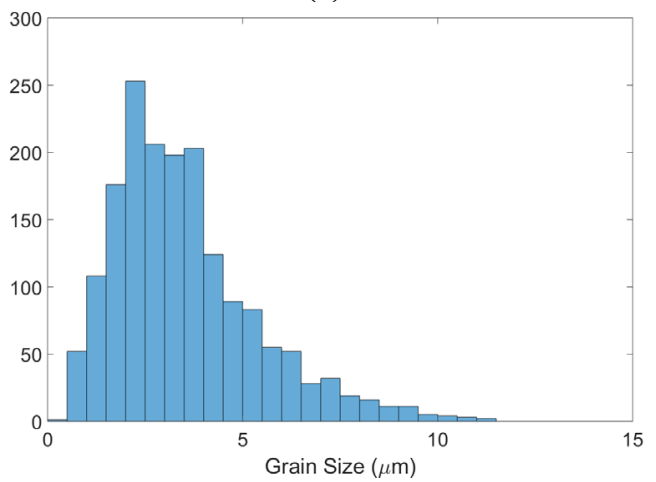

(h)

Figure 3.4. Optical micrographs of the etched alloys with grain size distribution histograms. 


\subsection{Mechanical Properties}

\subsubsection{Tensile and Compression Testing}

The elastic modulus, yield strength (YS), ultimate tensile strength (UTS), and elongation at break (\% EL) were determined (Table 3.2) from tensile stress-strain curves of the RS and ECAP processed $\mathrm{Mg}-1.2 \mathrm{Zn}-0.8 \mathrm{Ca}-0.2 \mathrm{Mn}$ and $\mathrm{Mg}-1.8 \mathrm{Zn}-0.8 \mathrm{Ca}-0.2 \mathrm{Mn}$ alloys (Figure 3.5). The tensile mechanical behavior of the RS processed samples exhibited a more ductile behavior $(\sim 3 \%$ EL) than the ECAP processed samples. The ECAP samples exhibited an almost brittle fracture behavior with elongations only of $\sim 0.4 \%$ EL (Figure 3.5). Comparing the YS and UTS between the two processing techniques, the YS and UTS of the ECAP Mg-1.8Zn-0.8Ca-0.2Mn alloy was about $40 \mathrm{MPa}$ higher than the RS processed alloy. The ECAP Mg-1.2Zn-0.8Ca-0.2Mn alloy fractured before yielding occurred, so a YS was not determined. The UTS of the Mg-1.2Zn-0.8Ca-0.2Mn alloy appears higher in the stress-strain curve in Figure 3.5 but in Table 3.2 the UTS average is lower than the RS processed alloy. The variation in UTS of the processed alloy is much larger in the ECAP processed alloys because some samples did experience stresses higher than the RS alloys whereas other samples fractured at lower stresses than the RS alloys. All four alloys had relatively close elastic moduli at about $\sim 45 \mathrm{GPa}$. The ECAP Mg$1.8 \mathrm{Zn}-0.8 \mathrm{Ca}-0.2 \mathrm{Mn}$ alloy exhibited the lowest modulus at $37 \pm 5 \mathrm{GPa}$ while the RS Mg$1.2 \mathrm{Zn}-0.8 \mathrm{Ca}-0.2 \mathrm{Mn}$ had the highest modulus at $48 \pm 8 \mathrm{GPa}$.

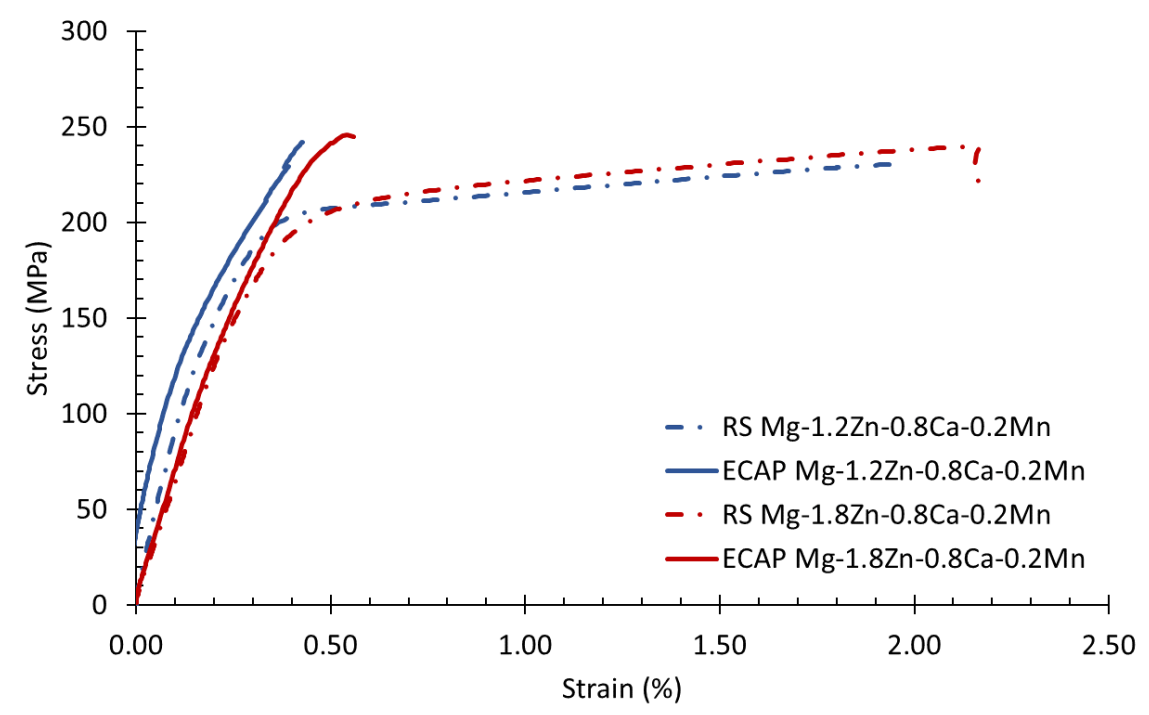

Figure 3.5. Tensile stress-strain curves for RS and ECAP Mg-1.2Zn-0.8Ca-0.2Mn and $\mathrm{Mg}-1.8 \mathrm{Zn}-0.8 \mathrm{Ca}-0.2 \mathrm{Mn}$ alloys. 
Table 3.2. Tensile mechanical properties of RS and ECAP Mg-1.2Zn-0.8Ca-0.2Mn and $\mathrm{Mg}-1.8 \mathrm{Zn}-0.8 \mathrm{Ca}-0.2 \mathrm{Mn}$

\begin{tabular}{ccccc}
\hline Alloy & $\begin{array}{c}\text { Modulus } \\
(\mathbf{G P a})\end{array}$ & $\begin{array}{c}\text { Yield Strength } \\
(\mathbf{M P a})\end{array}$ & $\begin{array}{c}\text { UTS } \\
(\mathbf{M P a})\end{array}$ & $\begin{array}{c}\text { Elongation } \\
\mathbf{( \% )}\end{array}$ \\
\hline RS & $48 \pm 8$ & $190 \pm 6$ & $250 \pm 20$ & $3 \pm 1$ \\
$\begin{array}{c}\mathrm{Mg}-1.2 \mathrm{Zn}-0.8 \mathrm{Ca}-0.2 \mathrm{Mn} \\
\text { ECAP }\end{array}$ & $41 \pm 5$ & - & $230 \pm 50$ & $0.4 \pm 0.1$ \\
$\begin{array}{c}\mathrm{Mg}-1.2 \mathrm{Zn}-0.8 \mathrm{Ca}-0.2 \mathrm{Mn} \\
\mathrm{RS}\end{array}$ & $43 \pm 9$ & $190 \pm 10$ & $230 \pm 20$ & $2 \pm 1$ \\
$\begin{array}{c}\mathrm{Mg}-1.8 \mathrm{Zn}-0.8 \mathrm{Ca}-0.2 \mathrm{Mn} \\
\text { ECAP }\end{array}$ & $37 \pm 5$ & $236 \pm 10$ & $280 \pm 30$ & $0.9 \pm 0.1$ \\
$\begin{array}{c}\mathrm{Mg}-1.8 \mathrm{Zn}-0.8 \mathrm{Ca}-0.2 \mathrm{Mn} \\
\mathrm{n}\end{array}$ & & & & \\
\hline
\end{tabular}

The fracture surfaces of the RS processed alloys exhibited a more ductile failure mode; the surfaces were dimpled and did not reveal large flaws on the surface compared to the ECAP processed alloys (Figure 3.6a). The ECAP processed alloys possessed longitudinal fissures on the fracture surface in a "ribbon" like nature (Figure 3.6b). The layers between these fissures were smooth and did not exhibit the small dimpling that the RS processed alloys had. SEM-EDS of the fracture surfaces revealed an oxide layer was present in the ECAP processed alloys surfaces but not in the RS processed alloys.

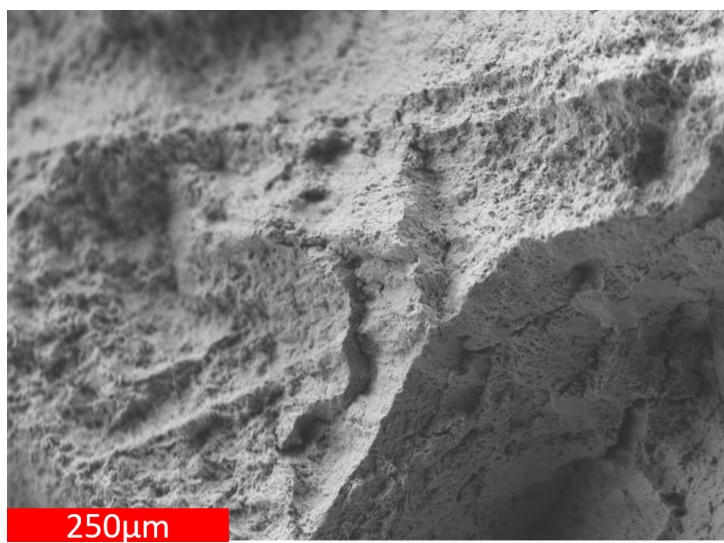

(a)

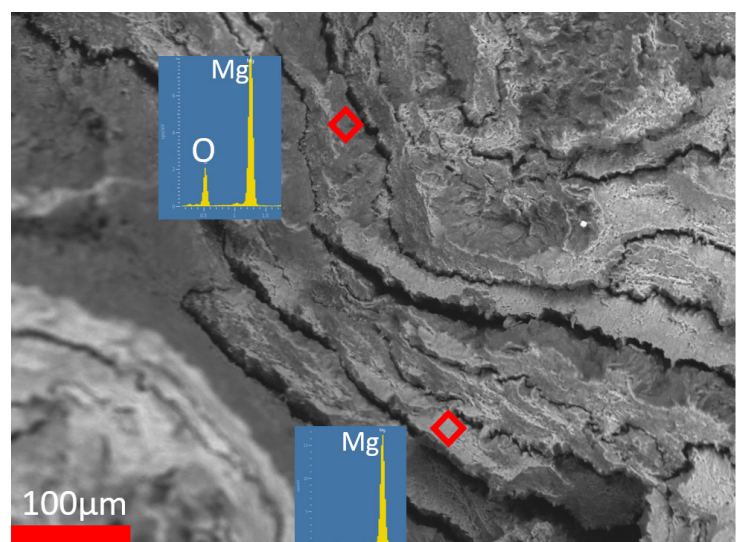

(b)

Figure 3.6. Fracture surfaces of (a) RS (SE SEM image) and (b) ECAP (BSE SEM image with EDS spectra) $\mathrm{Mg}-1.8 \mathrm{Zn}-0.8 \mathrm{Ca}-0.2 \mathrm{Mn}$ tensile samples.

The yield and ultimate compressive strengths (CYS and UCS) (Table 3.3) were determined for the RS and ECAP processed alloys from compressive stress-strain curves (Figure 3.7). The RS processed alloys had compressive strengths (dashed lines) nearly identical between alloys (Figure 3.7) (Table 3.3). In the ECAP condition, the CYS and UCS were not as identical between alloys where the Mg- $1.2 \mathrm{Zn}-0.8 \mathrm{Ca}-0.2 \mathrm{Mn}$ had a UCS about $70 \mathrm{MPa}$ lower than the Mg-1.8Zn-0.8Ca-0.2Mn alloy (Figure 3.7) (Table 3.3). 
The RS and ECAP processed alloys exhibited two different compressive mechanical behaviors. The RS processed alloys had a lower CYS ( 160 MPa) compared to the ECAP processed alloys ( 210 MPa) but then the stress increased for the RS processed alloys at a faster rate as strain increased compared to the ECAP processed alloys. While the ECAP processed alloys had a higher CYS, the RS processed alloys had a higher UCS ( 365 $\mathrm{MPa}$ ) compared to the ECAP alloys.

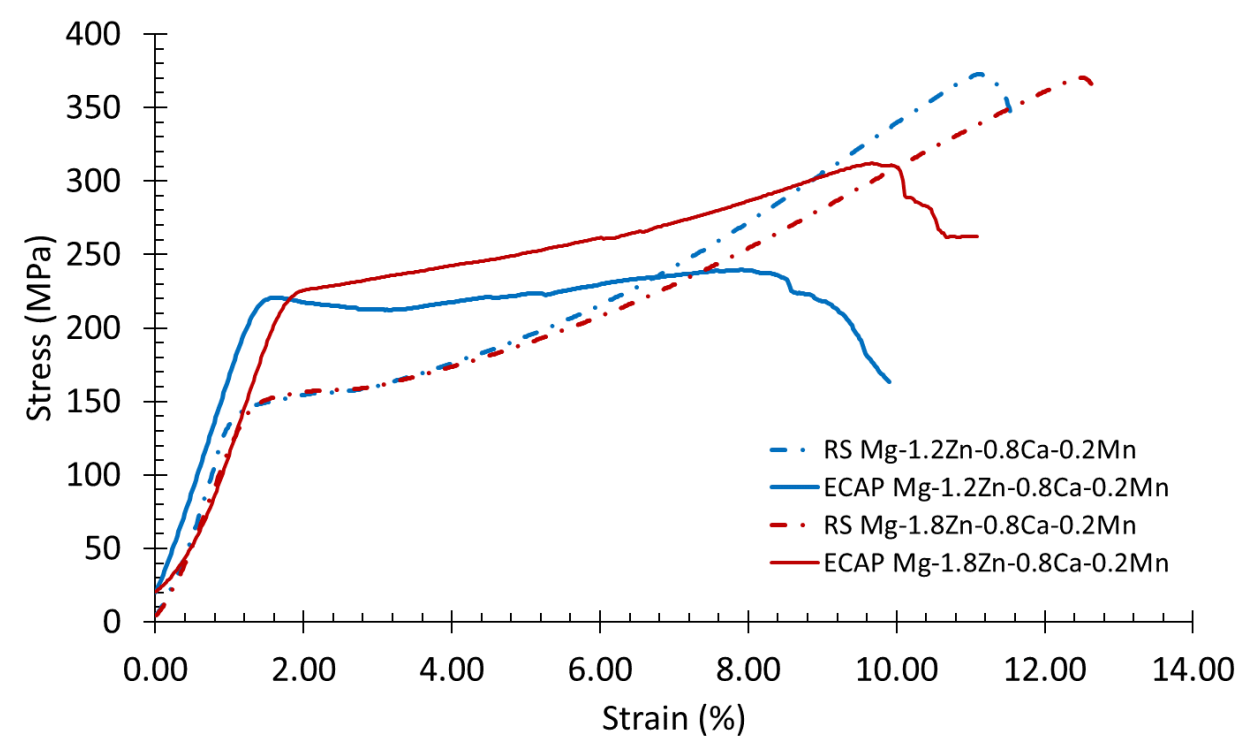

Figure 3.7. Compressive stress-strain curves for RS and ECAP Mg-1.2Zn-0.8Ca-0.2Mn and $\mathrm{Mg}-1.8 \mathrm{Zn}-0.8 \mathrm{Ca}-0.2 \mathrm{Mn}$ alloys.

Table 3.3. Compression mechanical properties of $\mathrm{Mg}-1.2 \mathrm{Zn}-0.8 \mathrm{Ca}-0.2 \mathrm{Mn}$ and $\mathrm{Mg}$ $1.8 \mathrm{Zn}-0.8 \mathrm{Ca}-0.2 \mathrm{Mn}$.

\begin{tabular}{ccc}
\hline Alloy & $\begin{array}{c}\text { CYS } \\
(\mathbf{G P a})\end{array}$ & $\begin{array}{c}\text { UCS } \\
\text { (MPa) }\end{array}$ \\
\hline RS & $154 \pm 4$ & $360 \pm 40$ \\
$\mathrm{Mg}-1.2 \mathrm{Zn}-0.8 \mathrm{Ca}-0.2 \mathrm{Mn}$ & & \\
$\begin{array}{c}\mathrm{ECAP} \\
\mathrm{Mg}-1.2 \mathrm{Zn}-0.8 \mathrm{Ca}-0.2 \mathrm{Mn} \\
\mathrm{RS}\end{array}$ & $200 \pm 10$ & $230 \pm 20$ \\
$\begin{array}{c}\mathrm{Mg}-1.8 \mathrm{Zn}-0.8 \mathrm{Ca}-0.2 \mathrm{Mn} \\
\text { ECAP }\end{array}$ & $160 \pm 5$ & $379 \pm 8$ \\
$\mathrm{Mg}-1.8 \mathrm{Zn}-0.8 \mathrm{Ca}-0.2 \mathrm{Mn}$ & $230 \pm 20$ & $290 \pm 50$ \\
\hline
\end{tabular}

The RS and ECAP processed alloys also exhibited two different failure modes similar to the tensile test failure modes. The fracture surface images in figure 3.8 were taken from the same top view perspective. The RS alloy compressive fracture surfaces appeared relatively smooth that appeared to be "sheared apart" indicative to a shearing failure mode (Figure 3.8a). The ECAP processed alloys again possessed the same layering 
structure observed in the tensile samples but the layers "shattered" apart under the compressive load along the cracks running through the sample ( Figure 3.8b). From SEM-EDS of the fracture surface, an oxide was also found on the surfaces between the layers in the same manner that was found on fracture surfaces of the ECAP tensile samples. The shattering of these samples could account for the stress leveling off at higher strains.

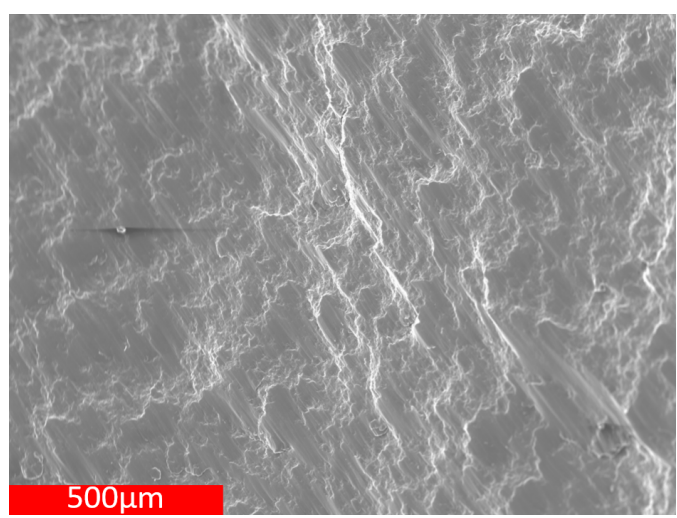

(a)

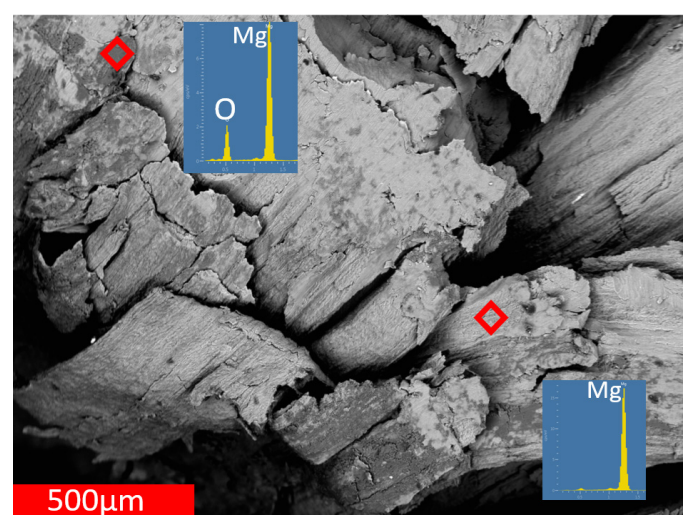

(b)

Figure 3.8. Fracture surfaces of (a) RS (SE SEM image) and (b) ECAP (BSE SEM image) $\mathrm{Mg}-1.8 \mathrm{Zn}-0.8 \mathrm{Ca}-0.2 \mathrm{Mn}$ compression samples.

\subsubsection{Hardness Testing}

Vickers micro-hardness testing was performed on surfaces perpendicular (transverse) and parallel (longitudinal) to the extrusion and ECAP direction to determine if there was a difference in hardness on these two surfaces indicating a slight difference texture. The RS $\mathrm{Mg}-1.2 \mathrm{Zn}-0.8 \mathrm{a}-0.2 \mathrm{Mn}$ alloy exhibited a significantly higher hardness on the transverse surface compared to the longitudinal surface (Table 3.4). The ECAP processed Mg$1.2 \mathrm{Zn}-0.8 \mathrm{Ca}-0.2 \mathrm{Mn}$ alloy and both the RS and ECAP processed $\mathrm{Mg}-1.8 \mathrm{Zn}-0.8 \mathrm{Ca}-0.2 \mathrm{Mn}$ alloys did not show a significant difference in hardness between the two different surfaces. Between the RS processed and ECAP'ed samples, the hardness increased by about $20 \mathrm{H}_{\mathrm{v}}$ for the $\mathrm{Mg}-1.2 \mathrm{Zn}-0.8 \mathrm{Ca}-0.2 \mathrm{Mn}$ and by about $10 \mathrm{HV}$ for the $\mathrm{Mg}-1.8 \mathrm{Zn}-0.8 \mathrm{Ca}-$ $0.2 \mathrm{Mn}$ alloys (Table 3.4). 
Table 3.4. Table of Vickers microhardness taken on the surfacess perpendicular (transverse) and parallel (longitudinal) to the extrusion and ECAP direction.

\begin{tabular}{|c|c|c|}
\hline Alloy & $\begin{array}{c}\text { Transverse } \\
\left(\mathrm{H}_{\mathrm{v}}\right)\end{array}$ & $\begin{array}{c}\text { Longitudinal } \\
\left(\mathrm{H}_{\mathrm{v}}\right)\end{array}$ \\
\hline $\begin{array}{c}\mathrm{RS} \\
\mathrm{Mg}-1.2 \mathrm{Zn}-0.8 \mathrm{Ca}-0.2 \mathrm{Mn}\end{array}$ & $68 \pm 2$ & $62 \pm 3$ \\
\hline $\begin{array}{c}\text { ECAP } \\
\mathrm{Mg}-1.2 \mathrm{Zn}-0.8 \mathrm{Ca}-0.2 \mathrm{Mn}\end{array}$ & $83 \pm 2$ & $84 \pm 3$ \\
\hline $\begin{array}{c}\mathrm{RS} \\
\mathrm{Mg}-1.8 \mathrm{Zn}-0.8 \mathrm{Ca}-0.2 \mathrm{Mn}\end{array}$ & $63 \pm 3$ & $64 \pm 4$ \\
\hline $\begin{array}{c}\text { ECAP } \\
\mathrm{Mg}-1.8 \mathrm{Zn}-0.8 \mathrm{Ca}-0.2 \mathrm{Mn}\end{array}$ & $75 \pm 2$ & $75 \pm 4$ \\
\hline
\end{tabular}

\subsection{Corrosion Properties}

\subsubsection{Electrochemical Testing}

Electrochemical tests were performed to evaluate the corrosion rates and underlying mechanisms of corrosion of the $\mathrm{Mg}-\mathrm{Zn}-\mathrm{Ca}$ alloys. Corrosion rates were calculated from potentiodynamic curves using the Tafel extrapolation method (Figure 3.9). The electrochemical potential $\left(\mathrm{E}_{\mathrm{V}}\right)$ of the ECAP processed $\mathrm{Mg}-1.2 \mathrm{Zn}-0.8 \mathrm{Ca}-0.2 \mathrm{Mn}$ alloy indicates that it is more noble than the RS processed alloy. However, the calculated corrosion rate of the ECAP processed alloy was almost double the calculated corrosion rate of the RS processed alloy (Table 3.5). The $\mathrm{E}_{\mathrm{V}}$ of the ECAP processed Mg-1.8Zn$0.8 \mathrm{Ca}-0.2 \mathrm{Mn}$ alloys did not change after ECAP but the corrosion rate of the ECAP processed alloy was significantly larger (Table 3.5).

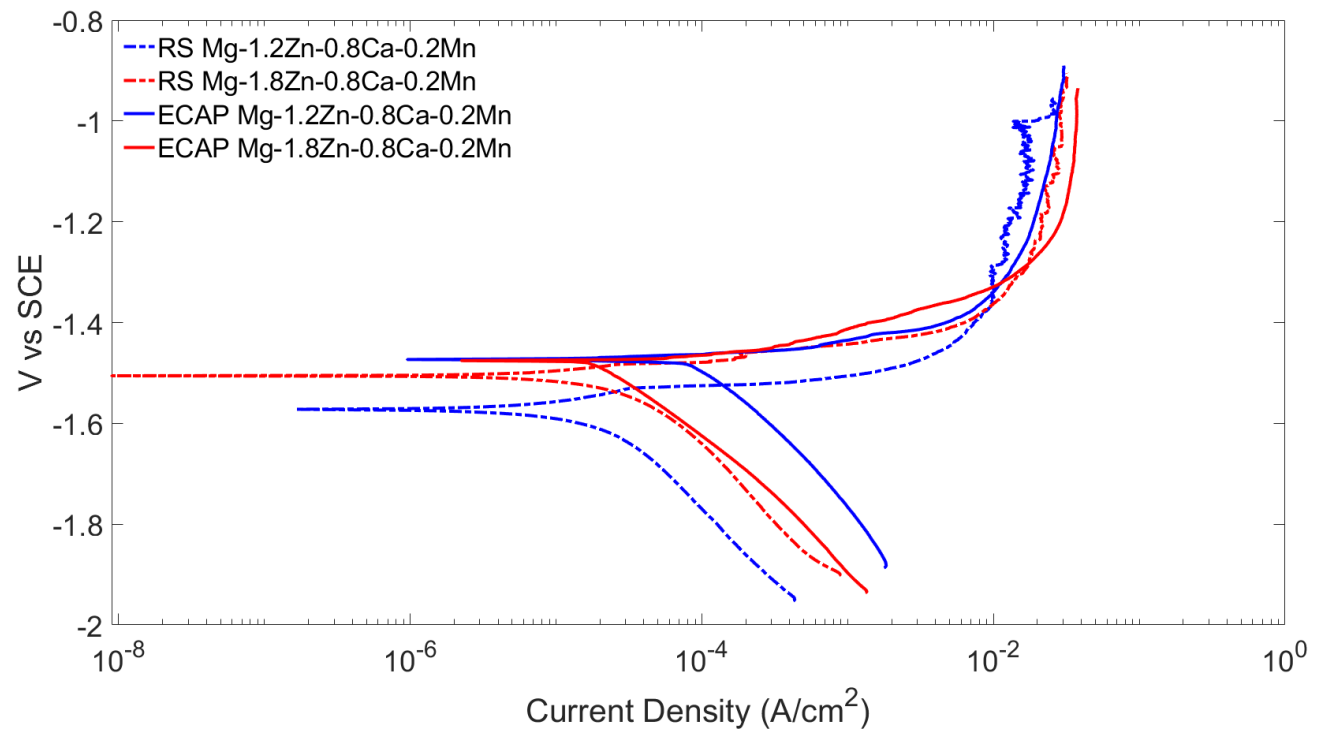

Figure 3.9. Potentiodynamic curves for RS and ECAP Mg-1.2Zn-0.8Ca- $0.2 \mathrm{Mn}$ and $\mathrm{Mg}-$ $1.8 \mathrm{Zn}-0.8 \mathrm{Ca}-0.2 \mathrm{Mn}$ alloys. 
Table 3.5. Electrochemical potential, current density, and corrosion rates calculated from Tafel extrapolation for Mg-1.2Zn-0.8Ca- $0.2 \mathrm{Mn}$ and $\mathrm{Mg}-1.8 \mathrm{Zn}--0.8 \mathrm{Ca}-0.2 \mathrm{Mn} \mathrm{RS}$ and ECAP alloys.

\begin{tabular}{cccc}
\hline Alloy & $\begin{array}{c}\mathbf{E}_{\mathbf{v}} \\
(\mathbf{V})\end{array}$ & $\begin{array}{c}\mathbf{i} \text { c } \\
\left(\boldsymbol{\mu A} / \mathbf{c m}^{2}\right)\end{array}$ & $\begin{array}{c}\text { Corrosion Rate } \\
(\mathbf{m m} / \mathbf{y r})\end{array}$ \\
\hline $\begin{array}{c}\mathrm{RS} \\
\mathrm{Mg}-1.2 \mathrm{Zn}-0.8 \mathrm{Ca}-0.2 \mathrm{Mn}\end{array}$ & $-1.53 \pm 0.05$ & $12 \pm 6$ & $1.1 \pm 0.7$ \\
$\begin{array}{c}\mathrm{ECAP} \\
\mathrm{Mg}-1.2 \mathrm{Zn}-0.8 \mathrm{Ca}-0.2 \mathrm{Mn} \\
\mathrm{RS}\end{array}$ & $-1.48 \pm 0.03$ & $90 \pm 10$ & $2.1 \pm 0.4$ \\
$\begin{array}{c}\mathrm{Mg}-1.8 \mathrm{Zn}-0.8 \mathrm{Ca}-0.2 \mathrm{Mn} \\
\mathrm{ECAP}\end{array}$ & $-1.49 \pm 0.02$ & $39 \pm 8$ & $1.7 \pm 0.7$ \\
$\mathrm{Mg}-1.8 \mathrm{Zn}-0.8 \mathrm{Ca}-0.2 \mathrm{Mn}$ & $-1.49 \pm 0.01$ & $36 \pm 3$ & $0.8 \pm 0.2$ \\
\hline
\end{tabular}

The Nyquist plots from EIS testing show larger high frequency (HF) capacitive loops for the RS processed alloys compared to the ECAP processed alloys. Larger diameter HF capacitive loops indicate slower dissolution kinetics during corrosion meaning lower corrosion rates [15]. The ECAP processed alloys exhibited almost identical HF capacitive loops but the RS processed $\mathrm{Mg}-1.2 \mathrm{Zn}-0.8 \mathrm{Ca}-0.2 \mathrm{Mn}$ capacitive loop was more than double the size of the RS processed $\mathrm{Mg}-1.8 \mathrm{Zn}-0.8 \mathrm{Ca}-0.2 \mathrm{Mn}$. The larger diameter loops for the RS processed alloys indicate that these alloys experienced slower corrosion kinetics than the ECAP alloys. The curves for the RS and ECAP processed Mg-1.8Zn$0.8 \mathrm{Ca}-0.2 \mathrm{Mn}$ alloys exhibit a slight inductive tail in the low frequency region of the curve on the right end. The slight inductive tails for the $\mathrm{Mg}-1.8 \mathrm{Zn}-0.8 \mathrm{Ca}-0.2 \mathrm{Mn}$ alloys suggest the alloy experienced pitting during corrosion or that intermediate phases were adsorbed on the alloy [43]. 


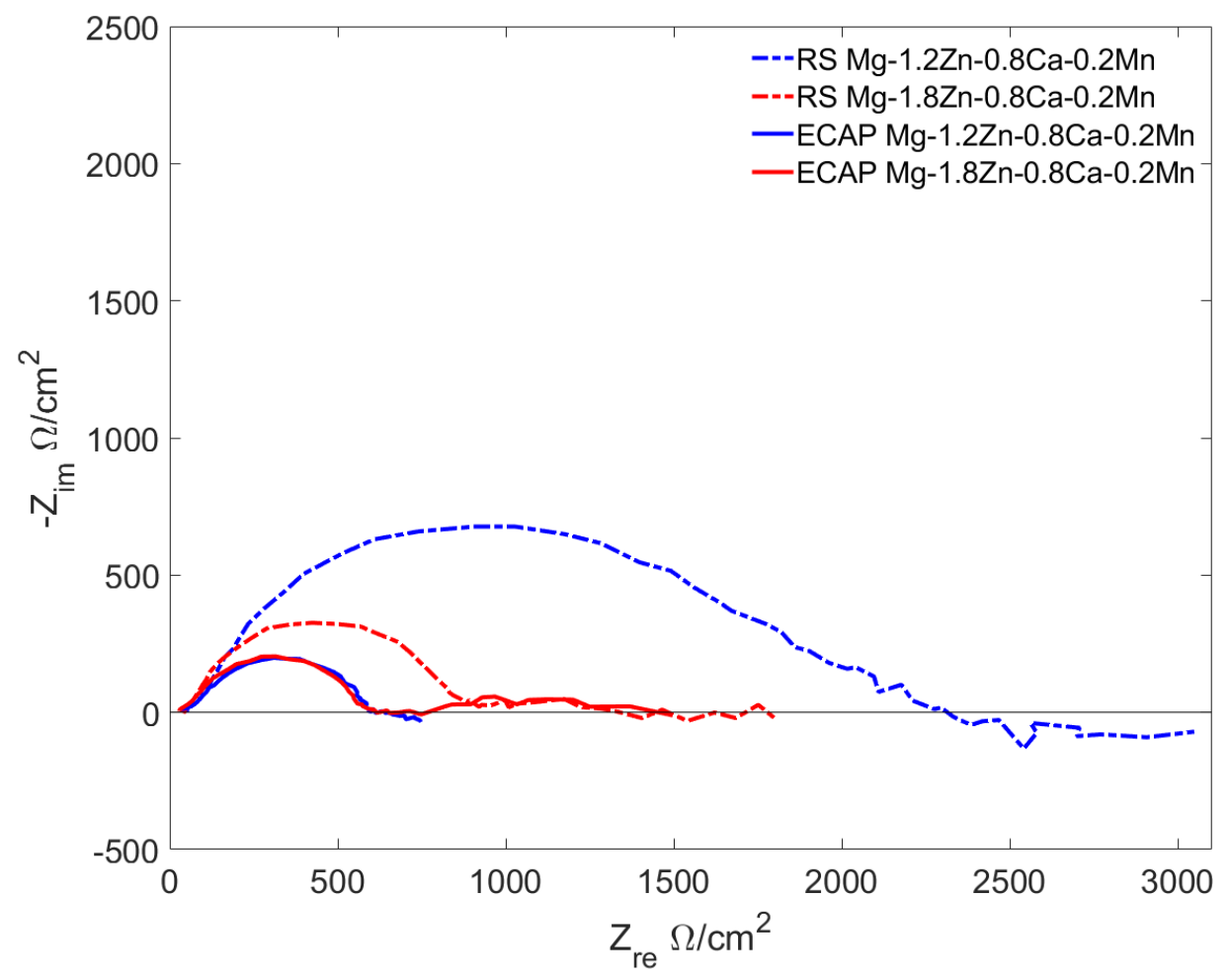

Figure 3.10. Nyquist plot from EIS testing of Mg-1.2Zn-0.8Ca-0.2Mn and Mg-1.8Zn$0.8 \mathrm{Ca}-0.2 \mathrm{Mn} \mathrm{RS}$ and ECAP alloys.

Examining the Bode plots, the RS processed $\mathrm{Mg}-1.2 \mathrm{Zn}-0.8 \mathrm{Ca}-0.2 \mathrm{Mn}$ alloy had the highest impedance, $|Z|,\left(\sim 2200 \Omega / \mathrm{cm}^{2}\right)$ of the four samples tested over all frequencies. The ECAP processed $\mathrm{Mg}-1.2 \mathrm{Zn}-0.8 \mathrm{Ca}-0.2 \mathrm{Mn}$ alloy had the lowest impedance $(\sim 800$ $\Omega / \mathrm{cm}^{2}$ ) of the four alloys at low frequencies and then at high frequencies it possessed an impedance higher than the $\mathrm{Mg}-1.8 \mathrm{Zn}-0.8 \mathrm{Ca}-0.2 \mathrm{Mn}$ processed alloys. The $\mathrm{Mg}-1.8 \mathrm{Zn}-$ $0.8 \mathrm{Ca}-0.2 \mathrm{Mn}$ alloys had an impedance of about $1500 \Omega / \mathrm{cm}^{2}$ at low frequencies and then the impedance dropped farther than the ECAP $\mathrm{Mg}-1.2 \mathrm{Zn}-0.8 \mathrm{Ca}-0.2 \mathrm{Mn}$ alloy at high frequencies. Examining the phase shift curves, the peaks of the RS processed alloys peaked higher $\left(\sim 55^{\circ}\right)$ than the ECAP processed alloys $\left(40^{\circ}\right)$. The phase shift between the $\mathrm{Mg}-1.2 \mathrm{Zn}-0.8 \mathrm{Ca}-0.2 \mathrm{Mn}$ and $\mathrm{Mg}-1.8 \mathrm{Zn}-0.8 \mathrm{Ca}-0.2 \mathrm{Mn}$ alloys demonstrates a lower susceptibility to corrosion. 


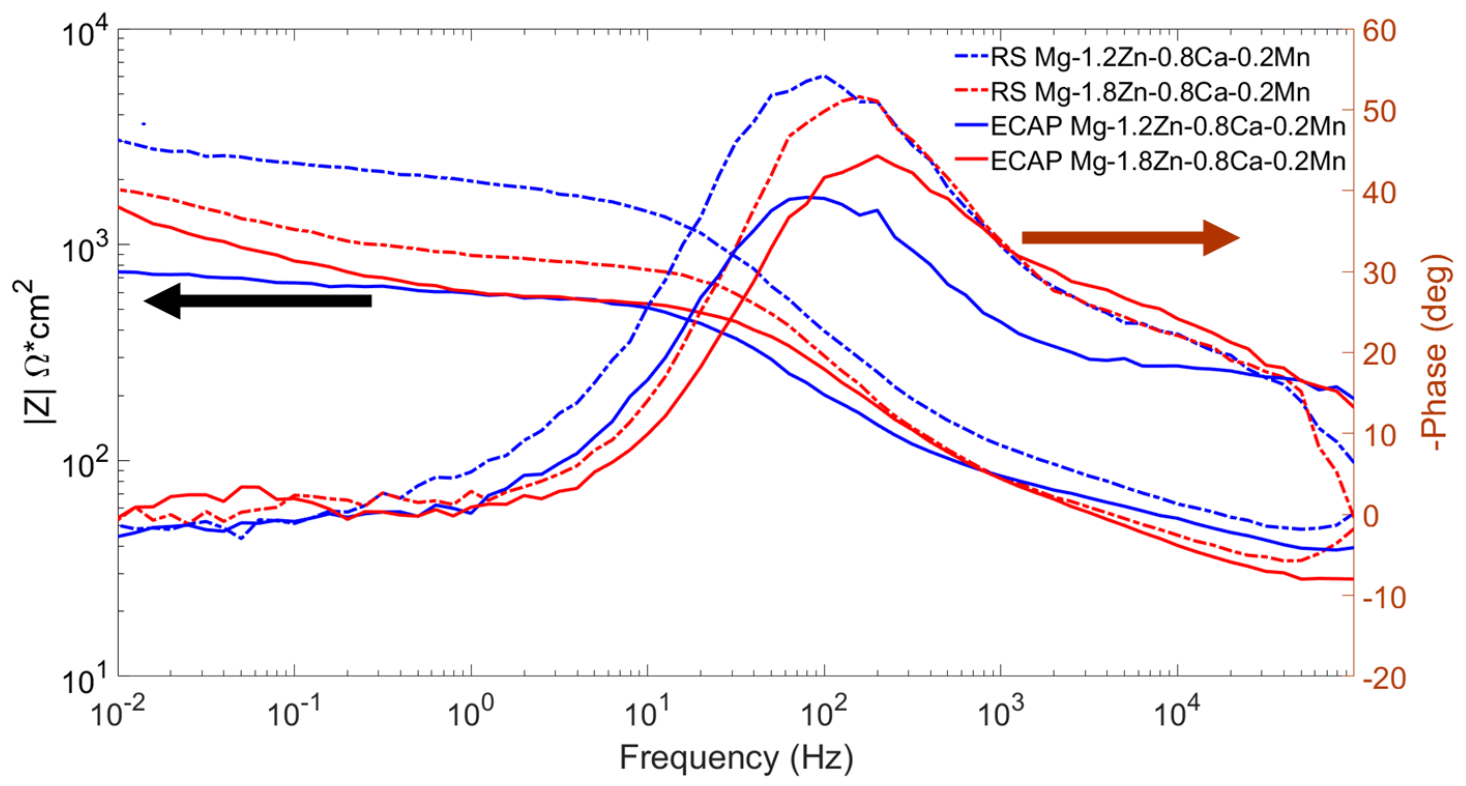

Figure 3.11. Bode plot from EIS testing of $\mathrm{Mg}-1.2 \mathrm{Zn}-0.8 \mathrm{Ca}-0.2 \mathrm{Mn}$ and $\mathrm{Mg}-1.8 \mathrm{Zn}-$ $0.8 \mathrm{Ca}-0.2 \mathrm{Mn} \mathrm{RS}$ and ECAP alloys.

\subsubsection{Immersion Testing}

The Mg-1.2Zn-0.8Ca-0.2Mn alloy exhibited lower degradation rates compared to the $\mathrm{Mg}-1.8 \mathrm{Zn}-0.8 \mathrm{Ca}-0.2 \mathrm{Mn}$ alloy in both processing conditions (Figure 3.12). For the RS processed alloys, the degradation rate slowed down over time until after 10 days when the degradation rate rapidly increased. The ECAP $\mathrm{Mg}-1.8 \mathrm{Zn}-0.8 \mathrm{Ca}-0.2 \mathrm{Mn}$ alloy exhibited a degradation rate that continually decreased over time. For the Mg-1.2Zn$0.8 \mathrm{Ca}-0.2 \mathrm{Mn}$ ECAP alloy over the 10 day period, the immersion sample degradation rate followed the same trend as the ECAP Mg-1.8Zn-0.8Ca- $0.2 \mathrm{Mn}$ but had overall lower degradation rates. At 15 days, the ECAP Mg-1.2Zn-0.8Ca-0.2Mn samples degraded too heavily over the immersion time that the degradation rate could not be determined. Though considering that the samples degraded too far to be analyzed, the samples would appear to follow the same trends as the RS alloy, where past 10 days the degradation of the material rapidly increases.

The size and amount of pits were larger on the surface of the ECAP processed alloys for 2 days and 10 days compared to the RS processed alloys immersed for the same duration (Figure 3.13). This trend in the condition of the corrosion surfaces between the ECAP and $\mathrm{RS}$ processed alloys correlates to the higher degradation rates calculated from the mass loss experiments. The surfaces of the RS and ECAP processed Mg-1.8Zn-0.8Ca$0.2 \mathrm{Mn}$ alloys exhibit larger pits and more severely corroded features compared to the $\mathrm{Mg}-1.2 \mathrm{Zn}-0.8 \mathrm{Ca}-0.2 \mathrm{Mn}$ alloys of the same processing route. In the RS processed alloy images, there appears to be deep crevices along the surface that look like the cracks in the ECAP alloys. 


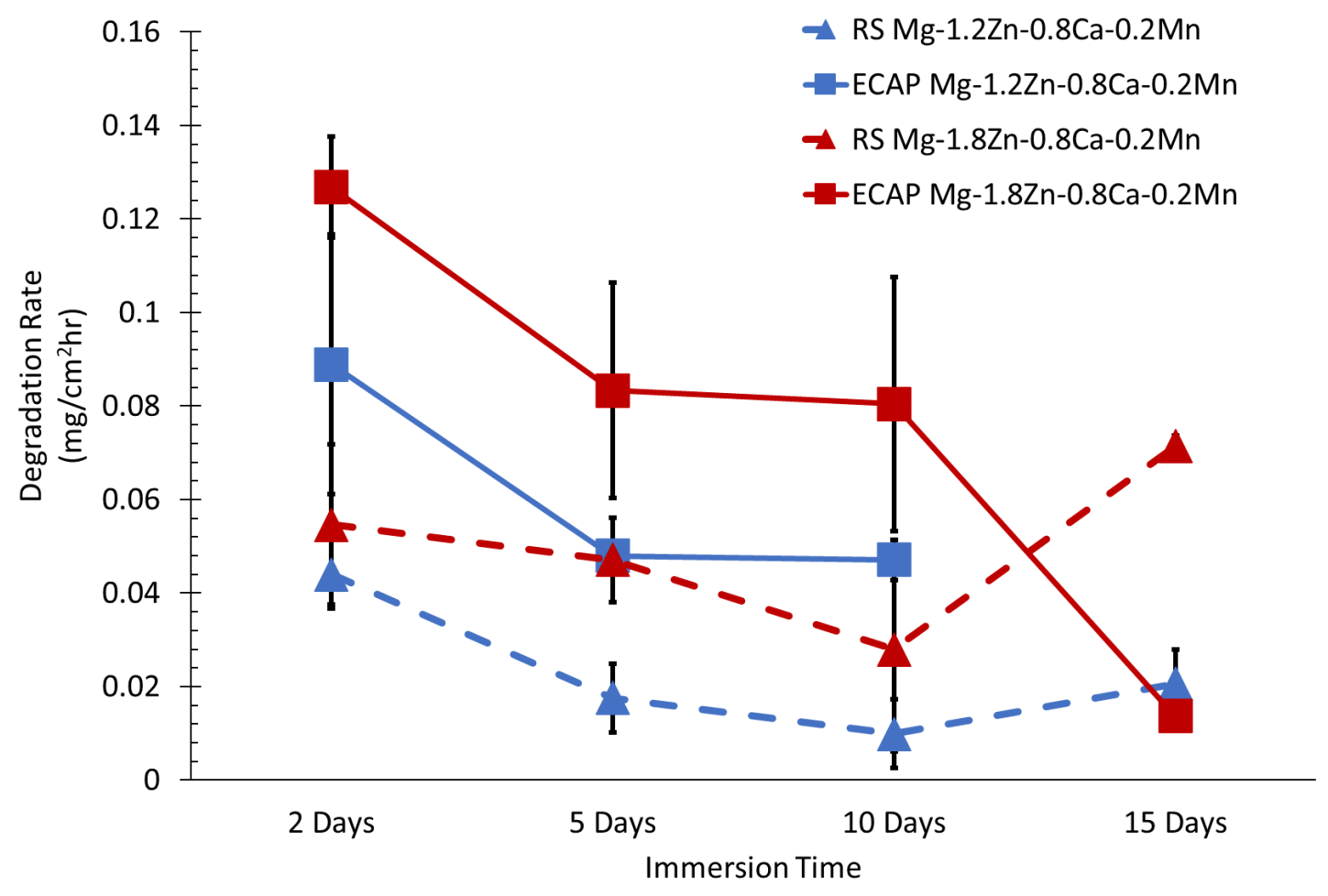

Figure 3.12. Weight loss of Mg-1.2Zn- $0.8 \mathrm{Ca}-0.2 \mathrm{Mn}$ (blue) and $\mathrm{Mg}-1.8 \mathrm{Zn}-0.8 \mathrm{Ca}-0.2 \mathrm{Mn}$ (red) RS (triangles) and RS+ECAP (squares) alloys.

The side profiles of the immersed samples before the corrosion products were removed were examined (Figure 3.14). In each of the immersion samples, a $\mathrm{Mg}(\mathrm{OH})_{2}$ layer (darkest, middle layer) formed on the surface of the magnesium alloys (gray, inner-most layer) and then a Ca-P hydroxyapatite (top, lightest layer) formed on top of the $\mathrm{Mg}(\mathrm{OH})_{2}$ layer. The $\mathrm{Ca}$-P hydroxyapatite layer thickened as the immersion time increased while the $\mathrm{Mg}(\mathrm{OH})_{2}$ remained at about the same thickness. Comparing the RS to the ECAP processed alloys of the same composition, the $\mathrm{Mg}(\mathrm{OH})_{2}$ layer on the ECAP alloys was thicker after two days compared to the RS processed alloys but possessed larger cracks in the layer. The ECAP processed samples developed a thicker Ca-P hydroxyapatite layer as the immersion duration increased but the $\mathrm{Mg}(\mathrm{OH})_{2}$ layer remained about the same thickness and integrity. 


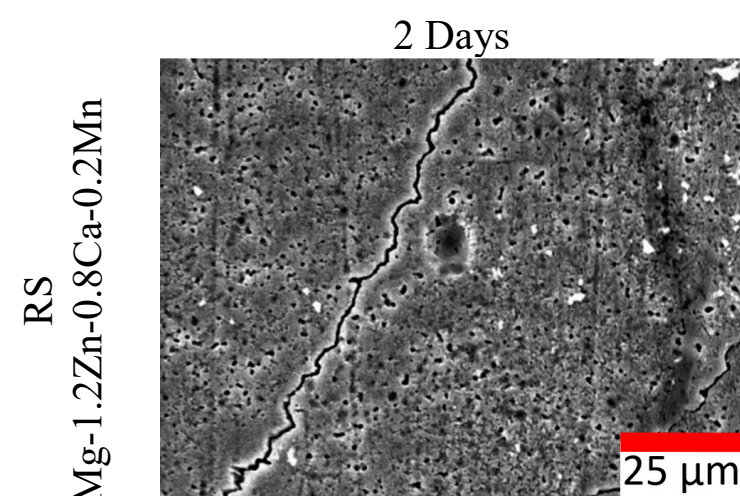

(a)

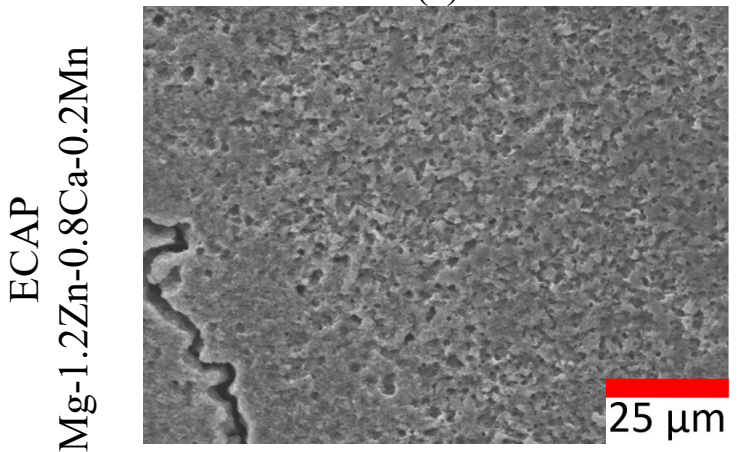

(c)

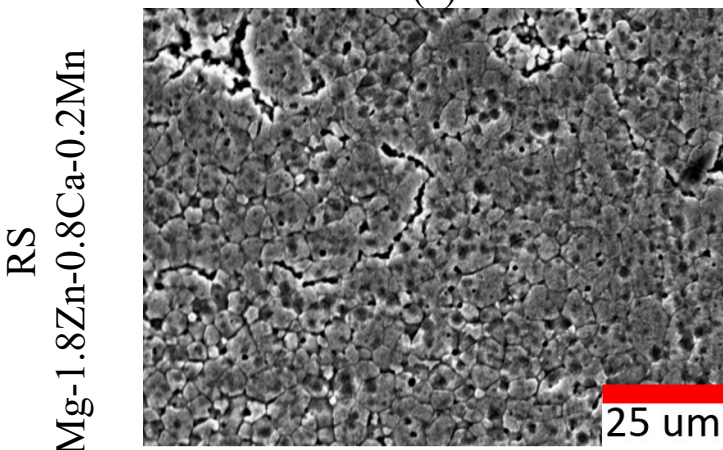

(e)

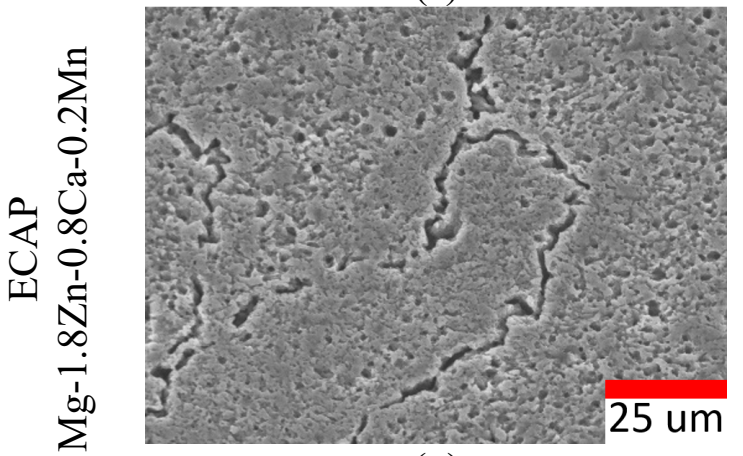

(g)

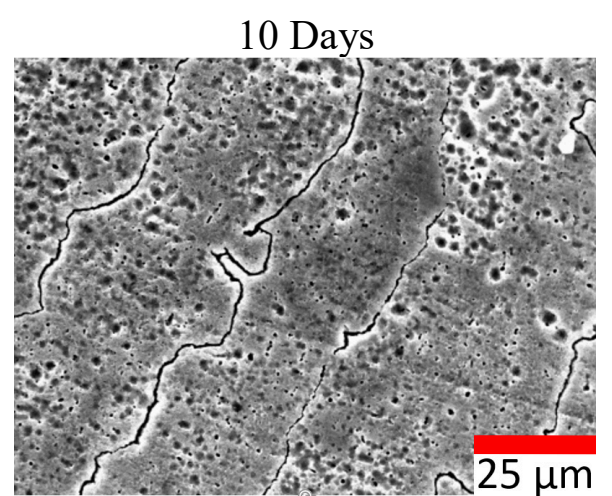

(b)

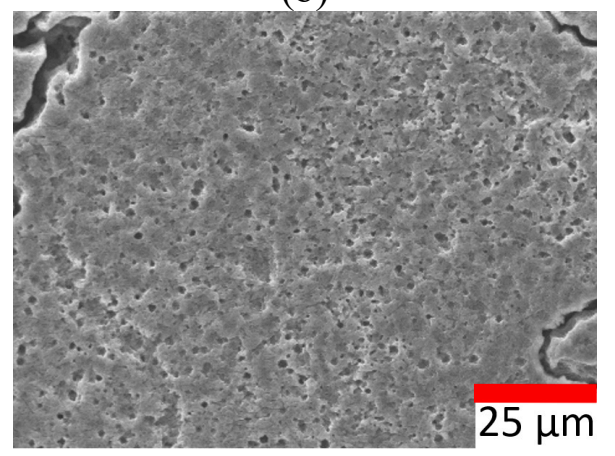

(d)

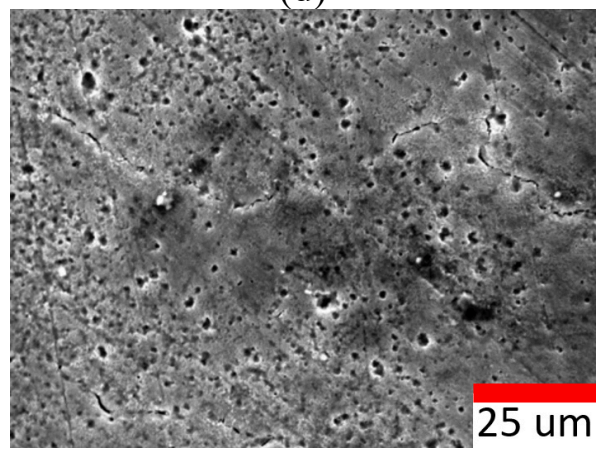

(f)

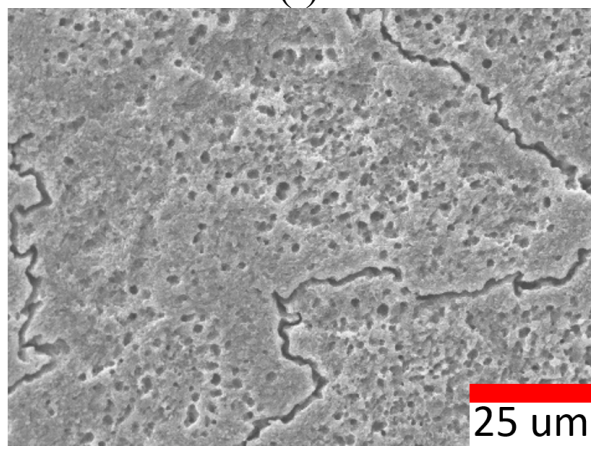

(h)

Figure 3.13. Surface morphology of cleaned samples immersed for 2 and 10 days of RS and ECAP Mg-1.5Zn-1.2Ca-0.4Mn and Mg-2.2Zn-1.2Ca-0.4Mn alloys. 


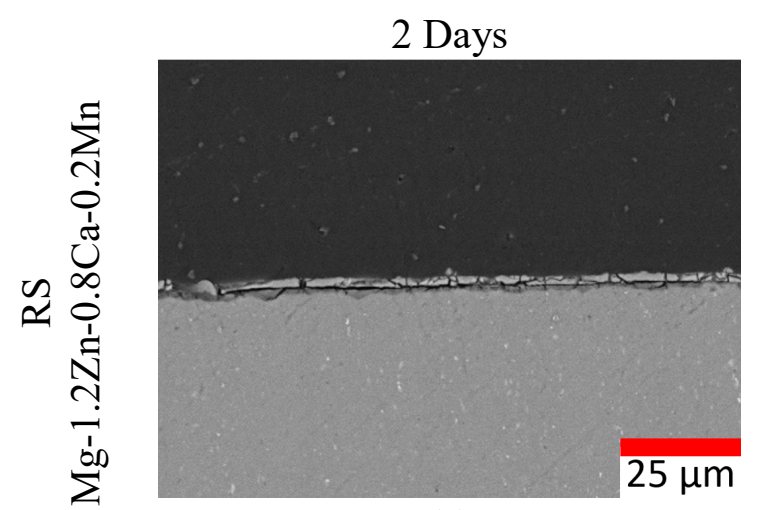

(a)

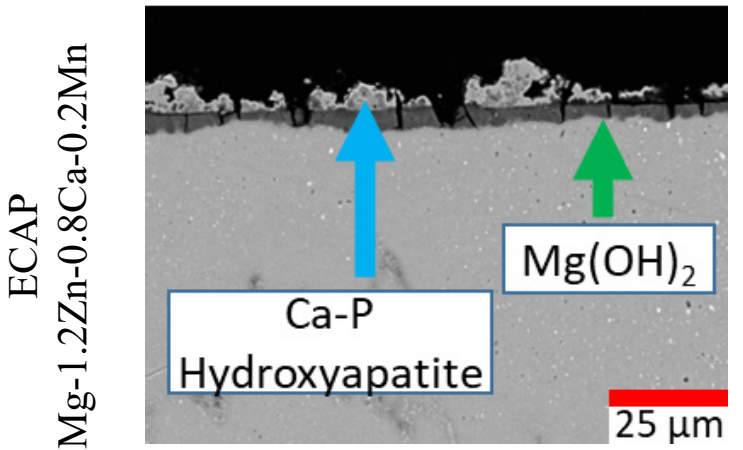

(c)

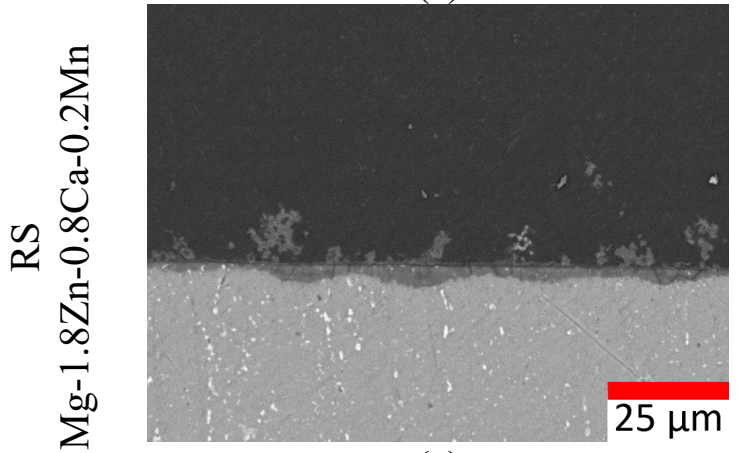

(e)

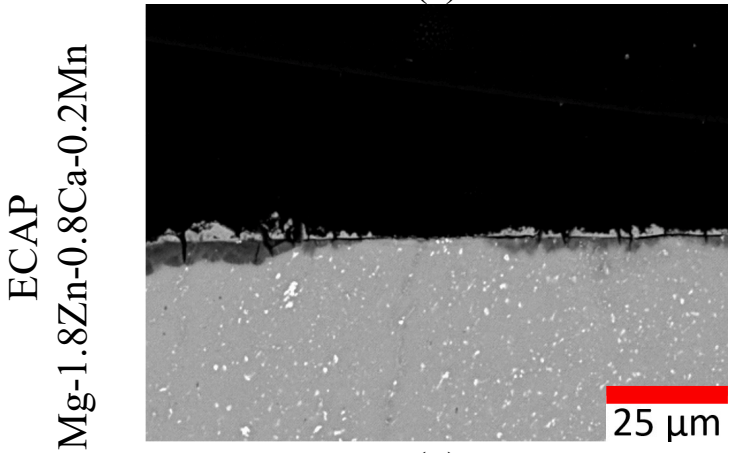

(g)

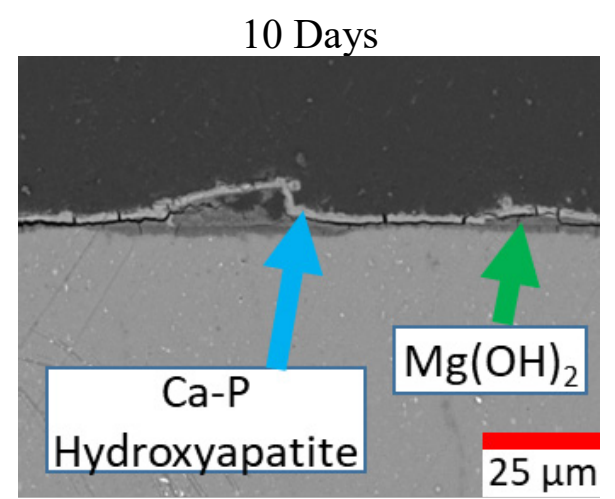

(b)

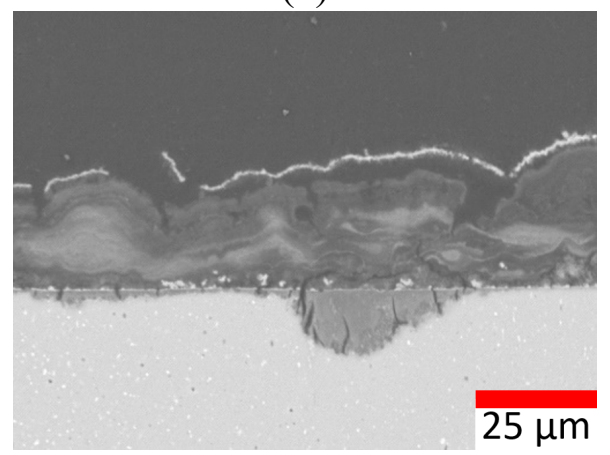

(d)

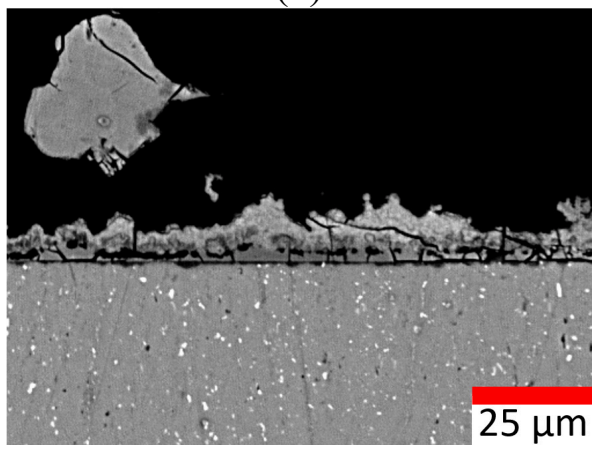

(f)

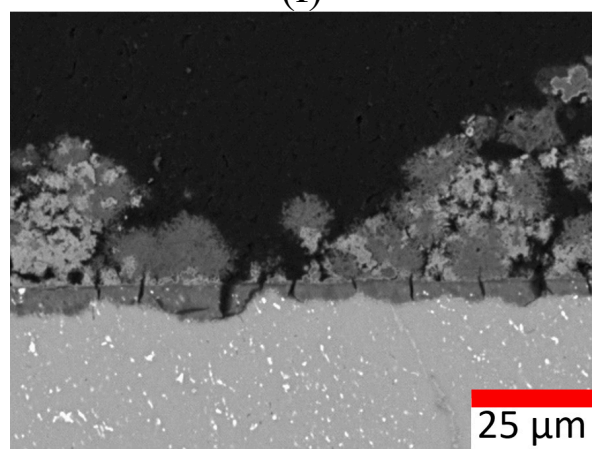

(h)

Figure 3.14. BSE SEM images of cross sections of immersion samples immersed for 2 and 10 days showing the evolution of the $\mathrm{Mg}(\mathrm{OH})_{2}$ and Ca-P hydroxyapatite layers. 


\section{Discussion}

\subsection{Microstructure}

ICP-OES analysis gave the actual compositions of the two alloys produced to compare with their target compositions. In Table 2.1, the measured compositions of $\mathrm{Zn}, \mathrm{Ca}$, and Mn were all lower than the target compositions. The decrease in each element composition could have been due to the melt spinning process which does not expel all material during ejection. Though the actual and target compositions did not match, the composition was consistent over multiple melt spins as compositions for $\mathrm{Zn}, \mathrm{Ca}$ and $\mathrm{Mn}$ varied by only $\sim 0.07 \mathrm{wt} \%$. This indicates that the process was consistent. This consistency led to relabeling the alloys to reflect their actual composition instead of developing a new process for alloy development.

\subsubsection{Phase Analysis}

BSE FE-SEM analysis allowed for the identification of nano-sized $\mathrm{Ca}_{2} \mathrm{Mg}_{6} \mathrm{Zn}_{3}$ precipitates. These precipitates were identified based on precipitate size and morphology found in literature since compositional identification could not be performed [15]. The resolution of the SEM-EDS and interaction volume were too large to analyze these precipitates since they were only about $50 \mathrm{~nm}$ large. The nanosized precipitates were a result from melt spinning increasing the solubility of $\mathrm{Ca}$ and $\mathrm{Zn}$ within the magnesium matrix due to the rapid cooling rate. This prevented coarse $\mathrm{Ca}_{2} \mathrm{Mg}_{6} \mathrm{Zn}_{3}$ precipitates from forming during solidification [15,34]. These nano-sized precipitates are more abundant after ECAP processing as it induced the dynamic precipitation of the $\mathrm{Ca}_{2} \mathrm{Mg}_{6} \mathrm{Zn}_{3}$ phase. Solute atoms remaining within the matrix and grain boundaries act as heterogeneous nucleation sites for these precipitates to form and the low processing temperature $\left(200^{\circ} \mathrm{C}\right)$ prevents these precipitates from coarsening. The nano-sized ternary phase precipitates can prevent grain boundary motion and hinder grain growth during thermomechanical processing through a process known as grain boundary pinning [44]. The pinning of grain boundaries improves the mechanical strength of the alloy by preventing motion of boundaries and dislocations [44].

Larger $\mathrm{Mg}_{2} \mathrm{Ca}$ and $\mathrm{Ca}_{2} \mathrm{Mg}_{6} \mathrm{Zn}_{3}$ precipitates are also found throughout the magnesium matrix in stringer-like fashion along the extrusion direction. These precipitates were larger than the nano-size precipitates as they form prior to melt spinning and subsequently coarsen during the extrusion process. The larger $\mathrm{Mg}_{2} \mathrm{Ca}$ and $\mathrm{Ca}_{2} \mathrm{Mg}_{6} \mathrm{Zn}_{3}$ could only be identified through SEM-EDS because the volume fraction of precipitates was too low for XRD to separate enough peaks from the background for identification.

The interaction volume of the electron beam was considered when identifying the $\mathrm{Mg}_{2} \mathrm{Ca}$ and $\mathrm{Ca}_{2} \mathrm{Mg}_{6} \mathrm{Zn}_{3}$ precipitate. The interaction volume is larger than the precipitate volume so the magnesium matrix surrounding the precipitate in question is also sampled. This leads to a higher magnesium weight fraction and lower $\mathrm{Ca}$ and $\mathrm{Zn}$ weight fractions that what the $\mathrm{Mg}_{2} \mathrm{Ca}$ and $\mathrm{Ca}_{2} \mathrm{Mg}_{6} \mathrm{Zn}_{3}$ phases have stoichiometrically. As shown in Figure 3.2, the approximate $\mathrm{wt} \%$ of $\mathrm{Ca}$ and $\mathrm{Zn}$ are correct $\left(\mathrm{Mg}_{2} \mathrm{Ca}=23 \mathrm{wt} \% \mathrm{Mg} / 77 \mathrm{wt} \% \mathrm{Ca}\right.$ and $\mathrm{Ca}_{2} \mathrm{Mg}_{6} \mathrm{Zn}_{3}=34.5 \mathrm{wt} \% \mathrm{Mg} / 19.0 \mathrm{wt} \% \mathrm{Ca} / 46.5 \mathrm{wt} \% \mathrm{Zn}$ ) if $\mathrm{Mg}$ was not overpowering the measured spectra due to the interaction volume. Multiple powder diffraction files 
(PDFs) of possible Mg-Ca-Zn-Mn phases were compared to the remaining unidentified peaks in the XRD pattern, but no matches were found besides the pure magnesium PDF. The unconventional and rapid solidification processing of the alloys could have also led to a lattice parameter shift in these phases preventing any matching of the small peaks that could be isolated. The low volume fraction of these precipitates keeps the intensity of their diffraction patterns low in comparison to the magnesium matrix. Only the highest intensity peaks would be distinguishable in the diffraction pattern where three peaks are not enough to match a PDF, especially if a lattice parameter shift, and thus, a peak shift has occurred. After ECAP processing, more $\mathrm{Ca}_{2} \mathrm{Mg}_{6} \mathrm{Zn}_{3}$ precipitates form on the edges of the $\mathrm{Mg}_{2} \mathrm{Ca}$ precipitates. This formation could be due to the $\mathrm{Mg}_{2} \mathrm{Ca}$ precipitates acting as heterogeneous nucleation sites for the dynamic precipitation of coarser $\mathrm{Ca}_{2} \mathrm{Mg}_{6} \mathrm{Zn}_{3}$ precipitates compared to the nano-precipitates more dispersed through the matrix. Since the $\mathrm{Mg}_{2} \mathrm{Ca}$ precipitates offer up so much surface area for nucleation, the ternary precipitate starts to mold around them during ECAP processing.

\subsubsection{Grain Structure}

Grain size analysis through optical microscopy provided an understanding of the grain size and morphology in the RS and ECAP processed alloys. The equiaxed, fine grains present after the hot extrusion consolidated the melt spun ribbons indicates that dynamic recrystallization (DRX) took place. DRX in the RS processed alloys was promoted by the high number of solute atoms and fine precipitates within the magnesium matrix acting as heterogenous nucleation sites for grain recrystallization [15]. The DRX'ed grain structure is markedly different from the initial melt spun ribbon grain structure. The ribbon grain structure has fine grains forming along the surface in contact with the copper wheel and then columnar-like grains formed normal to the surface of the copper wheel (Figure 4.1).

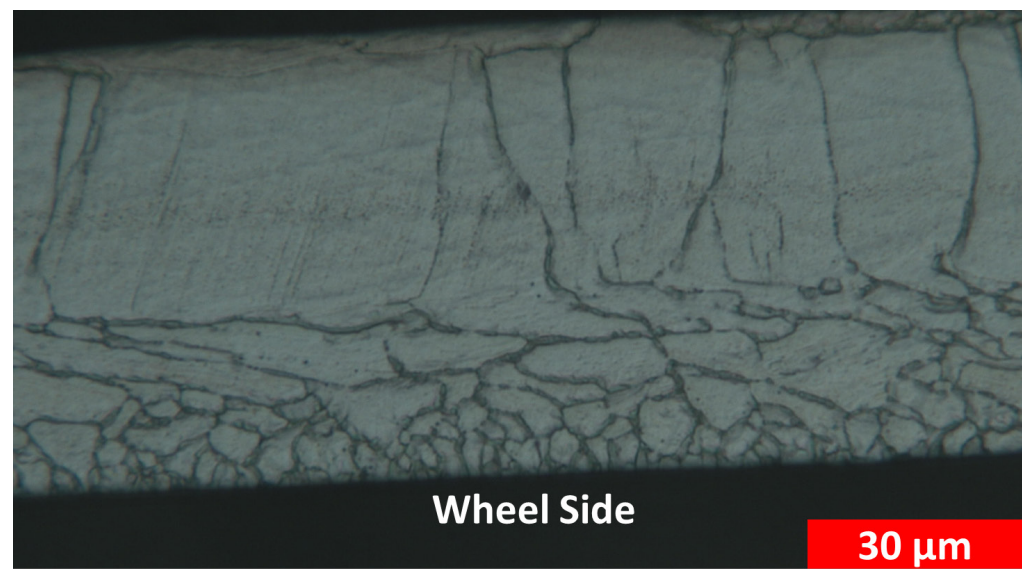

Figure 4.1. Melt spun ribbon of Mg-1.8Zn-0.8Ca-0.2Mn showing columnar grain structure forming above the small grains formed along the wheel surface.

The DRX'ed grain structure of the RS processed alloys is remarkably different from the ECAP processed alloys that display grains preferentially elongated, or deformed, along the extrusion/ECAP direction. The presence of deformed grains in the ECAP processed alloys indicates that DRX did not occur during the two passes through the ECAP die. In 
literature $[8,45,46]$, as the number of ECAP passes increases, the microstructure becomes more homogeneous and equiaxed due to DRX occurring and grains become finer with each pass. The lack of DRX limits the ductility of the alloy as the massive grain refinement accomplished through DRX introduces a higher number of active slip systems by increasing the number of grains in the alloy. The deformed grains from the two passes of ECAP is likely a cause of the observed potential increase in mechanical strength of the two ECAP alloys compared to the RS alloys. DRX was not observed in the ECAP processed alloys after two passes at $200^{\circ} \mathrm{C}$. Grain morphology in the ECAP processed alloys showed elongation of grains along the ECAP direction indicating that deformation was occurring instead of DRX. Since DRX did not occur, the UFG structure that was desired from combining two non-equilibrium processes was not achieved after the two ECAP passes. In literature $[8,46]$, the number of passes to reach UFG structures reached upwards of 8 passes and started with larger average grain sizes $(\sim 100 \mu \mathrm{m})$. Literature has shown that grain size, processing conditions, and precipitate size all influence DRX behavior [47]. Initial grain size is known to influence DRX by helping determine the number of grain boundaries which act as nucleation sites. The smaller the grain size, the more grain boundaries to act as nucleation sites. Even though a smaller grain size offers more areas for new grains to form, a larger grain size allows for more dislocations and shear bands which can also act as nucleation sites. The processing temperature has proven to influence the type of DRX (discontinuous or continuous). Smaller precipitate sizes have proven to prevent DRX by slowing down boundary movement [47]. The small initial grain size in the RS processed alloys $(<10 \mu \mathrm{m})$ compared to the initial grain size of ECAP previously done in literature $(50 \mathrm{~s} \mu \mathrm{m})[8,16]$, a supersaturated matrix, nanoprecipitates, and processing temperature all could have led to incomplete DRX. Additional ECAP passes were planned to determine if DRX would occur with further processing, but additional passes consistently lead to the destruction of the samples.

Though DRX did not occur during ECAP, the grain size distribution graphs in Figure 3.4 show that grain refinement did occur. The distributions for the ECAP alloys are narrower than for the RS processed alloys indicating that the number of larger grains in the RS processed alloys were getting refined. The refinement of the grains sized closer to and above $10 \mu \mathrm{m}$ may not be the widespread refinement that was expected through ECAP but shows ECAP has the potential of inducing grain refinement significant enough to eventually cause changes in ductility and corrosion properties of $\mathrm{Mg}-\mathrm{Zn}-\mathrm{Ca}$ alloys.

\subsection{Mechanical Behavior}

RS and ECAP processed alloys exhibited brittle failure modes. This was unexpected behavior for these alloys since the RS and ECAP processes individually have shown to improve ductility in magnesium alloys (Table 4.1). 
Table 4.1. Properties of melt spun and ECAP processed Mg-Zn-Ca alloys

\begin{tabular}{|c|c|c|c|}
\hline Material & $\begin{array}{l}\text { Tensile Strength } \\
\text { (MPa) }\end{array}$ & $\begin{array}{l}\text { Elongation } \\
(\% \text { EL) }\end{array}$ & Reference \\
\hline $\begin{array}{c}\text { Melt Spun } \\
\mathrm{Mg}-2.0 \mathrm{Zn}-0.5 \mathrm{Ca}-0.4 \mathrm{Mn}\end{array}$ & $294 \pm 7$ & $19 \pm 3$ & [15] \\
\hline $\begin{array}{c}\text { ECAP } \\
\mathrm{Mg}-1.0 \mathrm{Zn}-0.2 \mathrm{Ca}\end{array}$ & $195 \pm 8$ & $10 \pm 1$ & [45] \\
\hline
\end{tabular}

Inspection of the fracture surfaces of the RS processed alloys indicated these alloys failed prematurely due to flaws within the samples. In ductile fracture, dimpling is evident on the fracture surfaces and in brittle fracture, fracture surfaces are relatively smooth and there is typically evidence of fracture emanating from a defect such as a crack, inclusion, etc. The RS processed alloys had relatively smooth surfaces suggesting a somewhat homogeneous structure. Though the fracture surfaces did have some features, the absence of dimpling indicates that the RS processed alloys failed via brittle fracture likely due to flawss within the alloys. The consistency in ductility of both RS processed alloys ( $2-3 \%$ EL) indicates that the presence of extrinsic flaws was consistent between samples. This consistency implies that these flaws are due to a consistent error in the alloys, likely from processing, and not an outlier in a sample.

In the ECAP processed alloys, the ductility at fracture was below 1\% EL. Evidence of flawss was apparent in the fracture surfaces of the ECAP samples. Large cracks that extended through the sample along the extrusion/ECAP direction covered the fracture surface (Figure 3.6b and Figure 3.8b). Because ECAP processing introduces equivalent strains of 0.76 per pass, the high amount of strain causes even the smallest flaws within the material to worsen with each pass. The large strain imposed during the ECAP process causes fractures to form around any preexisting flaws in the RS processed material. These fractures will continue to grow during processing and eventually lead to the premature failure of the sample observed here. The large cracks contributed to the lower elongation of the ECAP processed alloys in tensile and compression testing. These cracks extended along the extrusion/ECAP direction so during tensile and compression testing, the layers that these cracks created, are either pulled apart or pushed together, directly stressing the weakest point in the alloys leading to premature failure.

The layers these cracks made look similar to ribbons. The arrangement of layers indicates that these cracks could have been caused by incomplete ribbon consolidation during hot extrusion. Though the RS processed alloys appeared completely consolidated, the low ductility from tensile testing compared to values reported in literature indicates that there were consistent cracks within these alloys as well. These cracks could have existed, and then grown to a more prominent size during ECAP processing. The incomplete consolidation of the melt spun ribbons could have been due to using a low extrusion ratio that could not completely consolidate the ribbons. These flaws were not discovered until after processing was completed and tensile testing was done so consolidation with a higher extrusion ratio and subsequent ECAP processing could not have been carried out in the expected time frame of this project. Extruding with a higher extrusion ratio also 
would have also created further complications with processing because the produced material would have a diameter smaller than the diameter required to use the ECAP die without creating entirely new tooling.

SEM-EDS analysis of the ECAP tensile and compression fracture surfaces revealed that an oxide formed in the cracks and around the edges of these cracks, presumably MgO. This oxide could have formed during ECAP processing since this is a thermomechanical process in an atmosphere that contained oxygen so when these cracks formed at elevated temperatures, the oxide formed quickly. The formation of this oxide could also further explain why the ductility of the ECAP processed alloys was so low. This indicates that the measured UTS and ductility are not representative of the metal alloy but a combination of the metal alloy and oxide, similar to how a composite works.

Because of these crackss within the alloys, the measured strength and ductility (both tensile and compressive) were not in agreement with reported values in literature of similarly processed $\mathrm{Mg}-\mathrm{Zn}-\mathrm{Ca}$ alloys. Despite the premature failure of these alloys, tensile and compression testing showed the potential in performance these alloys had. The addition of $0.6 \mathrm{wt} \% \mathrm{Zn}$ did not cause a significant change in the mechanical strength or ductility between alloys in the same processing state. Comparing the RS and ECAP tensile and compressive stress-strain curves, the two curves for the two different processes followed similar paths with the ECAP alloys exhibiting higher yield strengths than the RS alloys. For the ECAP Mg-1.2Zn-0.8Ca-0.2Mn alloy, the UTS was considered as the YS too since failure occurred at about the $0.2 \%$ offset. The large standard deviation in the UTS for the ECAP Mg-1.2Zn-0.8Ca-0.2Mn alloy was due to the high variability in crack size after ECAP processing. The size and magnitude of cracks that developed through ECAP varied between samples which caused a high variation in strength seen from the ECAP alloys. This is the cause of why the average UTS of the Mg-1.2Zn-0.8Ca$0.2 \mathrm{Mn}$ ECAP alloy was lower compared to the RS processed alloy of the same composition even though two of the three samples withstood higher strengths than the RS $\mathrm{Mg}-1.2 \mathrm{Zn}-0.8 \mathrm{Ca}-0.2 \mathrm{Mn}$ alloy (Figure 8.2). The presence of a larger flaw in one sample caused it to fail at a lower strength than the other two samples. The YS and CYS were both significantly higher in the ECAP alloys than the RS processed alloys before failing at, or shortly after, the yield strengths were reached. Because yield strength is measured at $0.2 \%$ strain, these YS and CYS were comparable between the two processing conditions because it was below the strain where the ECAP alloys failed. This increase in strength was due to the ECAP process introducing new dislocations via the severe deformation processing and new precipitates through dynamic precipitation. Both of these mechanisms increase strength by inhibiting dislocation motion [36]. If these alloys were completely consolidated, the UTS and UCS of the ECAP alloys would have also been higher than the RS processed alloys considering the trends observed in the stressstrain curves before brittle fracture occurred.

The effects of the incomplete consolidation of melt spun ribbons were not as severe in compression testing compared to tensile testing. This is because of the direction of sample size and loading direction. Tensile dogbones were almost 4 times longer than compression samples which means that the maximum sized flaw in the tensile samples 
could be much larger than what is possible within a compression sample. The smaller sample size for compression testing means that the compression samples exhibited a mechanical strength closer to what was expected if samples did not contain cracks and oxides within the cracks. This is because the cracks are much smaller, and thus, would not fail as prematurely as tensile dogbones would. As mentioned previously, tensile testing, pulls apart the weakened unconsolidated layers when loaded but compression testing pushes the layers together. Pushing the layers together instead of pulling them apart allows for higher loads to be withstood before failure so compression ECAP processed alloys reached strains about equivalent to the RS processed alloys but the UCS was lower compared to the RS processed alloys. This was because after the CYS was reached, the samples began to splinter apart causing the slope for the stress-strain curves to flatten out compared to the RS processed alloys (Figure 3.7). The RS processed alloys broke into two pieces along a $45^{\circ}$ angle to the extrusion/ECAP direction in an almost symmetric fashion. The breaks were almost identical across all samples in the same processing condition. The continued rise in strength observed from the RS processed alloy is because compression testing does not exaggerate material flaws like cracks as much as tensile testing does. The fracture surface shows sheared layers between the alloy instead of one crack initiating fracture. This indicates a more consolidated material behavior compared the behavior observed in the ECAP alloys where the material splintered due to the oxides present between the cracks of the alloy.

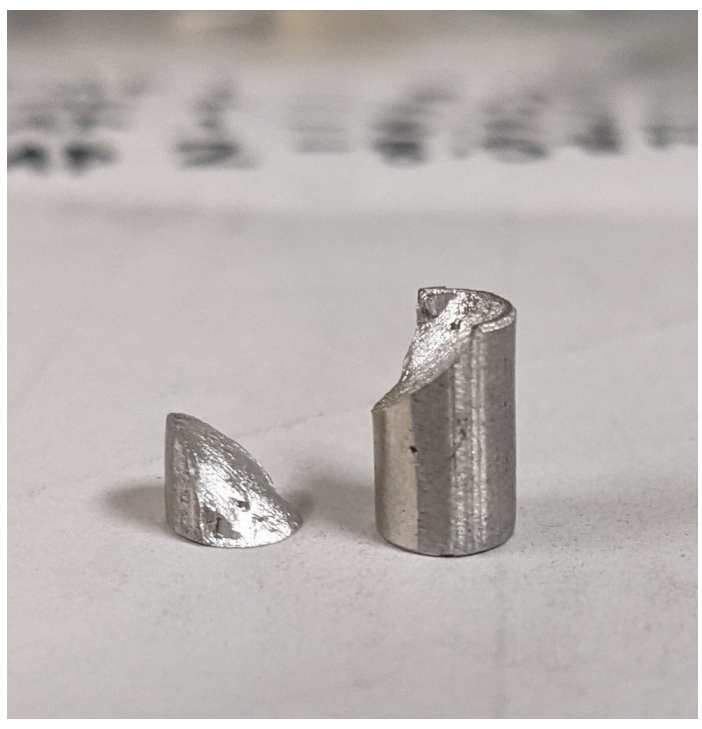

(a)

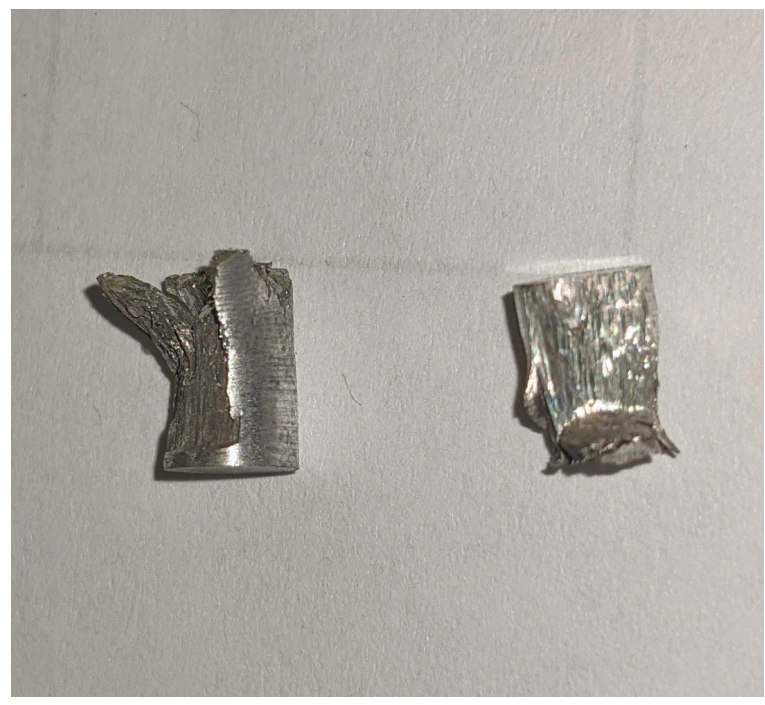

(b)

Figure 4.2.(a) RS and (b) ECAP Mg-1.8Zn-0.8Ca0.2Mn compression samples after testing.

Microvickers hardness measurements were the most representative of the mechanical strength of these non-equilibrium processed alloys because test volume is on the scale of microns that the cracks from extrusion and ECAP were not tested in measurements. Both RS processed alloys exhibited hardness values around $65 \mathrm{H}_{\mathrm{v}}$, consistent with the tensile 
and compressive strengths of these two alloys indicating that the addition of $0.6 \mathrm{wt} \% \mathrm{Zn}$ does not affect mechanical properties after melt spinning and hot extrusion of ribbons. Hardness results showed that the hardness, and therefore strength, did increase after ECAP processing. The increase in hardness was larger $(\sim 10 \mathrm{HV})$ in the $\mathrm{Mg}-1.2 \mathrm{Zn}-0.8 \mathrm{Ca}-$ $0.2 \mathrm{Mn}$ alloy compared to the $\mathrm{Mg}-1.8 \mathrm{Zn}-0.8 \mathrm{Ca}-0.2 \mathrm{Mn}$ alloy after ECAP processing. The increase in hardness supports the indicators of potential increase in UTS for ECAP processed alloys that tensile and compression testing showed since hardness measurements are related to the UTS of a material.

As mentioned previously, the dynamic precipitation of precipitates during ECAP processing would cause an increase in strength. The larger number of nano-precipitates inhibits dislocation motion and pins grain boundaries so that the material cannot yield as easily. The grain morphology and size also play a role in increasing the strength of the ECAP alloys. Both alloys after ECAP processing showed elongated grains, evidence of deformation occurring instead of DRX. If DRX occurred equiaxed grains similar to the RS processed alloys but smaller in size would have been present. The deformation inhibits dislocation motion by introducing more dislocations which prevent dislocation motion, and thus, increase the strength of these alloys. The Mg-1.2Zn-0.8Ca- $0.2 \mathrm{Mn}$ alloy did experience a grain size reduction by about $0.5 \mu \mathrm{m}$ in average while the $\mathrm{Mg}-1.8 \mathrm{Zn}-$ $0.8 \mathrm{Ca}-0.2 \mathrm{Mn}$ alloy did not experience a significant grain size reduction. According to the Hall-Petch equation, smaller grain sizes increase strength proportionately so the larger increase in strength of the ECAP Mg- $1.2 \mathrm{Zn}-0.8 \mathrm{Ca}-0.2 \mathrm{Mn}$ could be due to the larger observed grain size reduction. This is because it would be expected that the $\mathrm{Mg}-1.8 \mathrm{Zn}-$ $0.8 \mathrm{Ca}-0.2 \mathrm{Mn}$ have a larger increase in strength due to the higher amount of $\mathrm{Zn}$ in the alloy available to form precipitates. The larger increase in hardness for the Mg-1.2Zn$0.8 \mathrm{Ca}-0.2 \mathrm{Mn}$ indicates that grain size reduction has a more significant effect on the mechanical strength of the alloy than nano-precipitates.

Hardness was also performed on the longitudinal and transverse surfaces to the extrusion and ECAP direction to determine if texturing due to ECAP processing was present. This was done since electron backscatter diffraction (EBSD) did not have a resolution capable of measuring grains under 10 microns. Comparing the hardness between surfaces for each alloy, only the RS Mg-1.2Zn-0.8Ca-0.2Mn showed evidence of texturing. The lack of observed texturing from this test method could be due to the mechanics of microvickers hardness. The diamond tip that is used creates an indent that causes deformation in all directions rather than load unilaterally as compression and tensile testing does. Since hardness is the measure of this deformation which happens in both the longitudinal and transverse surfaces, this could explain why hardness would have been almost identical between directions. Despite the lack of evidence of texturing from hardness testing, this does not mean that ECAP did not cause texturing of the alloy along the extrusion/ECAP directions. 


\subsection{Corrosion Behavior}

\subsubsection{Potentiodynamic Tests}

It has been recommended by Shi et al. that potentiodynamic testing be done in conjunction with weight loss or hydrogen loss corrosion measurements because results can vary due to the negative difference effect (NDE) and non-steady state conditions that magnesium alloys experience during potentiodynamic testing [7]. The NDE is characterized by the initial plateau above the OCP on the anodic reaction curve [30]. The presence of this plateau is not accounted for in the Tafel extrapolation method of determining the corrosion rate from a potentiodynamic curve. Magnesium also does not reach steady-state corrosion conditions as fast as more passive alloys like aluminums. This can prove to be a problem with Tafel extrapolations as well because this method assumes steady-state conditions. To mitigate this factor, samples were immersed for an hour to best attain steady-state conditions. Because of the NDE, only the cathodic reaction was used for the Tafel extrapolation for $\mathrm{E}_{V}$ and $\mathrm{i}_{\mathrm{CORR}}$ by determining where the cathodic linear approximation intersected with the OCP of the curve. Despite icoRR and $E_{V}$ values potentially not agreeing with reported values in literature, results are comparable within this study since the same test conditions were utilized.

The Mg-1.8Zn-0.8Ca-0.2Mn alloys had a more noble $\mathrm{E}_{\mathrm{v}}$ than the $\mathrm{Mg}-1.2 \mathrm{Zn}-0.8 \mathrm{Ca}-0.2 \mathrm{Mn}$ alloys which was attributed to the higher $\mathrm{Zn}$ content which is a more noble element which can help decrease the OCP in magnitude. At compositions below $4 \mathrm{wt} \%$, Zn helps improve corrosion resistance in $\mathrm{Mg}-\mathrm{Zn}-\mathrm{Ca}$ alloys by promoting the formation of $\mathrm{Ca}_{2} \mathrm{Mg}_{6} \mathrm{Zn}_{3}$. Comparing the $\mathrm{i}_{\text {corr }}$ for the two ECAP alloys, the $\mathrm{i}_{\text {corr }}$ of the Mg-1.2Zn$0.8 \mathrm{Ca}-0.2 \mathrm{Mn}$ alloy rose in average while the $\mathrm{i}_{\mathrm{CORR}}$ of the $\mathrm{Mg}-1.8 \mathrm{Zn}-0.8 \mathrm{Ca}-0.2 \mathrm{Mn}$ decreased. Though these changes are not significantly different from their respective RS processed $i_{\text {CORR }}$ values, these changes could be attributed to the oxide layers found in the ECAP alloys during fractography analysis. A $\mathrm{ZnO}$ could be forming along with the $\mathrm{MgO}$ in the $\mathrm{Mg}-1.8 \mathrm{Zn}-0.8 \mathrm{Ca}-0.2 \mathrm{Mn}$ alloy due to the higher weight fraction of $\mathrm{Zn}$ present within the alloy. If a $\mathrm{ZnO}$ was forming this could account for the change in trend in corrosion current in the ECAP alloys since $\mathrm{Zn}$ is a more noble element and more resistive to corrosion than $\mathrm{Mg}$ and $\mathrm{MgO}$.

Further examination of the potentiodynamic curves reveals that the RS processed alloys have a visible bump in beginning of the anodic curve in the area where the NDE is. This bump in $E_{V}$ could be an indication of the beginning of a shift towards a transpassive region in the anodic reaction. This shift can be caused by change in the corrosion environment $\mathrm{pH}$ which could be made possible due to the dissolution of $\mathrm{Mg}^{2+}$ ions creating a more basic solution [48]. The electrochemical conditions may have been in the perfect spot for this slight change to occur in the reaction before it is overpowered once more. This bump could be due to the change in the presence of $\operatorname{Mg}(\mathrm{OH})_{2}$ which is considered a passive region on the $\mathrm{Mg}$ Pourbaix diagram that is passive at $\mathrm{E}_{\mathrm{V}}>-3 \mathrm{~V}$ and $\mathrm{pH}>8$ [49]. The $\mathrm{Ev}_{\mathrm{V}}$ at the occurrence of the bump was well above the $-3 \mathrm{~V}$ and the $\mathrm{pH}$ could be above 8 since the solution starts at a $\mathrm{pH}$ of 7.4 and the dissolution of $\mathrm{Mg}^{2+}$ creates a basic solution with a $\mathrm{pH}$ of about $10.4-11$ by the end of the test. The change in 
$\mathrm{pH}$ during the test is observed using phenol red indicator in the HBSS, and the solution turns near basic around when the OCP is reached.

In the ECAP samples, this bump in the anodic curve was not observed. The absence of this bump could be due to the formation of a larger amount of $\mathrm{MgO}$ and $\mathrm{ZnO}$ during the ECAP process. The presence of $\mathrm{ZnO}$ could have helped stabilize the $\mathrm{MgO}$ and $\mathrm{Mg}(\mathrm{OH})_{2}$ such that the slight shift towards the transpassive region does not occur. The presence of $\mathrm{ZnO}$ playing a role in stabilizing the shift in reaction is also affirmed by the RS Mg$1.8 \mathrm{Zn}-0.8 \mathrm{Ca}-0.2 \mathrm{Mn}$ alloy having a much less prominent bump in the anodic curve than the RS Mg-1.2Zn-0.8Ca-0.2Mn alloy. The presence of $\mathrm{Zn}$ could help stabilize this shift and then once a larger volume fraction of oxides forms, the shift does not occur.

\subsubsection{EIS Tests}

The Nyquist plots shows similar behavior between the four processed alloys where their high to mid frequency capacitance loops all are about three times as wide as they are tall (Figure 3.10). The presence of the one high to mid frequency loop indicates that the mechanisms of corrosion are mainly driven by charge transfer from alloy to solution (dissolution of the metal) and electrochemical double-layer/oxide-film effects [15]. The aspect ratio of the Nyquist curves is caused by an irregular surface being exposed to the corrosive environment. In a simple Nyquist plot, the high to mid capacitance loop would have an aspect ratio closer to one if the surface was uniform and smooth. Since these samples were polished to a $3 \mu \mathrm{m}$ surface finish, the surfaces did have a roughness to them that also included the presence of other exposed phases and crack surfaces within the alloy. All these irregularities along the surface caused the widening of these loops. The RS Mg-1.2Zn-0.8Ca-0.2Mn alloy had the largest diameter loop, and thus, polarization resistance [50]. A higher polarization resistance is indicative of an improved corrosion resistance [48]. The RS Mg-1.8Zn-0.8Ca-0.2Mn alloy had a smaller capacitance loop, and thus, lower polarization resistance because of the higher amount of $\mathrm{Zn}$ within the alloy. The larger concentration of $\mathrm{Zn}$ leads to more microgalvanic couples between the $\mathrm{Mg}$ matrix and solute atoms and precipitates within the matrix since the $\mathrm{EV}_{\mathrm{V}}$ of $\mathrm{Mg}$ is different from the alloying elements and formed precipitates [51]. The two ECAP alloys had Nyquist curves almost identical to each other. They had the smallest capacitance loops of the four processed alloys tested indicating they have the lowest polarization resistance of all the samples tested. The more prevalent presence of oxides within the ECAP alloy could have attributed to this decrease in polarization resistance because of the presence of cracks which expose the interior of the alloy to corrosion leading to a lower corrosion resistance and accelerated corrosion rate. The two $\mathrm{Mg}-1.8 \mathrm{Zn}-0.8 \mathrm{Ca}-$ $0.2 \mathrm{Mn}$ alloy Nyquist curves (RS and ECAP) show early signs of a low capacitance loop in the right "tail end" of the curves that was not observed for the Mg-1.2Zn- $0.8 \mathrm{Ca}-0.2 \mathrm{Mn}$ alloys. This hint of a low capacitance loop in the higher $\mathrm{Zn}$ content alloys leads to an indication that a possible $\mathrm{Zn}$ oxide along with the $\mathrm{Mg}$ oxide is forming that could be acting as a parallel capacitor to the magnesium matrix. The second loops are faint which suggests that this mechanism is not prominent in the alloy but is related to $\mathrm{Zn}$ composition. The atomic fraction of $\mathrm{Zn}$ increase by $50 \%$ with the $0.6 \mathrm{wt} \% \mathrm{Zn}$ addition that the presence of more $\mathrm{Zn}$ within the alloy is the likely cause for this low capacitance 
loop since it occurred in both the RS and ECAP processed alloys. The Bode plot shows that the $\mathrm{Mg}-1.2 \mathrm{Zn}-0.8 \mathrm{Ca}-0.2 \mathrm{Mn} \mathrm{RS}$ and ECAP processed alloys experienced a peak phase angle at lower frequencies compared to the $\mathrm{Mg}-1.8 \mathrm{Zn}-0.8 \mathrm{Ca}-0.2 \mathrm{Mn}$ alloys. A phase angle shift to lower frequencies indicates a lower susceptibly to corrosion so the alloys with lower $\mathrm{Zn}$ compositions have a lower susceptibility to corrode. This is consistent with the Nyquist plots showing that a higher amount of $\mathrm{Zn}$ does decrease the corrosion resistance by introducing more microgalvanic couples within the alloy.

\subsubsection{Immersion Tests}

Immersion tests are still considered the "gold-standard" for corrosion testing magnesium for determining the corrosion rate because it does not rely on mechanistic assumptions [43]. In the immersion tests performed, the initial degradation rates (2 days) were much higher than the samples immersed for longer periods of time. The high initial degradation rates in this alloy were because the $\mathrm{Mg}(\mathrm{OH})_{2}$ and calcium phosphate hydroxyapatite layers have not formed to the protective films and the $\mathrm{Mg}_{2} \mathrm{Ca}$ precipitates rapidly corrode into solution due to the phase having an electrochemical potential lower than the $\mathrm{Mg}$ matrix. Once these layers begin to thicken, the degradation rate almost levels out to be constant for 5 days and 10 days. The progression of the formation of the $\mathrm{Mg}(\mathrm{OH})_{2}$ and $\mathrm{Ca}-\mathrm{P}$ hydroxyapatite layers can be observed in section 7 where only a thin layer of $\mathrm{Mg}(\mathrm{OH})_{2}$ has formed after two days, and subsequent days show these Ca-P

hydroxyapatite layer thickening. The $\mathrm{Mg}(\mathrm{OH})_{2}$ layer stays about the same thickness once formed as indicated by the cross-section images of the alloys. This layer is the first line of defense between the magnesium matrix and corrosive environment but the cracks in these two layers leave magnesium matrix exposed for corrosion to occur. The decrease in degradation rate observed after two days is because the high initial degradation rate is then averaged over more days with the lower degradation rate once the protective layers form. The leveling of the degradation rate at 10 days from 5 days would then have to be due to a slight increase in degradation rate after 5 days. If the degradation rate stayed the same once the initial degradation had passed, the degradation rate would continue to decrease from 5 days because the higher rate is being spread out over more days with a lower rate.

After 10 days, the RS processed alloys degradation rates increased again for immersion for 15 days. A breakdown in these $\mathrm{Mg}(\mathrm{OH})_{2}$ and Ca-P layers could be happening after the 10 day mark that exposes more and more of the magnesium matrix to the corrosive environment. At such long immersion times, undermining of $\mathrm{Ca}_{2} \mathrm{Mg}_{6} \mathrm{Zn}_{3}$, a more cathodic precipitate than the $\mathrm{Mg}$ matrix, is possible. Undermining occurs when the anodic material surrounding a cathodic precipitate preferentially corrodes at the interface between the matrix and precipitate until the anodic material holding onto the cathodic precipitate corrodes away completely and the precipitate falls out of the matrix instead of degrading away. Undermining exposes large pits on the surface which exposes unprotected surface area to corrode away which accelerates the corrosion rate. The $\mathrm{Mg}_{2} \mathrm{Ca}$ phase is more anodic, thus corroding away sacrificially to the magnesium matrix. Because it corrodes away sacrificially, minimizing the size of $\mathrm{Mg}_{2} \mathrm{Ca}$ precipitates is important. $\mathrm{Ca}_{2} \mathrm{Mg}_{6} \mathrm{Zn}_{3}$ is more cathodic than the magnesium matrix so it initially retards corrosion but at longer corrosion times due to the galvanic potential mismatch the 
magnesium matrix preferentially corrodes away around the precipitates eventually undermining the precipitates leaving pits exposed. Due to the effect $\mathrm{Ca}_{2} \mathrm{Mg}_{6} \mathrm{Zn}_{3}$ has on corrosion at longer times, minimizing the size and quantity of this phase is vital to control the corrosion rate which RS and ECAP processing attempted to improve.

The two ECAP processed alloys possessed higher degradation rates compared to their respective RS processed alloys which was consistent with the behavior observed in potentiodynamic and EIS measurements. After 15 days the ECAP Mg-1.2Zn-0.8Ca$0.2 \mathrm{Mn}$ alloy degraded so severely, pitting wise, that the samples crumbled during the cleaning process such that they couldn't be weighed while the ECAP Mg-1.8Zn-0.8Ca$0,2 \mathrm{Mn}$ alloys had the lowest degradation rates of the four alloys. The two ECAP processed alloy. This higher degradation rates over the first 10 days could be due to the presence of the oxide that formed during ECAP due to the insufficient consolidation of ribbons during hot extrusion as stated previously. The presence of more nanoprecipitates after ECAP also could've contributed to the faster degradation rate of the ECAP alloys. The ECAP Mg-1.8Zn-0.8Ca-0.2Mn alloy's deviation from this trend after 15 days immersed in HBSS could be due to the cleaning process not completely dissolving away the $\mathrm{Mg}(\mathrm{OH})_{2}$ and $\mathrm{Ca}-\mathrm{P}$ hydroxyapatite layers in pits not on the visible surface. Undissolved corrosion products on the samples would have added mass to the samples artificially decreasing the mass loss of the samples, and thus, the degradation rate.

Comparing the cleaned corrosion surfaces from the immersion testing samples, the state of degradation is consistent with trends observed from potentiodynamic, EIS, and mass loss corrosion testing. The ECAP processed alloys showed more progressed corrosion than the RS processed alloys of both compositions. The filiform-like corrosion arms, surface irregularities, and pitting is worse in each of the ECAP alloys compared the respective RS alloy. In the RS alloys, there are cracks that look similar to the ones in the ECAP alloys. These could be the cracks that worsen during ECAP processing and the corrosion occurring during immersion testing preferentially corroded away these areas containing flaws.

Examining the cross sections of the immersed coins before cleaning, the PRs processed alloys exhibit smoother $\mathrm{Mg}$ surfaces underneath the $\mathrm{Mg}(\mathrm{OH})_{2}$ and Ca-P hydroxyapatite layers. This is indicative of a more uniform corrosion behavior where pitting cannot accelerate the corrosion rate. Over time, the Ca-P layer does thicken on top of the $\mathrm{Mg}(\mathrm{OH})_{2}$ layer helping to retard the degradation rate as observed in Figure 3.12 until pitting on the surface accelerates this rate after 10 days by breaking apart these layers and exposing more surface area to the corrosive environment. This $\mathrm{Ca}-\mathrm{P}$ layer does get thicker over time faster on the ECAP processed alloys than on the RS processed alloys which could have helped aided in the drop in degradation rate of the $\mathrm{Mg}-1.8 \mathrm{Zn}-0.8 \mathrm{Ca}-$ $0.2 \mathrm{Mn}$ alloy. 


\section{Conclusions}

Despite the profound effects cracks had on the performance of the $\mathrm{Mg}-1.2 \mathrm{Zn}-0.8 \mathrm{Ca}$ $0.2 \mathrm{Mn}$ and $\mathrm{Mg}-1.8 \mathrm{Zn}-0.8 \mathrm{Ca}-0,2 \mathrm{Mn}$ alloys formulated and tested in this study, research results demonstrate a great potential for combining RS and ECAP processes to produce $\mathrm{Mg}$ alloys with improved the mechanical strength and controlled corrosion behavior. After melt spinning and hot extrusion nano-sized $\mathrm{Ca}_{2} \mathrm{Mg}_{6} \mathrm{Zn}_{3}$ precipitates were dispersed uniformly throughout the magnesium matrix and subsequent ECAP processing of the alloys induced dynamic precipitation of additional nano-sized $\mathrm{Ca}_{2} \mathrm{Mg}_{6} \mathrm{Zn}_{3}$ precipitates.

The increase in content of $\mathrm{Zn}$ from 1.2 to $1.8 \mathrm{wt} \%$ did not have any significant effect on the strength, ductility, and corrosion behavior of Mg-Zn-Ca-Mn alloy. In fact, the addition of $\mathrm{Zn}$ reduced the corrosion resistance of the alloy, with nearly no changes in the alloy's strength after ECAP processing.

The premature fracturing of both the RS and ECAP alloys caused by the presence of processing flaws prevented a broader evaluation of the alloys' ductility and direct comparison between RS and ECAP processes. Nevertheless, an increase in yield strength was recorded after ECAP processing of the alloys in both tensile and compression testing. This increase in alloy's strength is attributed to the dynamic precipitation of the Ca${ }_{2} \mathrm{Mg}_{6} \mathrm{Zn}_{3}$ phase and elongation of the grain structure during deformation.

ECAP processing appeared to decrease the corrosion resistance of both $\mathrm{Mg}-1.2 \mathrm{Zn}-0.8 \mathrm{Ca}$ $0.2 \mathrm{Mn}$ and $\mathrm{Mg}-1.8 \mathrm{Zn}-0.8 \mathrm{Ca}-0,2 \mathrm{Mn}$ alloys. However, this decrease in corrosion resistance could be caused by the presence of larger cracks in the samples exposing more surface area of the alloy to corrosion. Immersion testing also confirmed the drop in corrosion resistance after ECAP processing. 


\section{Reference List}

[1] F. Witte, N. Hort, C. Vogt, S. Cohen, K.U. Kainer, R. Willumeit, F. Feyerabend, Degradable biomaterials based on magnesium corrosion, Current Opinion in Solid State and Materials Science. 12 (2008) 63-72. https://doi.org/10.1016/j.cossms.2009.04.001.

[2] H.S. Brar, M.O. Platt, M. Sarntinoranont, P.I. Martin, M.V. Manuel, Magnesium as a biodegradable and bioabsorbable material for medical implants, JOM. 61 (2009) 31-34. https://doi.org/10.1007/s11837-009-0129-0.

[3] M.P. Staiger, A.M. Pietak, J. Huadmai, G. Dias, Magnesium and its alloys as orthopedic biomaterials: A review, Biomaterials. 27 (2006) 1728-1734. https://doi.org/10.1016/j.biomaterials.2005.10.003.

[4] L.H.C. Becerra, M.A.L.H. Rodríguez, H.E. Solís, R.L. Arroyo, A.T. Castro, Bioinspired biomaterial $\mathrm{Mg}-\mathrm{Zn}-\mathrm{Ca}$ : a review of the main mechanical and biological properties of Mg-based alloys, Biomed. Phys. Eng. Express. 6 (2020) 042001. https://doi.org/10.1088/2057-1976/ab9426.

[5] T. Kasa, iStock ORIF Image, n.d. https://www.istockphoto.com/photo/x-ray-lt-legap-fracture-fibula-and-mid-shaft-tibia-with-oost-orif-with-plates-andgm1165483119-320711668.

[6] G. Song, Control of biodegradation of biocompatable magnesium alloys, Corrosion Science. 49 (2007) 1696-1701. https://doi.org/10.1016/j.corsci.2007.01.001.

[7] Z. Shi, M. Liu, A. Atrens, Measurement of the corrosion rate of magnesium alloys using Tafel extrapolation, Corrosion Science. 52 (2010) 579-588. https://doi.org/10.1016/j.corsci.2009.10.016.

[8] E. Mostaed, M. Hashempour, A. Fabrizi, D. Dellasega, M. Bestetti, F. Bonollo, M. Vedani, Microstructure, texture evolution, mechanical properties and corrosion behavior of ECAP processed ZK60 magnesium alloy for biodegradable applications, Journal of the Mechanical Behavior of Biomedical Materials. 37 (2014) 307-322. https://doi.org/10.1016/j.jmbbm.2014.05.024.

[9] U. Riaz, I. Shabib, W. Haider, The current trends of Mg alloys in biomedical applications-A review, Journal of Biomedical Materials Research Part B: Applied Biomaterials. 107 (2019) 1970-1996. https://doi.org/10.1002/jbm.b.34290.

[10] C. Plaass, C. von Falck, S. Ettinger, L. Sonnow, F. Calderone, A. Weizbauer, J. Reifenrath, L. Claassen, H. Waizy, K. Daniilidis, C. Stukenborg-Colsman, H. Windhagen, Bioabsorbable magnesium versus standard titanium compression screws for fixation of distal metatarsal osteotomies -3 year results of a randomized clinical trial, Journal of Orthopaedic Science. 23 (2018) 321-327. https://doi.org/10.1016/j.jos.2017.11.005.

[11] G. Pagano, F. Aliberti, M. Guida, R. Oral, A. Siciliano, M. Trifuoggi, F. Tommasi, Rare earth elements in human and animal health: State of art and research priorities, Environmental Research. 142 (2015) 215-220. https://doi.org/10.1016/j.envres.2015.06.039.

[12] F. Feyerabend, J. Fischer, J. Holtz, F. Witte, R. Willumeit, H. Drücker, C. Vogt, N. Hort, Evaluation of short-term effects of rare earth and other elements used in magnesium alloys on primary cells and cell lines, Acta Biomaterialia. 6 (2010) 1834-1842. https://doi.org/10.1016/j.actbio.2009.09.024. 
[13] B.A. Shaw, Corrosion Resistance of Magnesium Alloys, in: Corrosion:

Fundamentals, Testing, and Protection, 2003: pp. 692-696.

http://ttp.demec.ufpr.br/disciplinas/TM315/Asm\%20Metals\%20Handbook\%20Volu me $\% 2013 \% 20$

\%20Corrosion\%20Fundamentals, \%20Testing,\%20And\%20Protection.pdf.

[14] D. Zhao, F. Witte, F. Lu, J. Wang, J. Li, L. Qin, Current status on clinical applications of magnesium-based orthopaedic implants: A review from clinical translational perspective, Biomaterials. 112 (2017) 287-302.

https://doi.org/10.1016/j.biomaterials.2016.10.017.

[15] E. Mostaed, M. Sikora-Jasinska, L. Wang, A. Mostaed, I.M. Reaney, J.W. Drelich, Tailoring the Mechanical and Degradation Performance of Mg-2.0Zn-0.5Ca-0.4Mn Alloy Through Microstructure Design, JOM. 72 (2020) 1880-1891. https://doi.org/10.1007/s11837-020-04085-9.

[16] L.B. Tong, J.H. Chu, Z.H. Jiang, S. Kamado, M.Y. Zheng, Ultra-fine grained Mg$\mathrm{Zn}-\mathrm{Ca}-\mathrm{Mn}$ alloy with simultaneously improved strength and ductility processed by equal channel angular pressing, Journal of Alloys and Compounds. 785 (2019) 410 421. https://doi.org/10.1016/j.jallcom.2019.01.181.

[17] J. Nagels, M. Stokdijk, P.M. Rozing, Stress shielding and bone resorption in shoulder arthroplasty, J Shoulder Elbow Surg. 12 (2003) 35-39. https://doi.org/10.1067/mse.2003.22.

[18] Y.F. Zheng, X.N. Gu, F. Witte, Biodegradable metals, Materials Science and Engineering: R: Reports. 77 (2014) 1-34. https://doi.org/10.1016/j.mser.2014.01.001.

[19] D. Zander, N.A. Zumdick, Influence of $\mathrm{Ca}$ and $\mathrm{Zn}$ on the microstructure and corrosion of biodegradable Mg-Ca-Zn alloys, Corrosion Science. 93 (2015) 222233. https://doi.org/10.1016/j.corsci.2015.01.027.

[20] A. Atrens, Z. Shi, S.U. Mehreen, S. Johnston, G.-L. Song, X. Chen, F. Pan, Review of $\mathrm{Mg}$ alloy corrosion rates, Journal of Magnesium and Alloys. 8 (2020) 989-998. https://doi.org/10.1016/j.jma.2020.08.002.

[21] N. Hort, Y. Huang, D. Fechner, M. Störmer, C. Blawert, F. Witte, C. Vogt, H. Drücker, R. Willumeit, K.U. Kainer, F. Feyerabend, Magnesium alloys as implant materials - Principles of property design for Mg-RE alloys, Acta Biomaterialia. 6 (2010) 1714-1725. https://doi.org/10.1016/j.actbio.2009.09.010.

[22] M. Liu, P. Schmutz, P.J. Uggowitzer, G. Song, A. Atrens, The influence of yttrium (Y) on the corrosion of Mg-Y binary alloys, Corrosion Science. 52 (2010) 36873701. https://doi.org/10.1016/j.corsci.2010.07.019.

[23] L. Yang, Y. Huang, Q. Peng, F. Feyerabend, K.U. Kainer, R. Willumeit, N. Hort, Mechanical and corrosion properties of binary $\mathrm{Mg}-$ Dy alloys for medical applications, Materials Science and Engineering: B. 176 (2011) 1827-1834. https://doi.org/10.1016/j.mseb.2011.02.025.

[24] X. Zhang, G. Yuan, L. Mao, J. Niu, W. Ding, Biocorrosion properties of asextruded $\mathrm{Mg}-\mathrm{Nd}-\mathrm{Zn}-\mathrm{Zr}$ alloy compared with commercial AZ31 and WE43 alloys, Materials Letters. 66 (2012) 209-211. https://doi.org/10.1016/j.matlet.2011.08.079.

[25] B. Zhang, Y. Hou, X. Wang, Y. Wang, L. Geng, Mechanical properties, degradation performance and cytotoxicity of $\mathrm{Mg}-\mathrm{Zn}-\mathrm{Ca}$ biomedical alloys with different 
compositions, Materials Science and Engineering: C. 31 (2011) 1667-1673. https://doi.org/10.1016/j.msec.2011.07.015.

[26] S. Cai, T. Lei, N. Li, F. Feng, Effects of Zn on microstructure, mechanical properties and corrosion behavior of $\mathrm{Mg}-\mathrm{Zn}$ alloys, Materials Science and Engineering: C. 32 (2012) 2570-2577. https://doi.org/10.1016/j.msec.2012.07.042.

[27] H.R. Bakhsheshi Rad, M.H. Idris, M.R.A. Kadir, S. Farahany, A. Fereidouni, M.Y. Yahya, Characterization and Corrosion Behavior of Biodegradable $\mathrm{Mg}-\mathrm{Ca}$ and $\mathrm{Mg}$ Ca-Zn Implant Alloys, AMM. 121-126 (2011) 568-572. https://doi.org/10.4028/www.scientific.net/AMM.121-126.568.

[28] Y. Chen, J. Dou, H. Yu, C. Chen, Degradable magnesium-based alloys for biomedical applications: The role of critical alloying elements, J Biomater Appl. 33 (2019) 1348-1372. https://doi.org/10.1177/0885328219834656.

[29] S. Agarwal, J. Curtin, B. Duffy, S. Jaiswal, Biodegradable magnesium alloys for orthopaedic applications: A review on corrosion, biocompatibility and surface modifications, Materials Science and Engineering: C. 68 (2016) 948-963. https://doi.org/10.1016/j.msec.2016.06.020.

[30] G. Song, A. Atrens, Understanding Magnesium Corrosion-A Framework for Improved Alloy Performance, Advanced Engineering Materials. 5 (2003) 837-858. https://doi.org/10.1002/adem.200310405.

[31] T.V. Larionova, W.-W. Park, B.-S. You, A ternary phase observed in rapidly solidified $\mathrm{Mg}-\mathrm{Ca}-\mathrm{Zn}$ alloys, Scripta Materialia. 45 (2001) 7-12. https://doi.org/10.1016/S1359-6462(01)00982-4.

[32] P. Jiang, C. Blawert, M.L. Zheludkevich, The Corrosion Performance and Mechanical Properties of Mg-Zn Based Alloys-A Review, CMD. 1 (2020) 92158. https://doi.org/10.3390/cmd1010007.

[33] E. Mostaed, M. Vedani, M. Hashempour, M. Bestetti, Influence of ECAP process on mechanical and corrosion properties of pure $\mathrm{Mg}$ and ZK60 magnesium alloy for biodegradable stent applications, Biomatter. 4 (2014) e28283. https://doi.org/10.4161/biom.28283.

[34] E.J. Lavernia, T.S. Srivatsan, The rapid solidification processing of materials: science, principles, technology, advances, and applications, J Mater Sci. 45 (2010) 287-325. https://doi.org/10.1007/s10853-009-3995-5.

[35] Y. Estrin, A. Vinogradov, Extreme grain refinement by severe plastic deformation: A wealth of challenging science, Acta Materialia. 61 (2013) 782-817. https://doi.org/10.1016/j.actamat.2012.10.038.

[36] W.D. Callister, D.G. Rethwisch, Fundamentals of materials science and engineering: an integrated approach, 4th ed, Wiley, Hoboken, N.J, 2012.

[37] Y. Iwahashi, J. Wang, Z. Horita, M. Nemoto, T.G. Langdon, Principle of equalchannel angular pressing for the processing of ultra-fine grained materials, Scripta Materialia. 35 (1996) 143-146. https://doi.org/10.1016/1359-6462(96)00107-8.

[38] V.M. Segal, Equal channel angular extrusion: from macromechanics to structure formation, Materials Science and Engineering: A. 271 (1999) 322-333. https://doi.org/10.1016/S0921-5093(99)00248-8. 
[39] G01 Committee, Practice for Calculation of Corrosion Rates and Related Information from Electrochemical Measurements, ASTM International, n.d. https://doi.org/10.1520/G0102-89R15E01.

[40] J01 Committee, Guide for Laboratory Immersion Corrosion Testing of Metals, ASTM International, n.d. https://doi.org/10.1520/G0031-12A.

[41] E28 Committee, Test Methods for Tension Testing of Metallic Materials, ASTM International, n.d. https://doi.org/10.1520/E0008_E0008M-16AE01.

[42] E28 Committee, Test Methods of Compression Testing of Metallic Materials at Room Temperature, ASTM International, n.d. https://doi.org/10.1520/E0009-19.

[43] S. Feliu, Electrochemical Impedance Spectroscopy for the Measurement of the Corrosion Rate of Magnesium Alloys: Brief Review and Challenges, Metals. 10 (2020) 775. https://doi.org/10.3390/met10060775.

[44] Y. Du, M. Zheng, B. Jiang, K. Zhou, Deformation-Induced Dynamic Precipitation and Resulting Microstructure in a Mg-Zn-Ca Alloy, JOM. 70 (2018) 1611-1615. https://doi.org/10.1007/s11837-018-2880-6.

[45] O.B. Kulyasova, I.A. Evdokimova, R.K. Islamgaliev, Evolution of the structure and mechanical properties of the $\mathrm{Mg}-1 \% \mathrm{Zn}-0.2 \% \mathrm{Ca}$ alloy during ECAP, IOP Conf. Ser.: Mater. Sci. Eng. 672 (2019) 012035. https://doi.org/10.1088/1757899X/672/1/012035.

[46] N. Martynenko, E. Lukyanova, V. Serebryany, D. Prosvirnin, V. Terentiev, G.

Raab, S. Dobatkin, Y. Estrin, Effect of equal channel angular pressing on structure, texture, mechanical and in-service properties of a biodegradable magnesium alloy, Materials Letters. 238 (2019) 218-221. https://doi.org/10.1016/j.matlet.2018.12.024.

[47] K. Huang, R.E. Logé, A review of dynamic recrystallization phenomena in metallic materials, Materials \& Design. 111 (2016) 548-574. https://doi.org/10.1016/j.matdes.2016.09.012.

[48] E. McCafferty, Introduction to Corrosion Science, Springer New York, New York, NY, 2010. https://doi.org/10.1007/978-1-4419-0455-3.

[49] M. Pourbaix, Atlas of electrochemical equilibria in aqueous solutions, National Assoc. of Corrosion Engineers [u.a.], Houston, Tex, 1974.

[50] S.A. Abdel-Gawad, M.A. Shoeib, Corrosion studies and microstructure of $\mathrm{Mg}-\mathrm{Zn}-\mathrm{Ca}$ alloys for biomedical applications, Surfaces and Interfaces. 14 (2019) 108-116. https://doi.org/10.1016/j.surfin.2018.11.011.

[51] E. Zhang, L. Yang, Microstructure, mechanical properties and bio-corrosion properties of $\mathrm{Mg}-\mathrm{Zn}-\mathrm{Mn}-\mathrm{Ca}$ alloy for biomedical application, Materials Science and Engineering: A. 497 (2008) 111-118. https://doi.org/10.1016/j.msea.2008.06.019. 


\section{Corrosion Morphology Images}


2 Days

5 Days

10 Days

15 Days
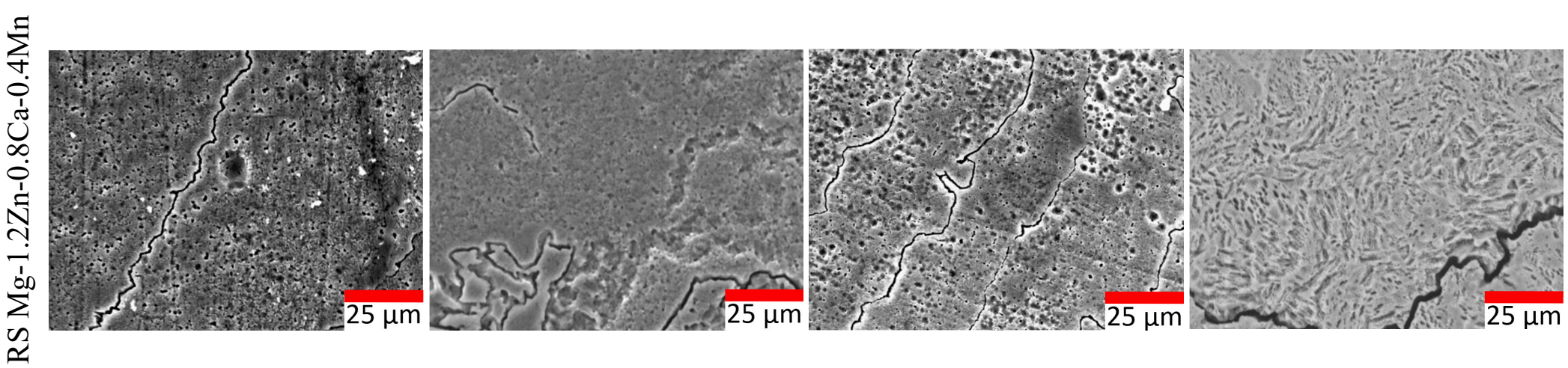

(a)

(b)

(c)

(d)

us
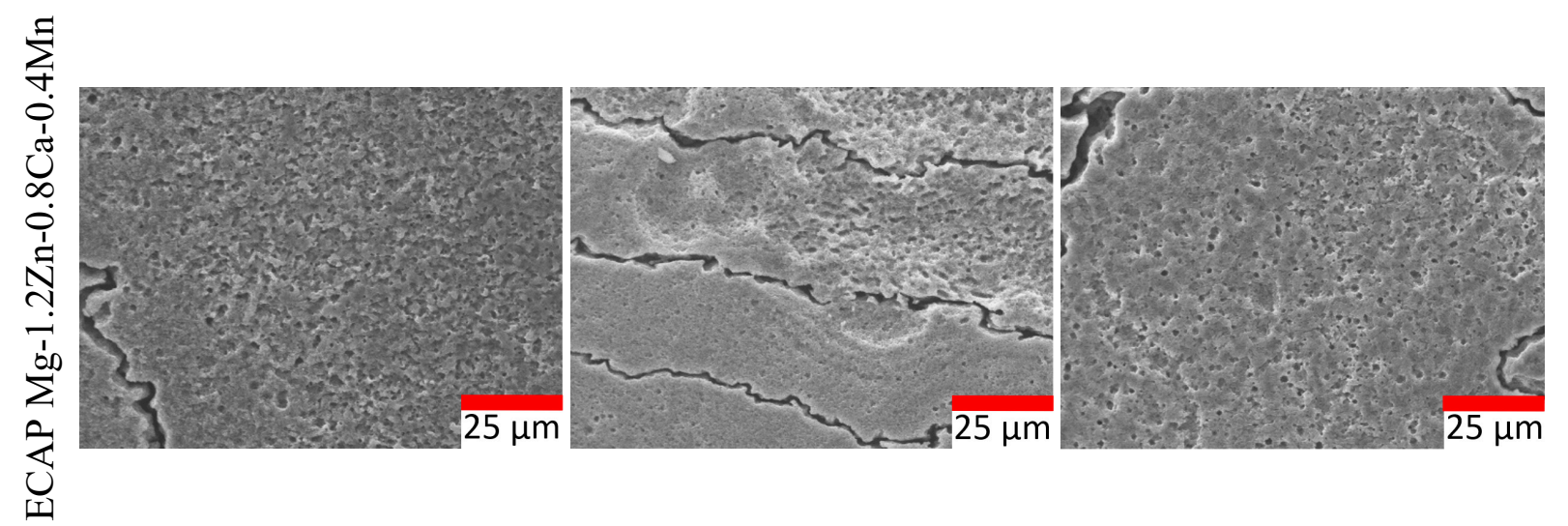

SAMPLES

(e)

(f)

(g)

(h)

Figure 7.1. BSE SEM images of the exposed surfaces of Mg-1.2Zn-0.8Ca- $0.2 \mathrm{Mn}$ for 2, 5, 10, and 15 day immersion times. 
2 Days

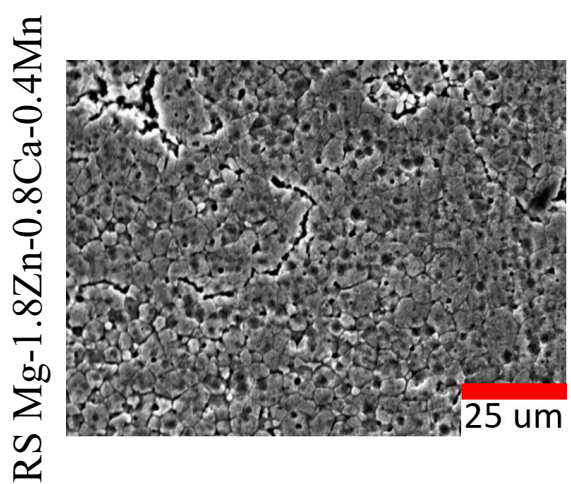

(a)

ñ
5 Days

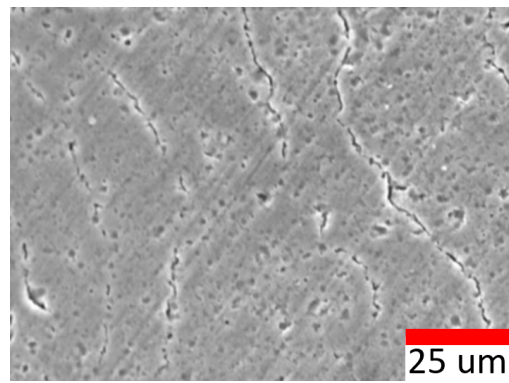

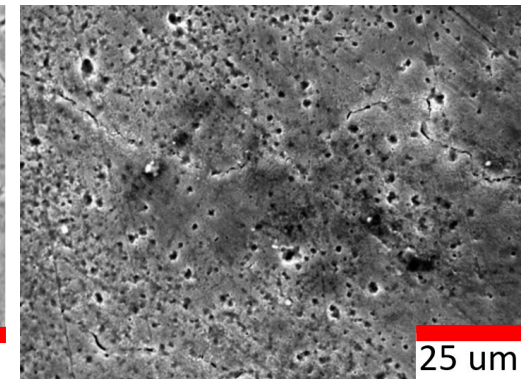

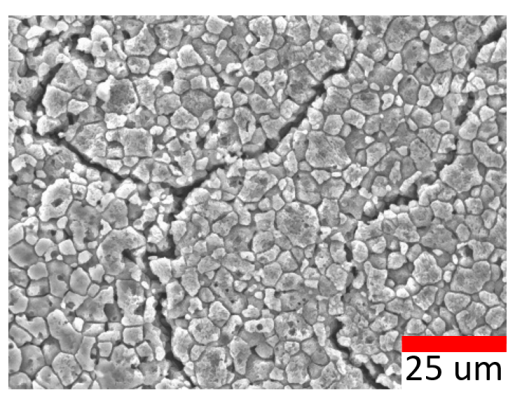

(b)

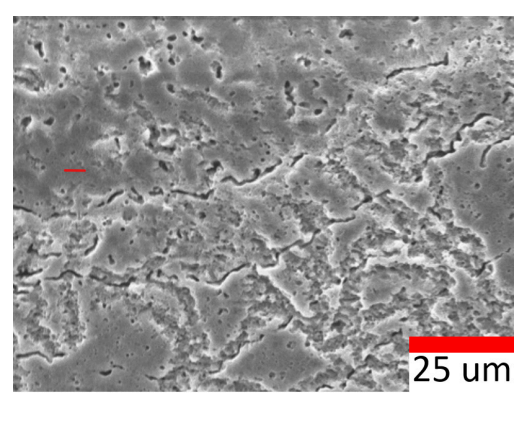

(c)

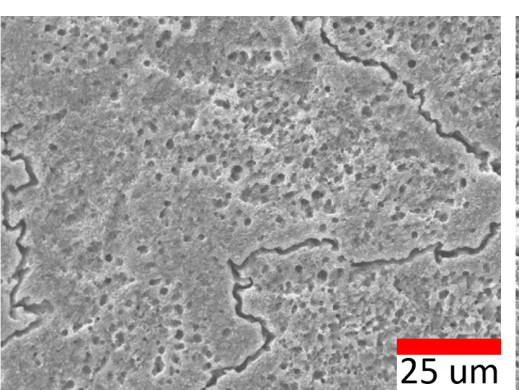

(d)

15 Days

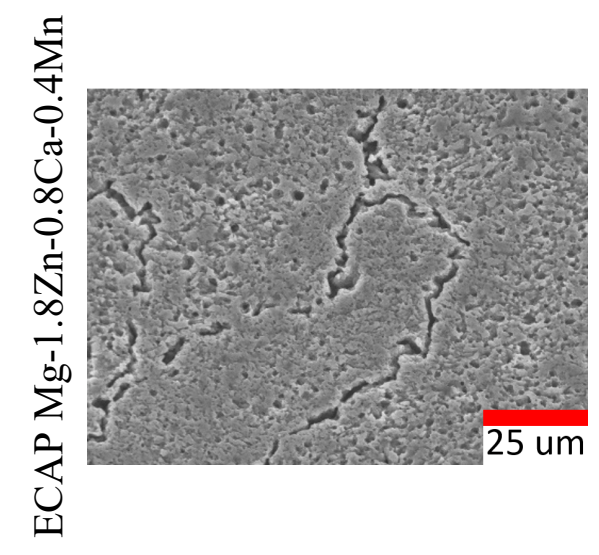

(e)

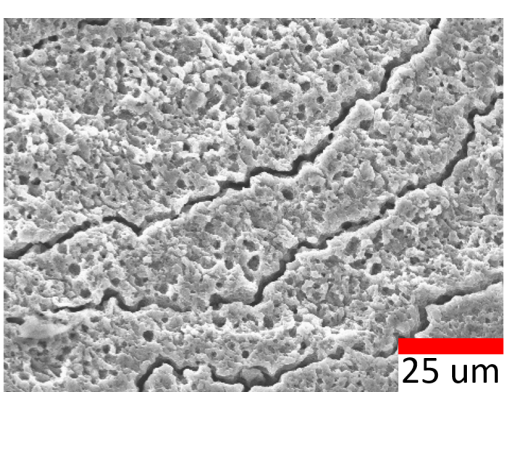

(h)

Figure 7.2. BSE SEM images of the exposed surfaces of $\mathrm{Mg}-1.8 \mathrm{Zn}-0.8 \mathrm{Ca}-0.2 \mathrm{Mn}$ for 2, 5, 10, and 15 day immersion times. 
2 Days

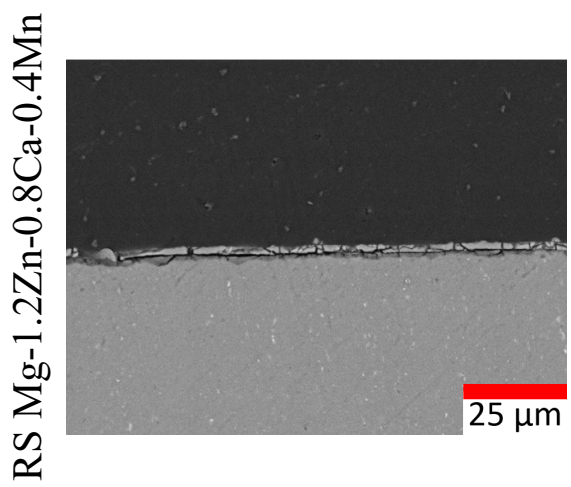

(a)

u
5 Days

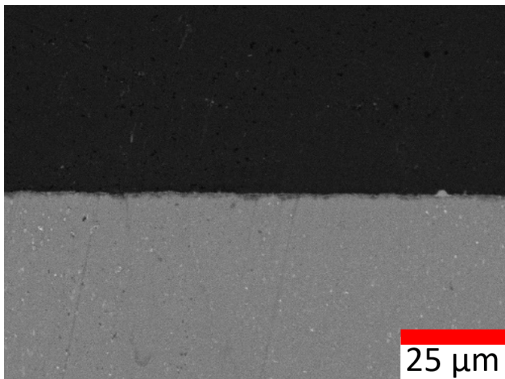

(b)

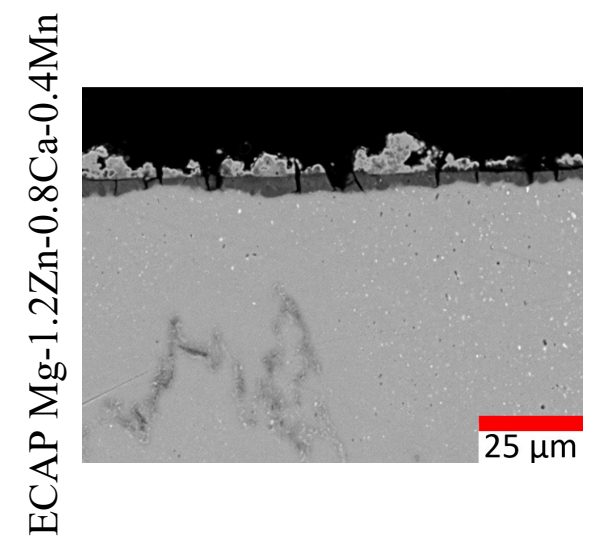

(e)
10 Days

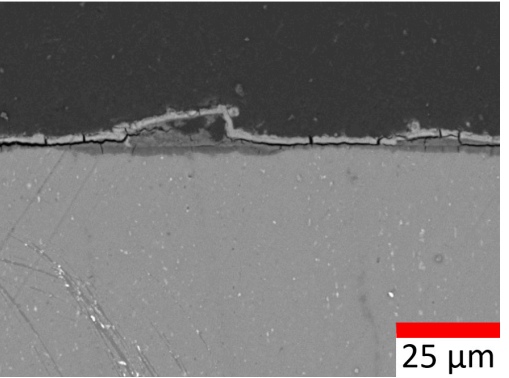

(c)

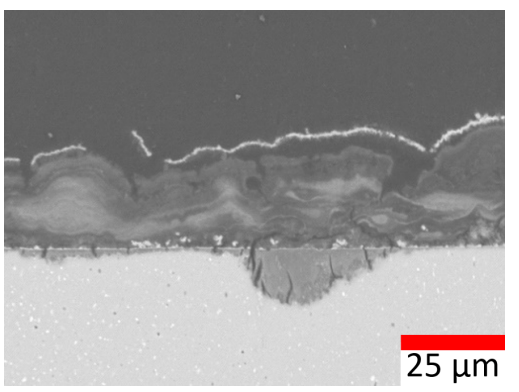

15 Days

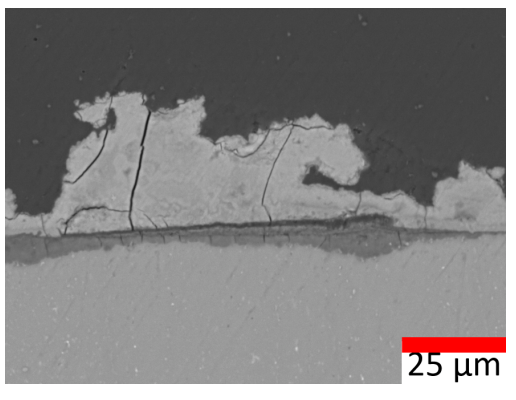

(d) (g)

SAMPLES

DEGRADED

(f) (h)

Figure 7.3. BSE SEM images of the side profiles of $\mathrm{Mg}-1.2 \mathrm{Zn}-0.8 \mathrm{Ca}-0.2 \mathrm{Mn}$ for $2,5,10$, and 15 day immersion times. 
2 Days

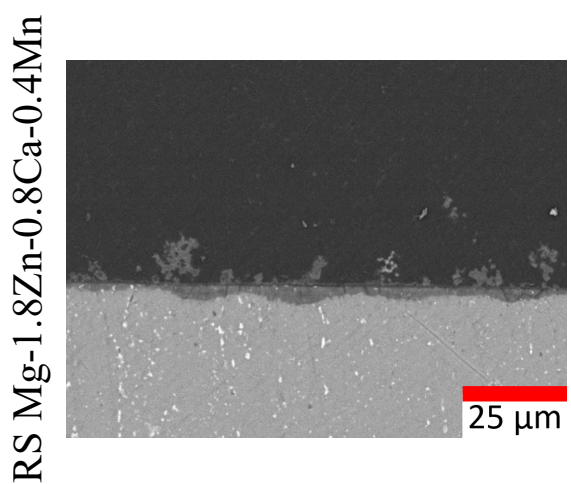

(a)

$\infty$

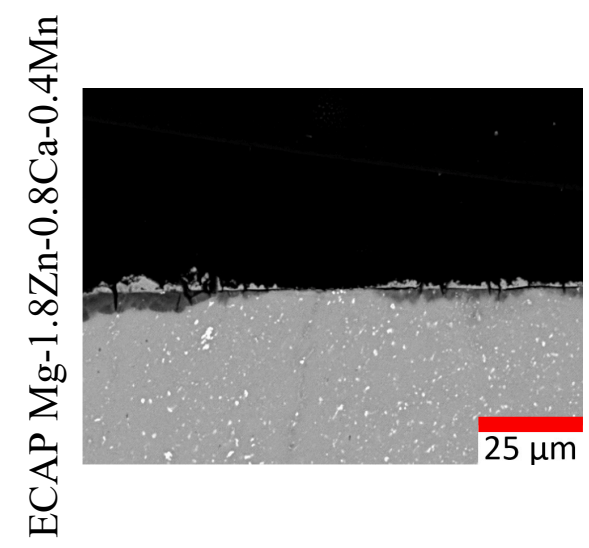

(e)
5 Days

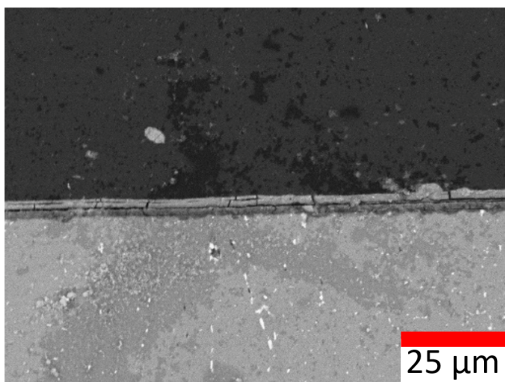

(b)

10 Days

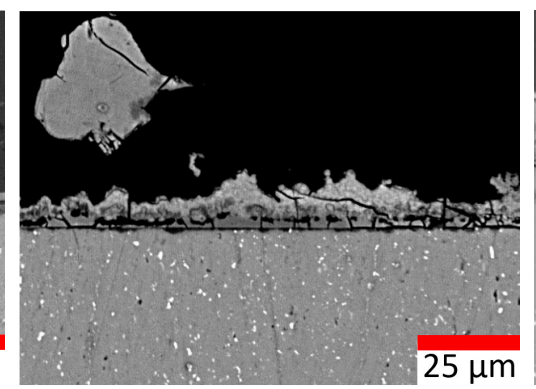

(c)

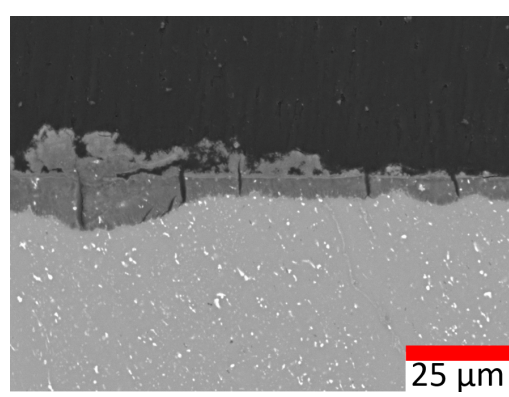

(f)

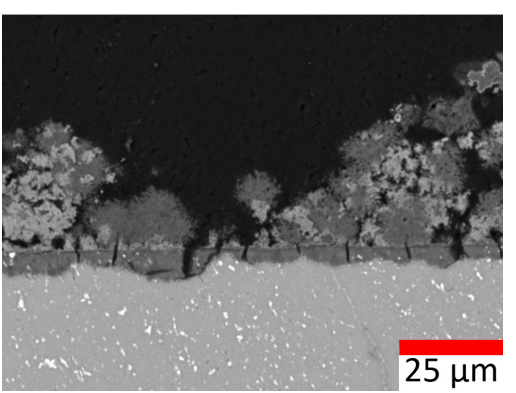

(g)
15 Days

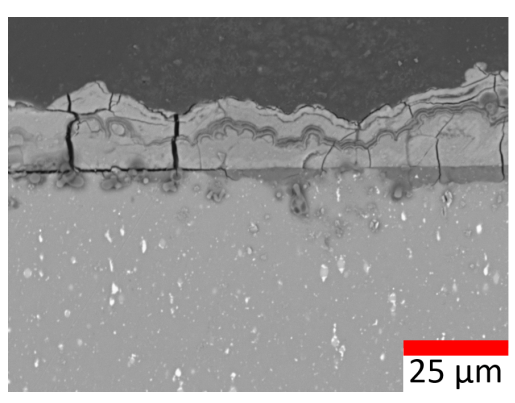

(d)

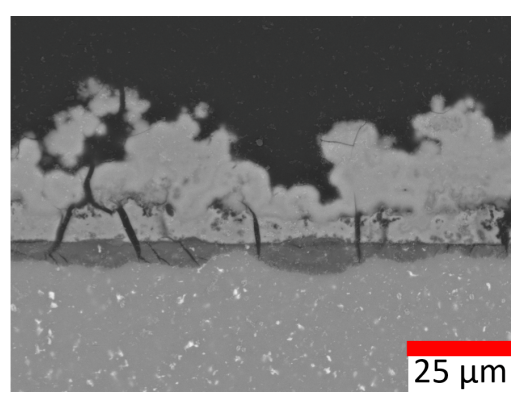

(h)

Figure 7.4. BSE SEM images of the side profiles of Mg-1.8Zn-0.8Ca-0.2Mn for 2, 5, 10, and 15 day immersion times. 


\section{Tensile and Compression Stress-Strain Curves 8.1 Tensile Stress-Strain Curves}

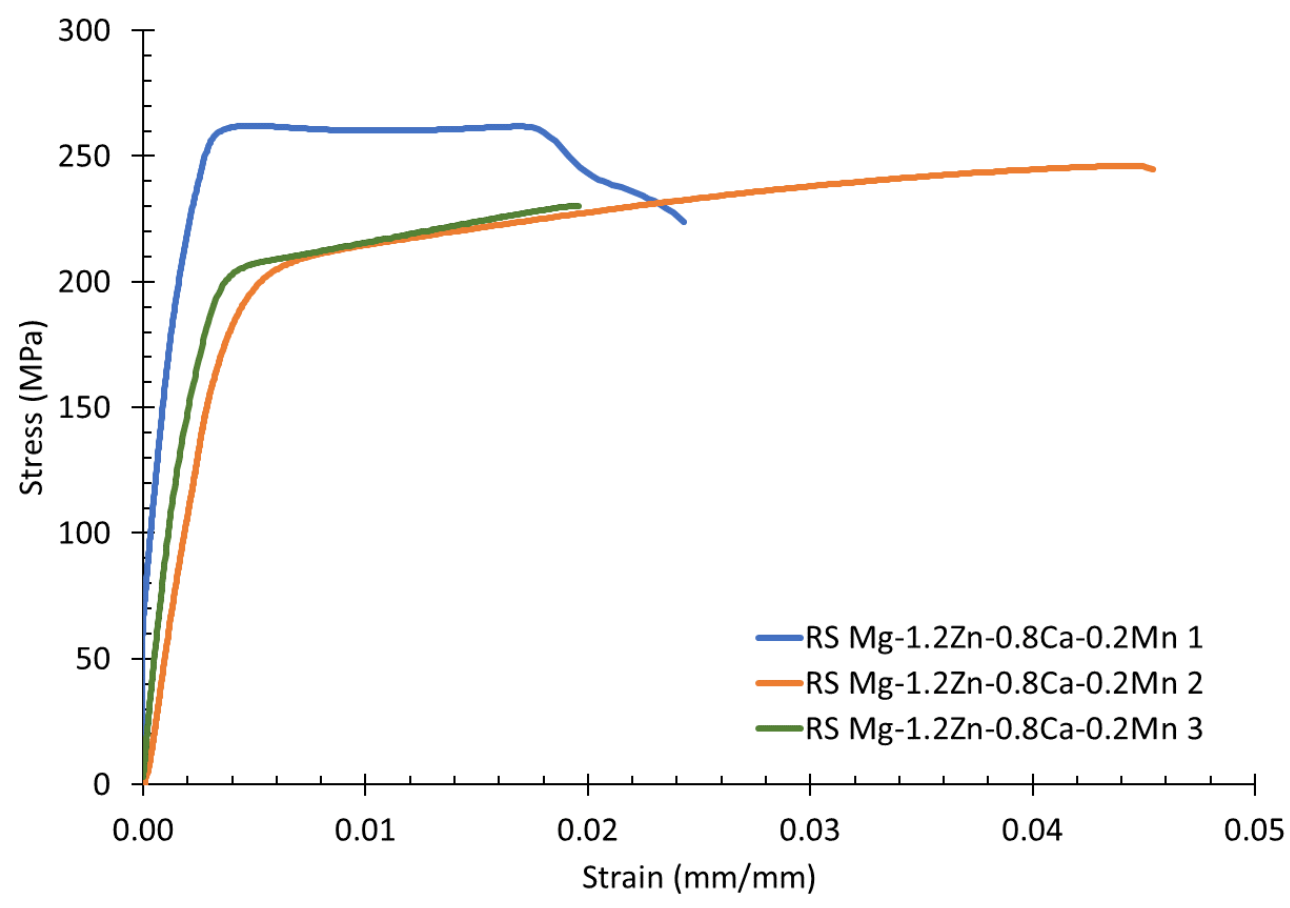

Figure 8.1. Tensile curves of the three RS Mg-1.2Zn-0.8Ca- $0.2 \mathrm{Mn}$ samples.

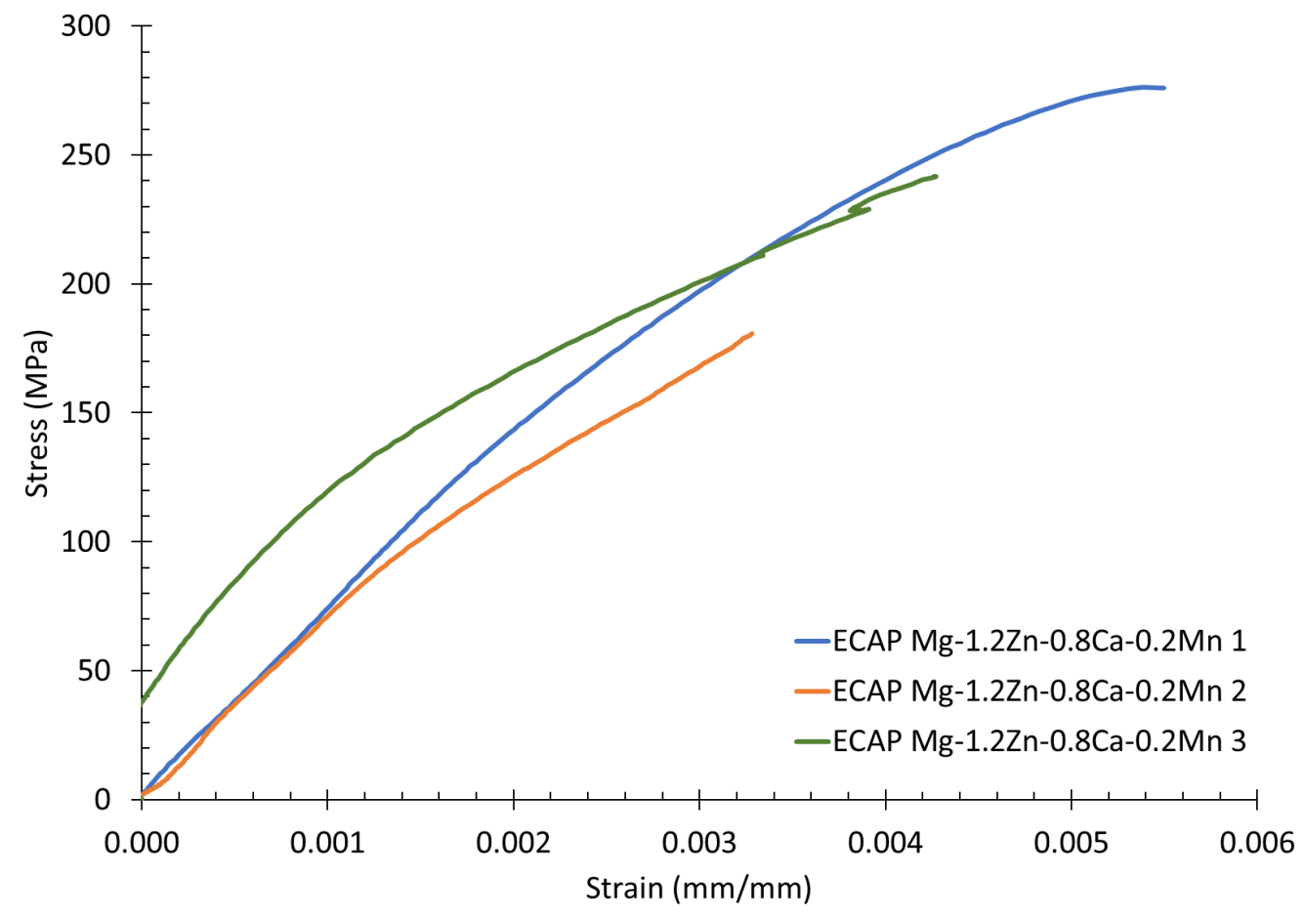

Figure 8.2. Tensile curves of the three ECAP Mg-1.2Zn-0.8Ca-0.2Mn samples. 


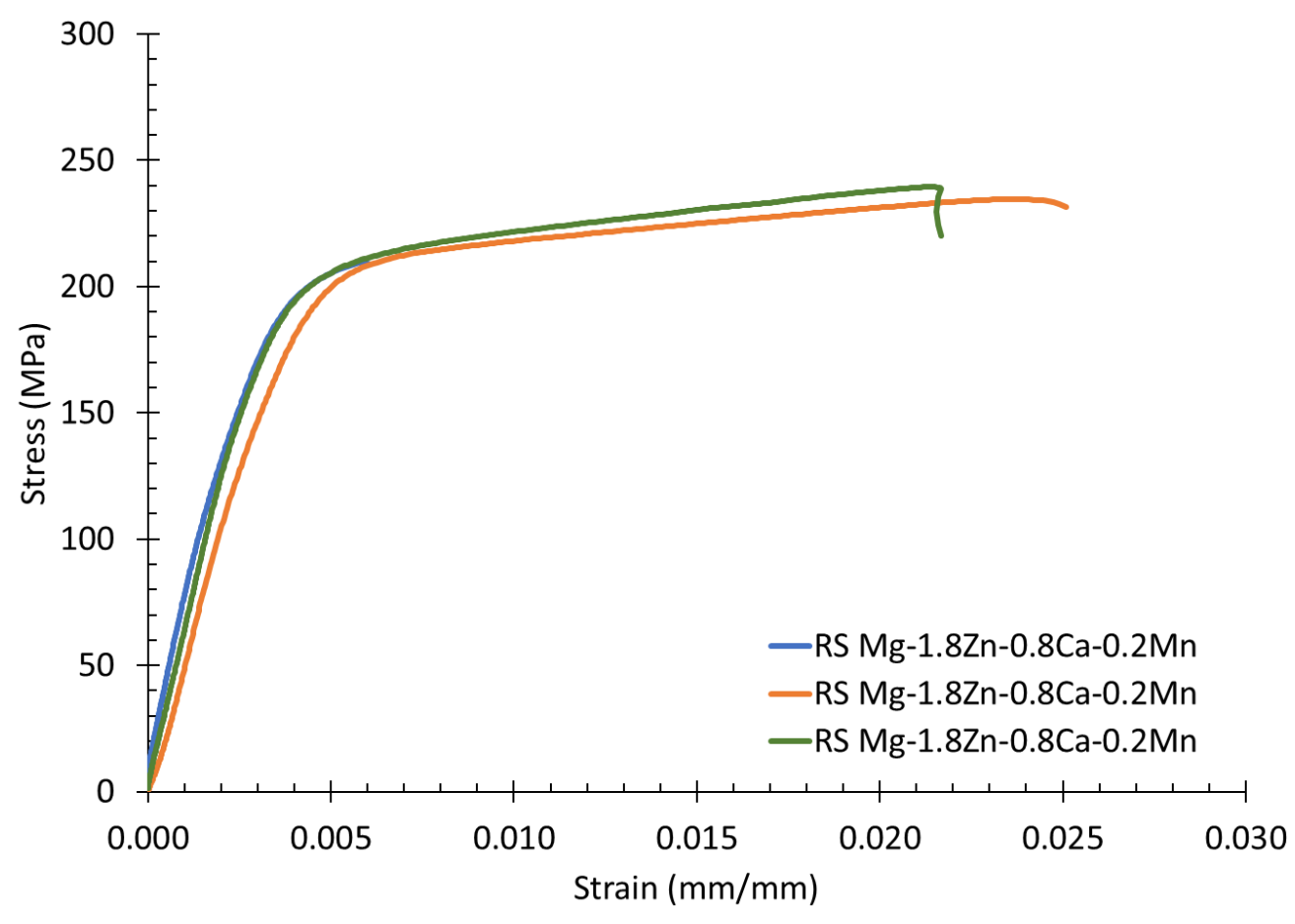

Figure 8.3. Tensile curves for the three RS Mg- $1.8 \mathrm{Zn}-0.8 \mathrm{Ca}-0.2 \mathrm{Mn}$ samples tested.

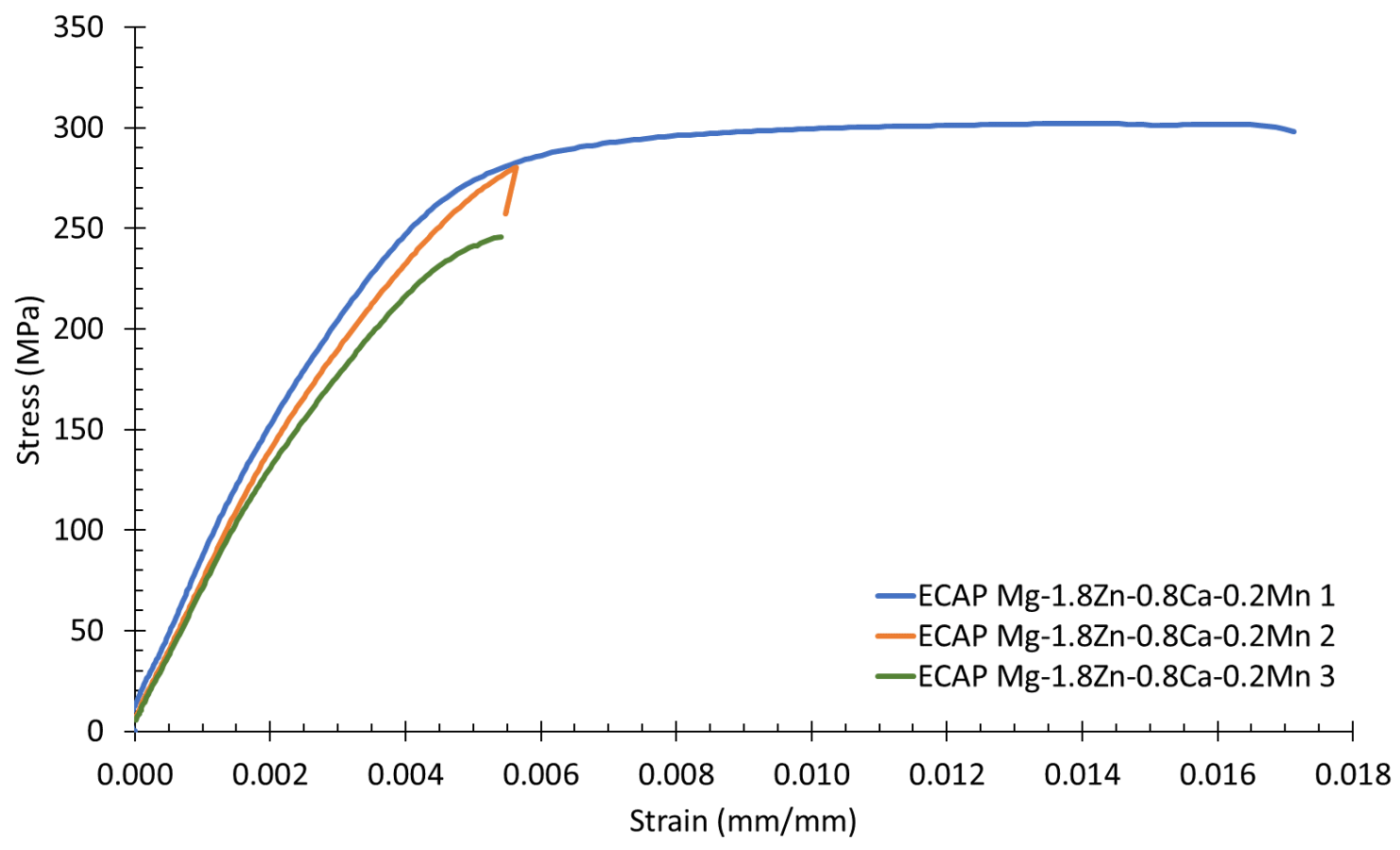

Figure 8.4. Tensile curves for the three ECAP Mg-1.8Zn-0.8Ca- $0.2 \mathrm{Mn}$ samples tested. 


\subsection{Compression Stress-Strain Curves}

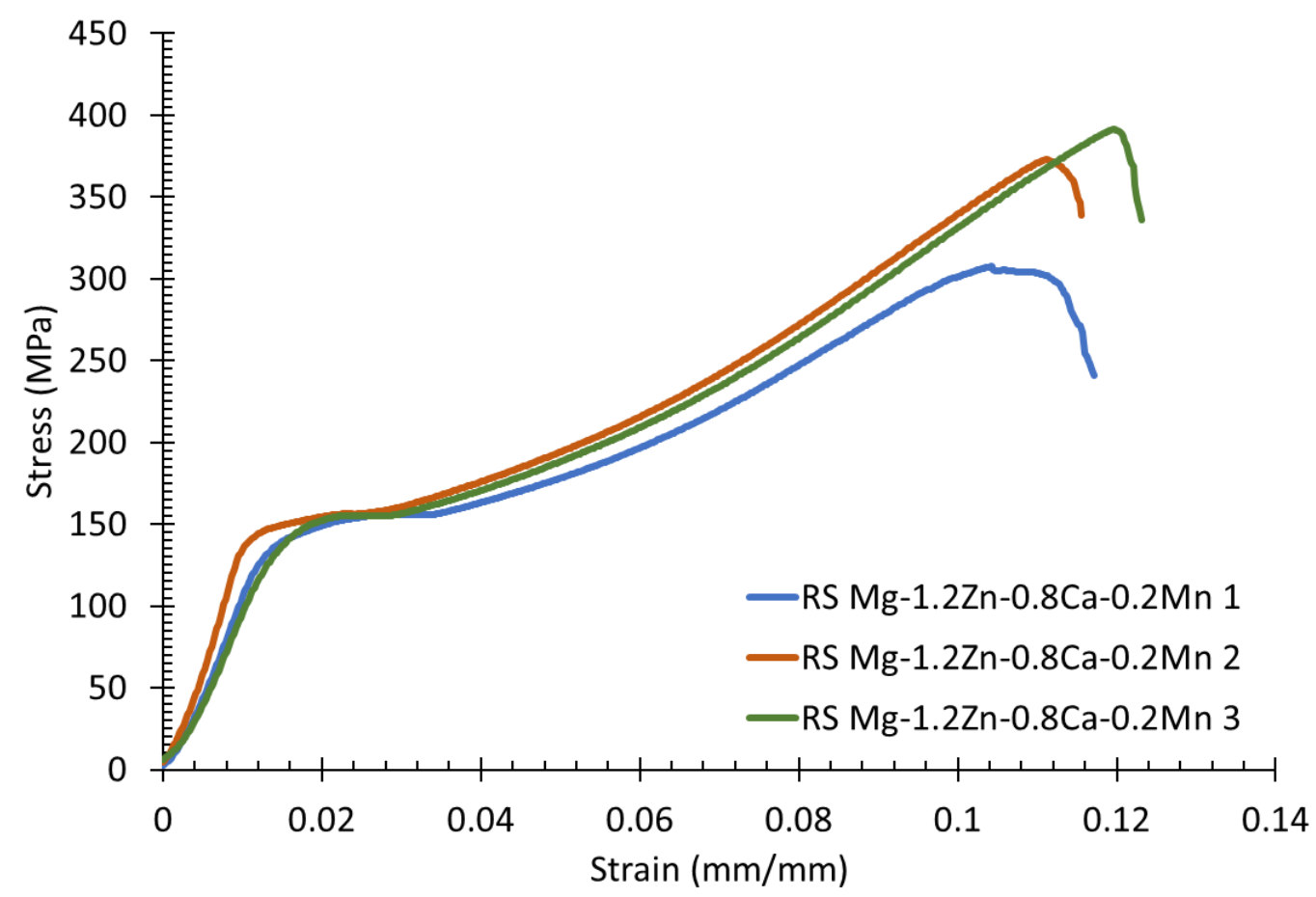

Figure 8.5. Compression stress-strain curves of the three RS Mg-1.2Zn-0.8Ca-0.2Mn samples tested.

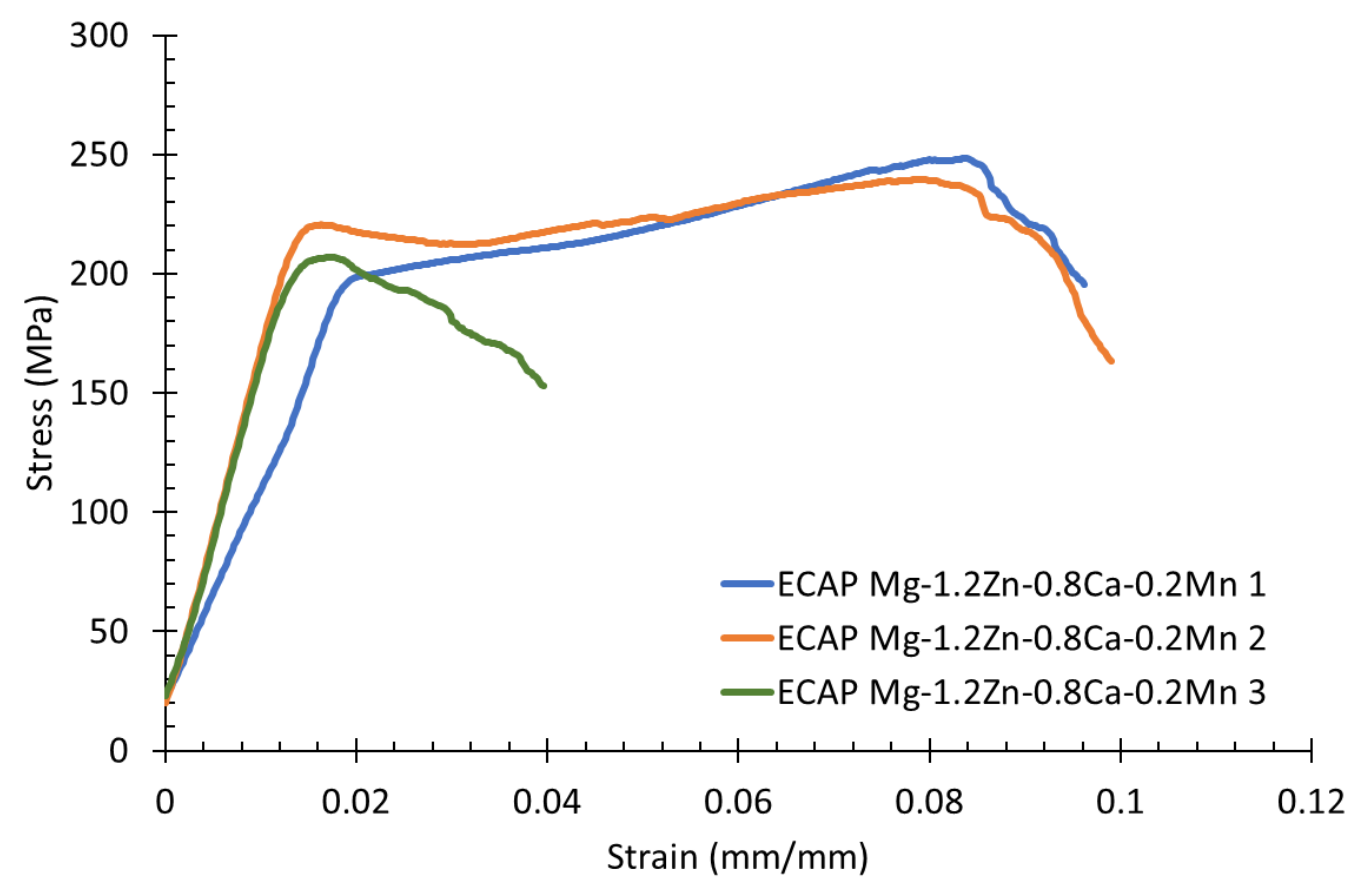

Figure 8.6. Compression stress-strain curves of the three ECAP Mg-1.2Zn-0.8ca-0.2Mn samples tested. 


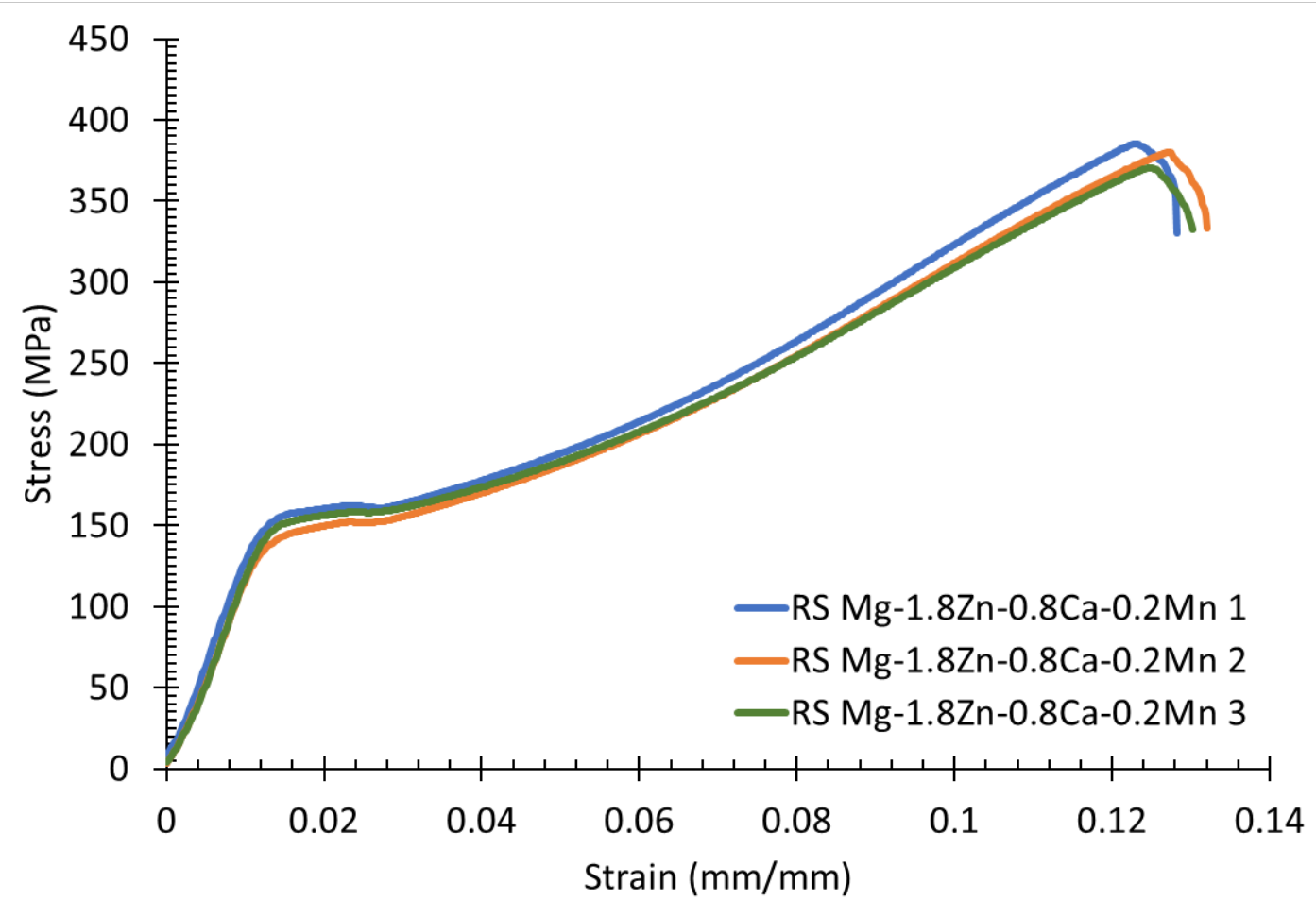

Figure 8.7. Compression stress-strain curves of the three RS Mg-1.8Zn- $0.8 \mathrm{Ca}-0.2 \mathrm{Mn}$ samples tested.

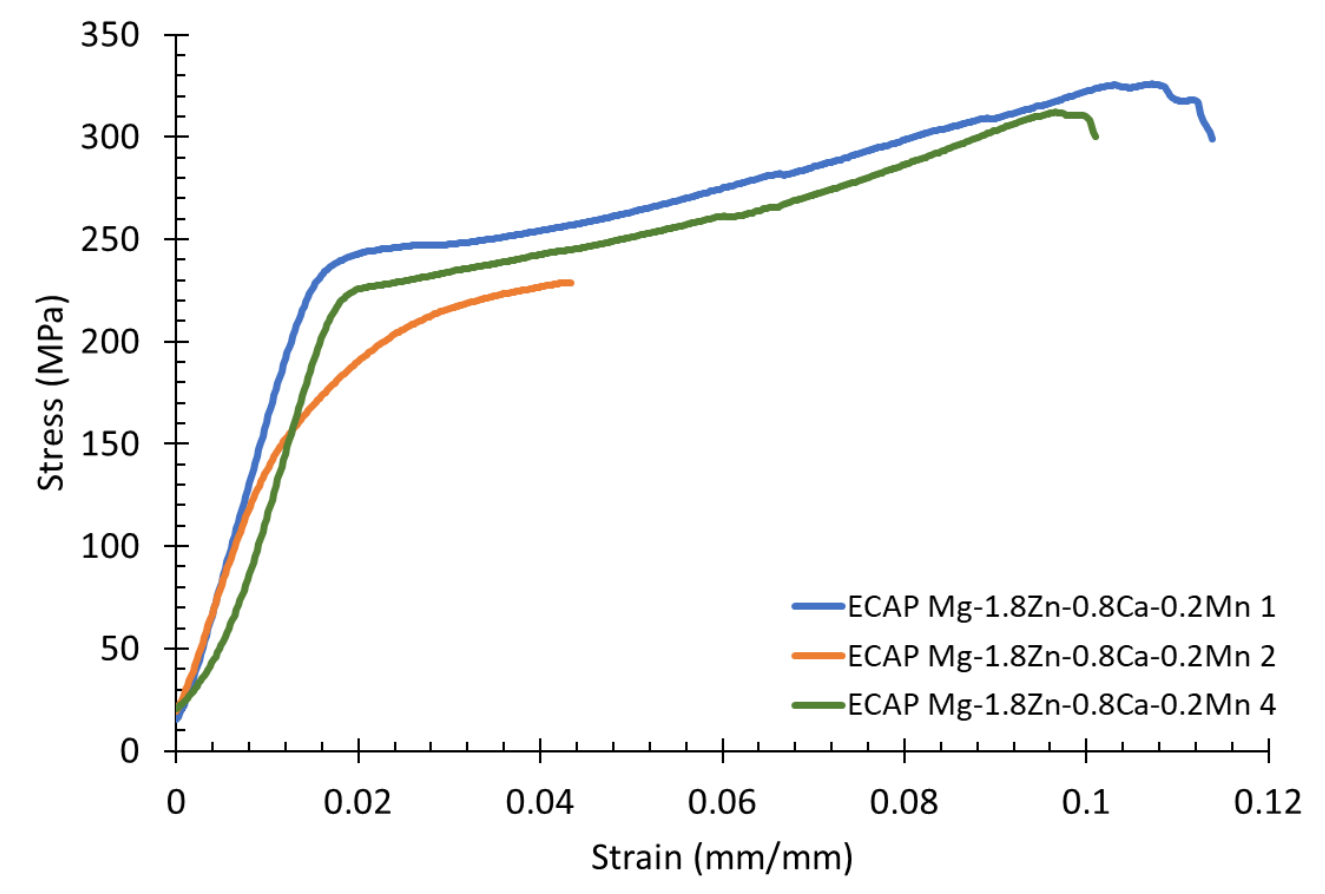

Figure 8.8. Compression stress-strain curves of the three ECAP Mg-1.8Zn-0.8Ca- $0.2 \mathrm{Mn}$ samples tested. 


\section{Corrosion Testing Curves}

\subsection{Potentiodynamic Curves}

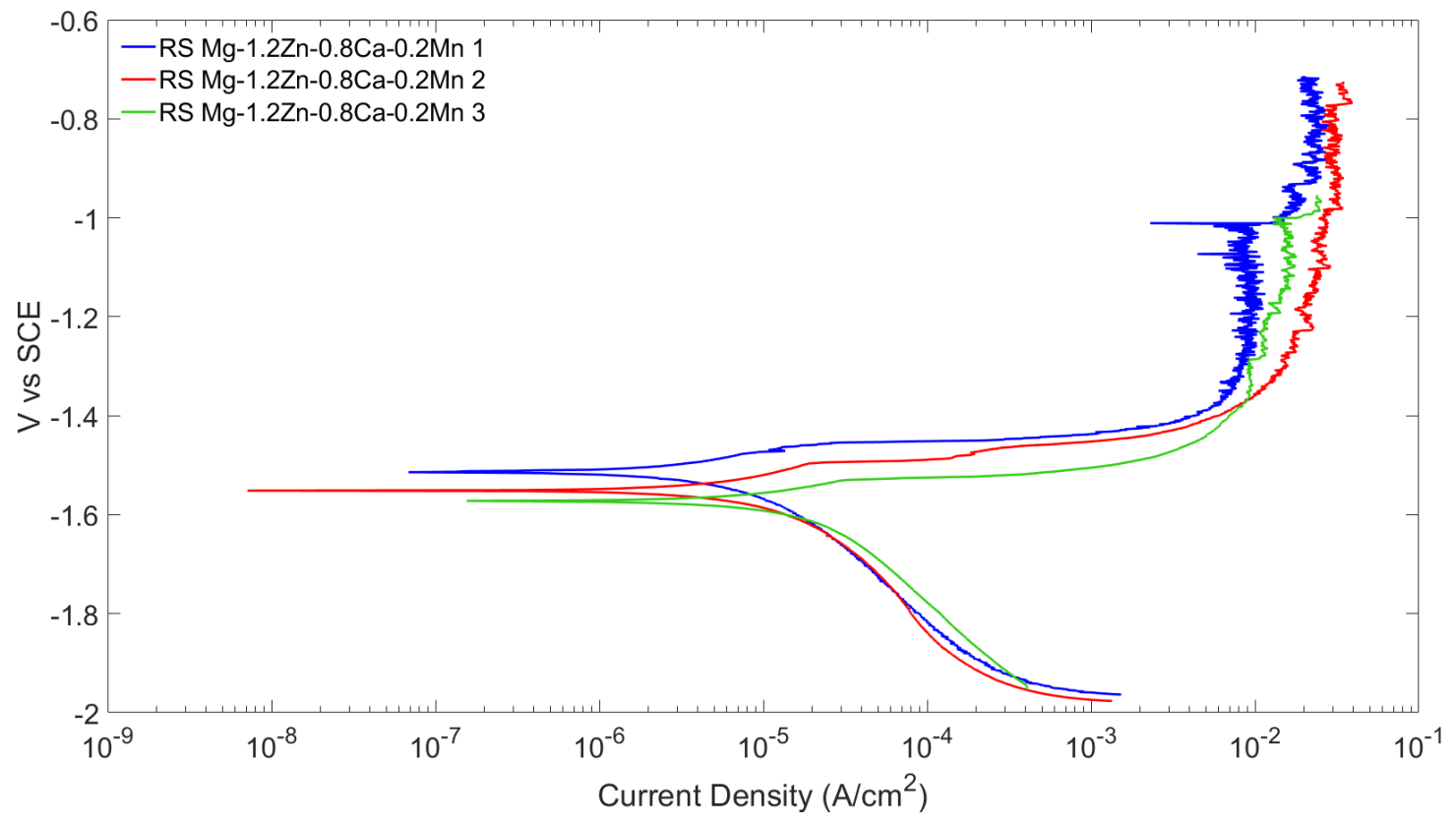

Figure 9.1. Potentiodynamic curves for three RS Mg-1.2Zn-0.8Ca-0.2Mn.

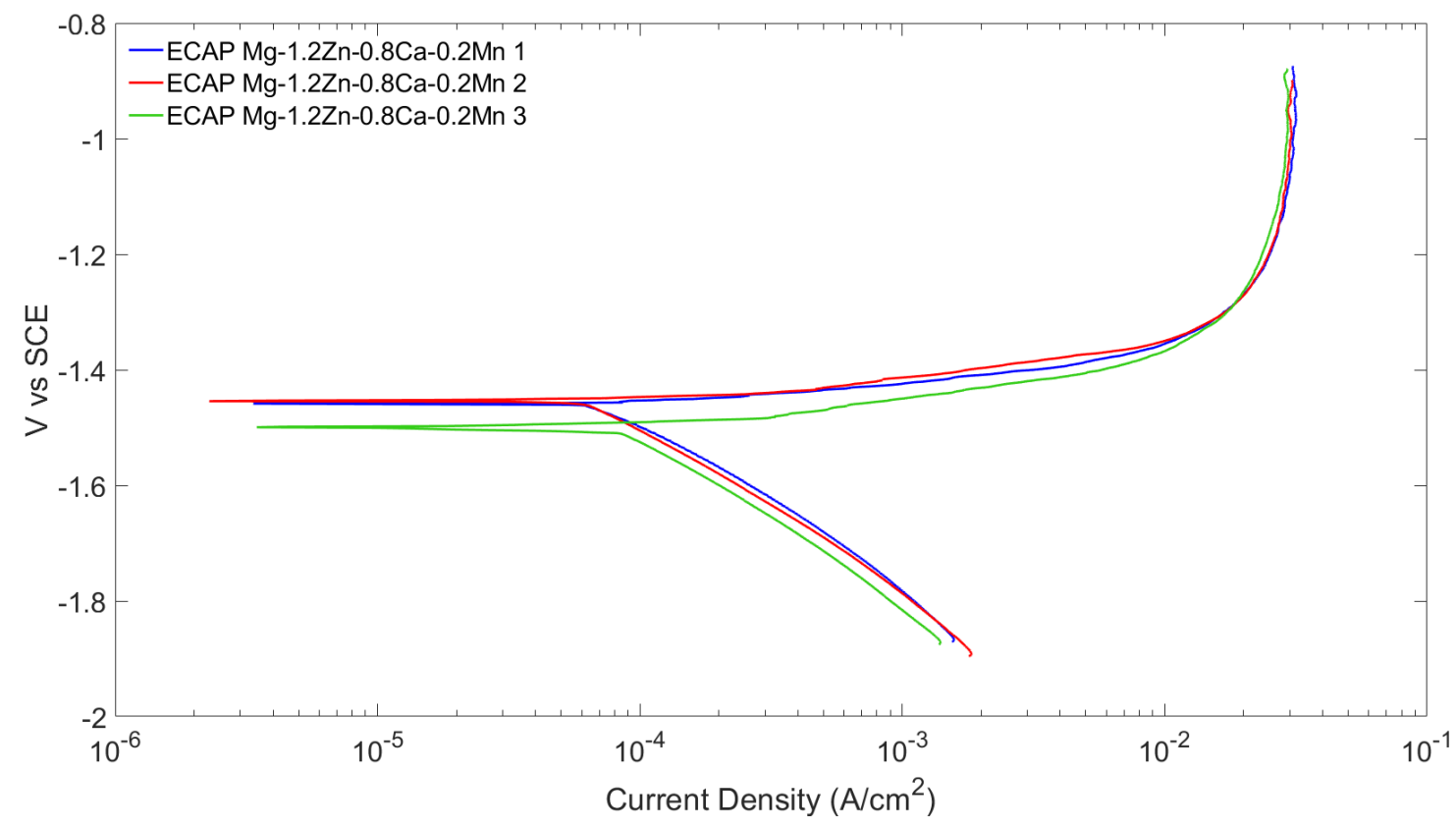

Figure 9.2. Potentiodynamic curves for three ECAP Mg-1.2Zn-0.8Ca-0.2Mn. 


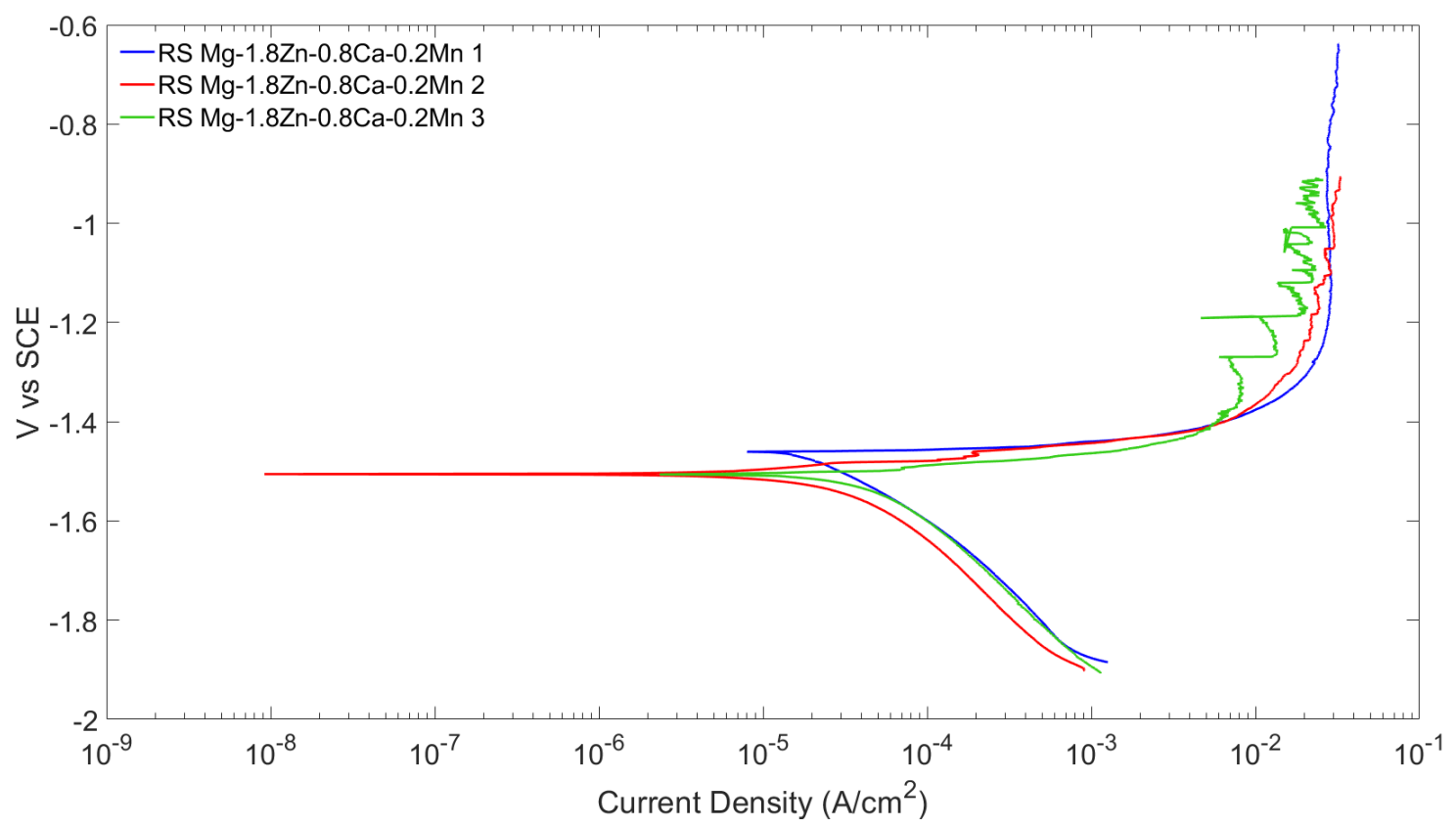

Figure 9.3. Potentiodynamic curves of the three RS Mg-1.8Zn-0.8Ca-0.2Mn alloys tested.

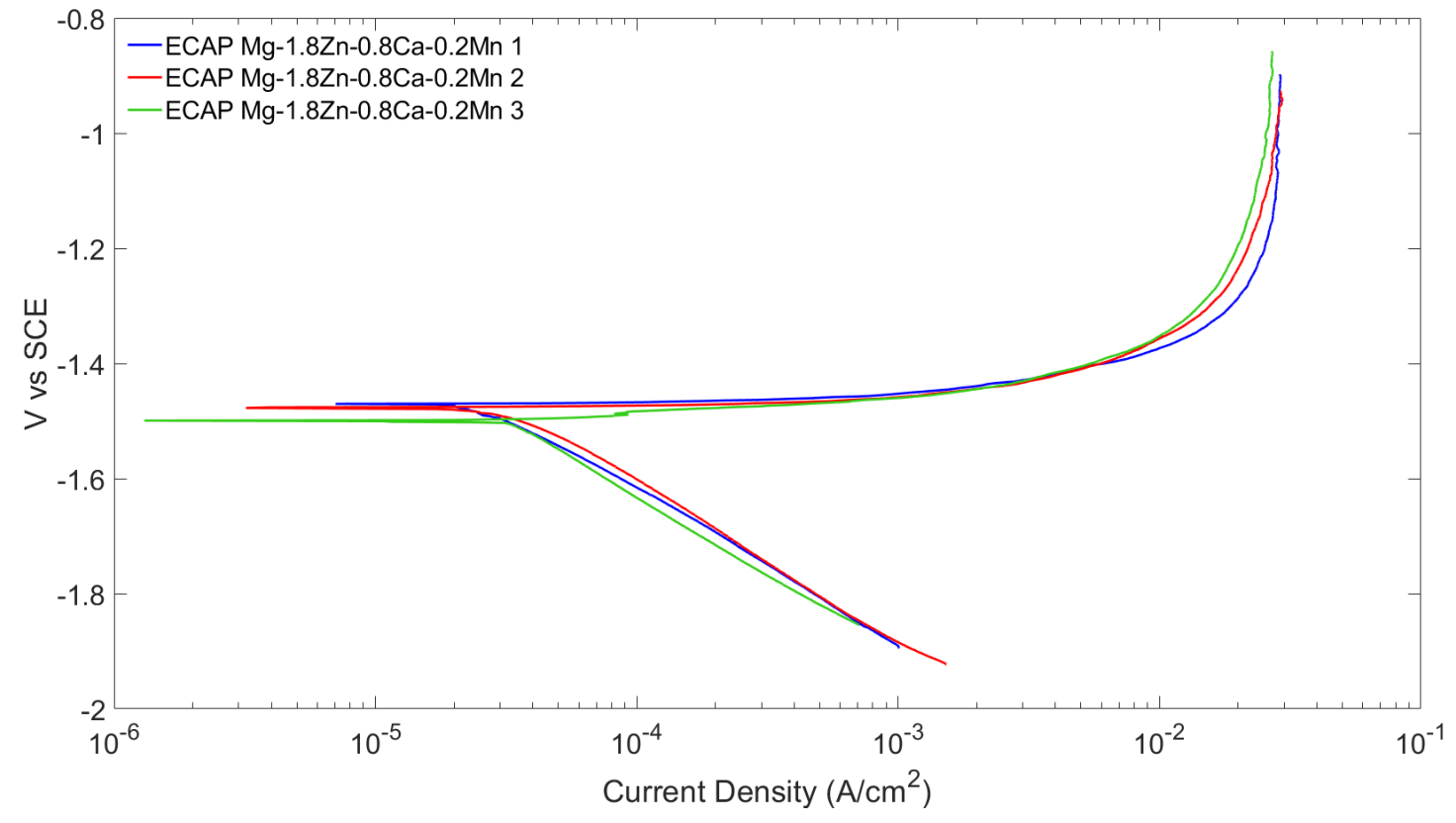

Figure 9.4. Potentiodynamic curves of the three ECAP Mg-1.8Zn-0.8Ca- $0.2 \mathrm{Mn}$ alloys tested. 


\subsection{Nyquist Plots}

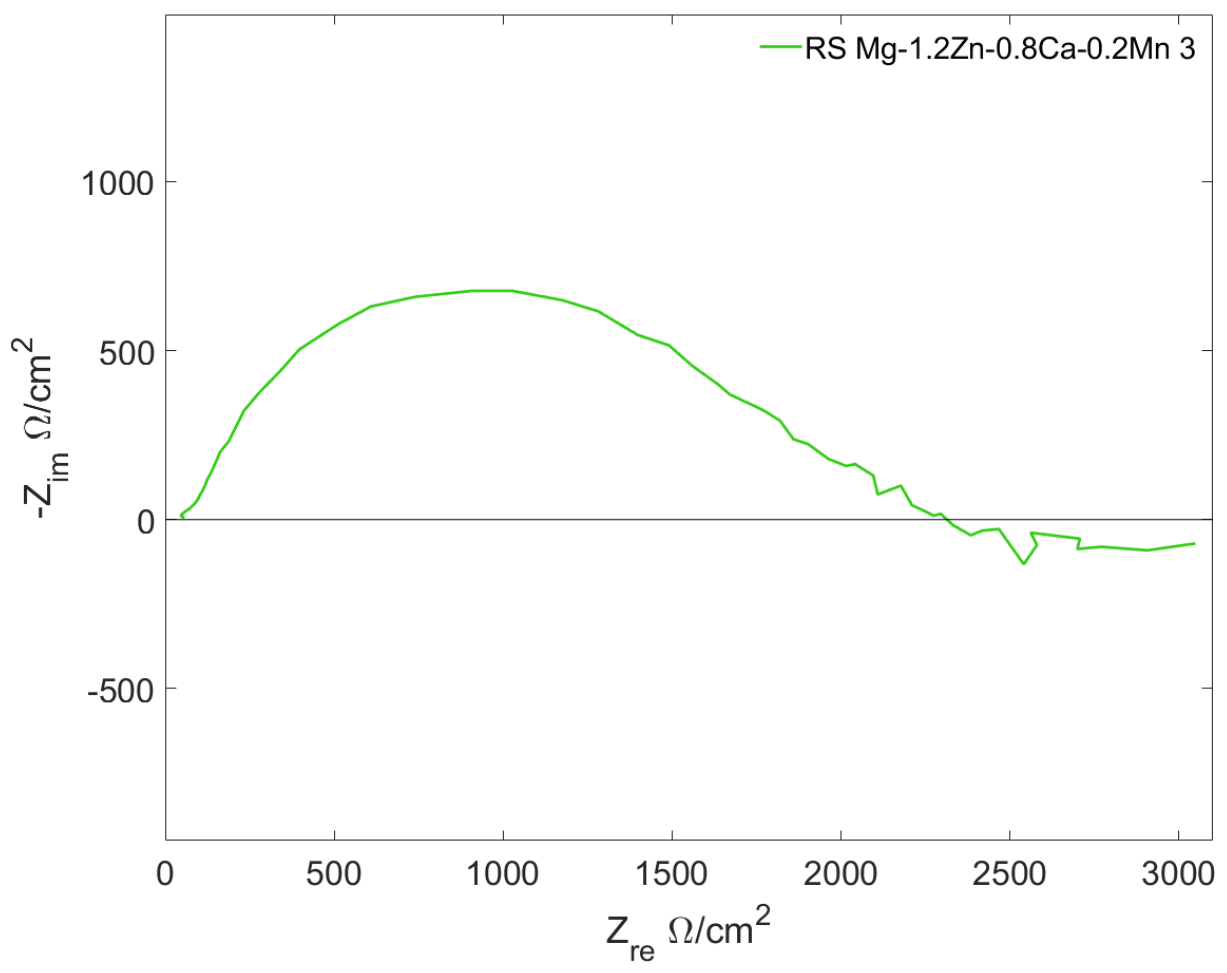

Figure 9.5. Nyquist Plot for RS Mg-1.2Zn-0.8Ca-0.2Mn.

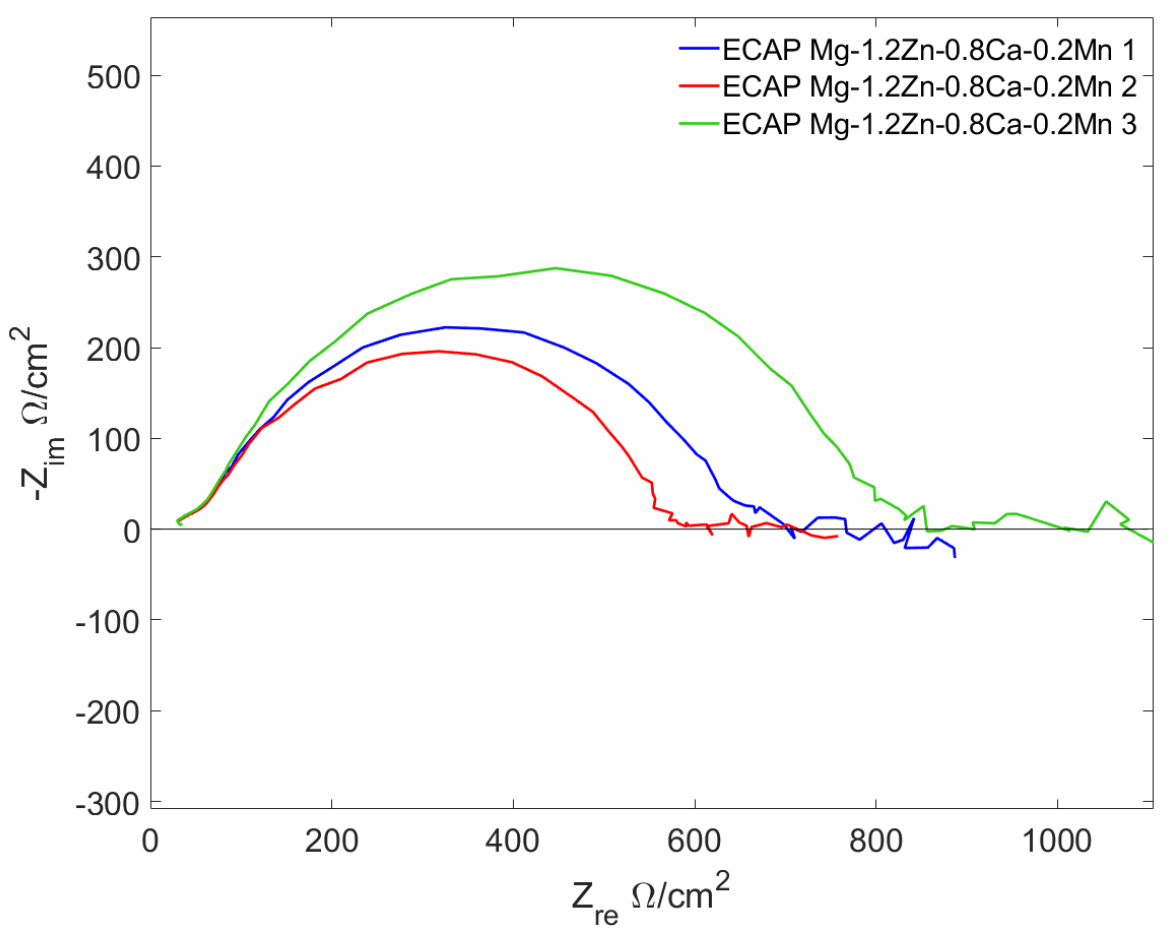

Figure 9.6. Nyquist plots for ECAP Mg-1.2Zn-0.8Ca-0.2Mn. 


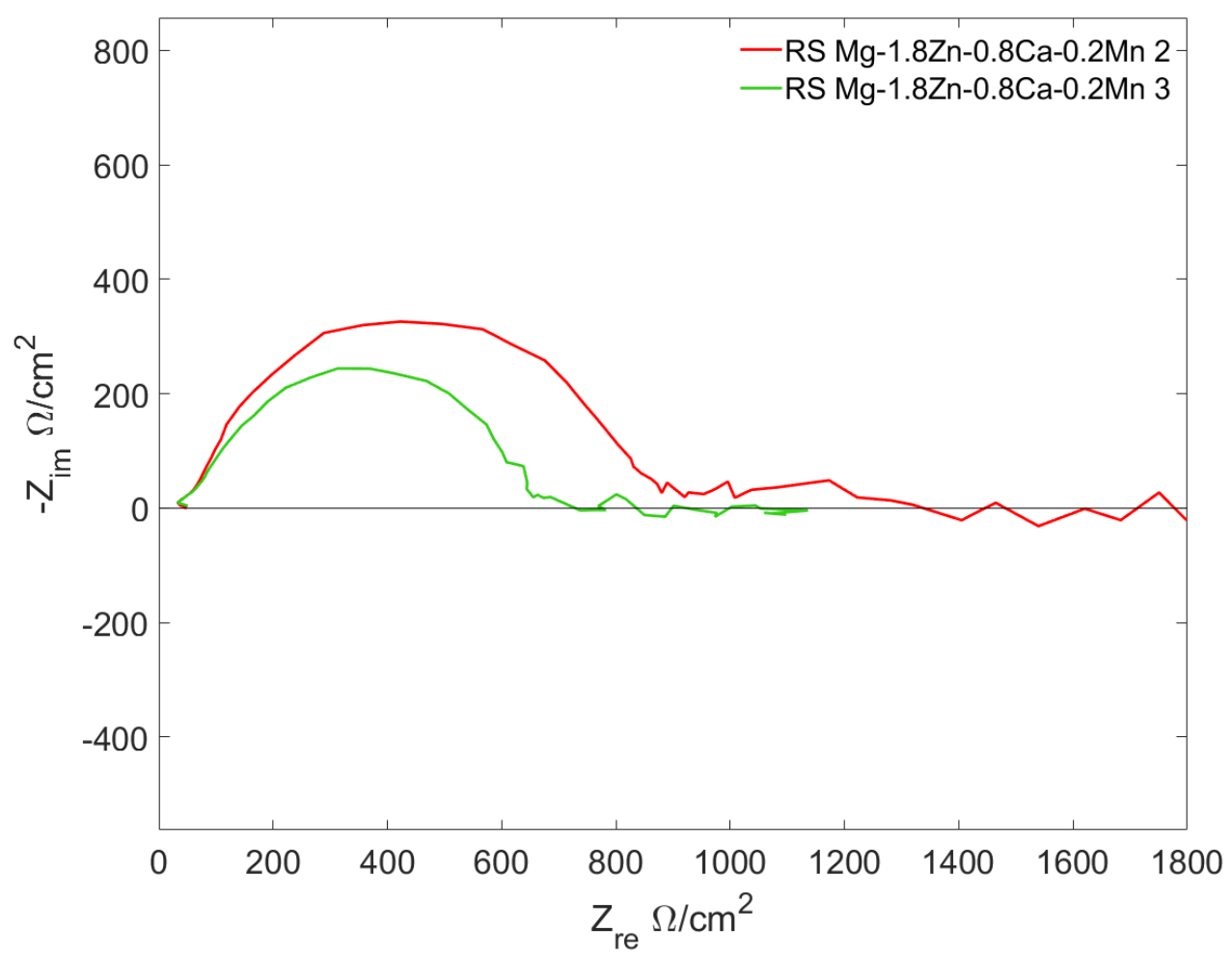

Figure 9.7. Nyquist plots for RS Mg-1.8Zn-0.8Ca-0.2Mn.

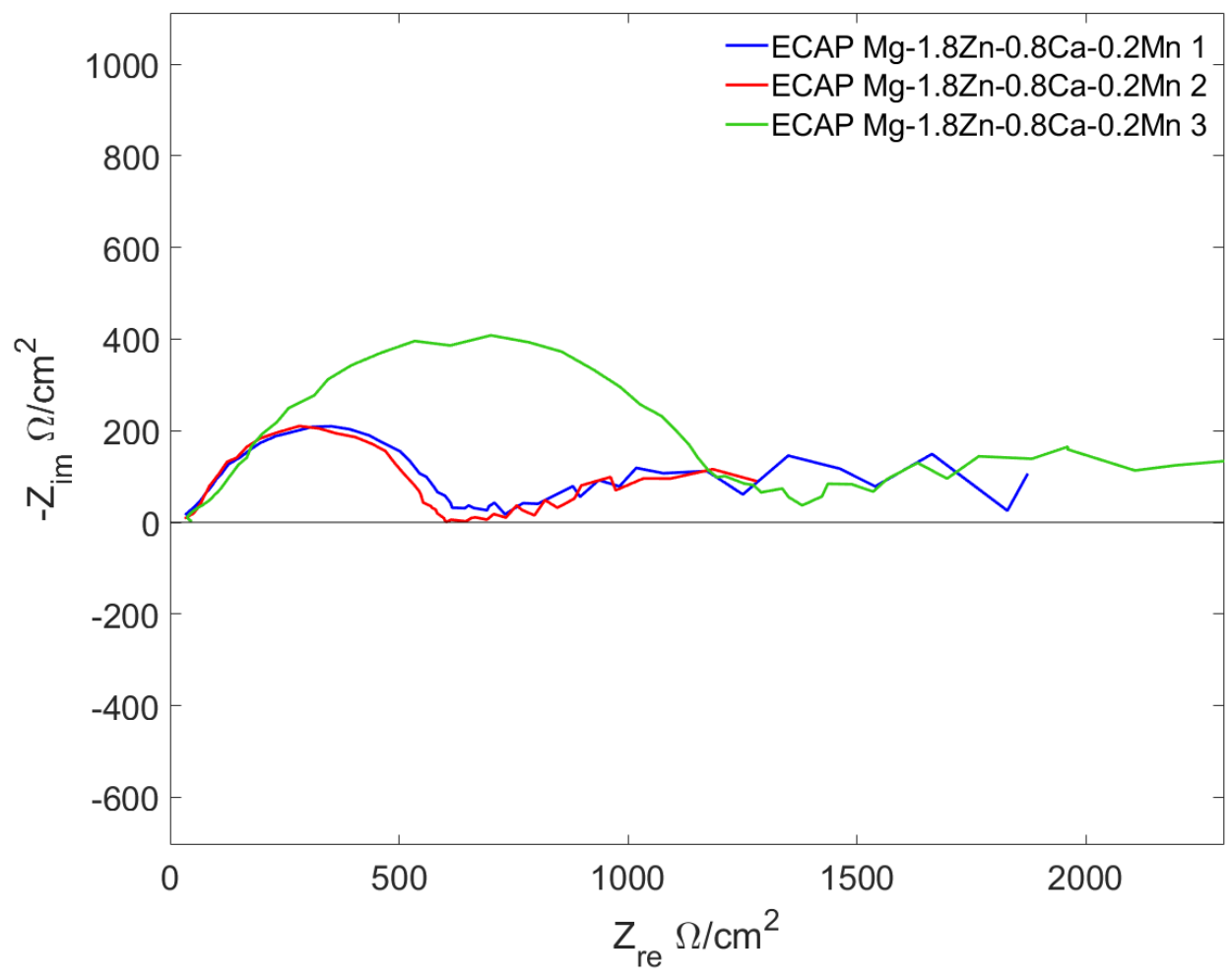

Figure 9.8. Nyquist plots for ECAP Mg-1.8Zn-0.8Ca- $0.2 \mathrm{Mn}$. 


\subsection{Bode Plots}

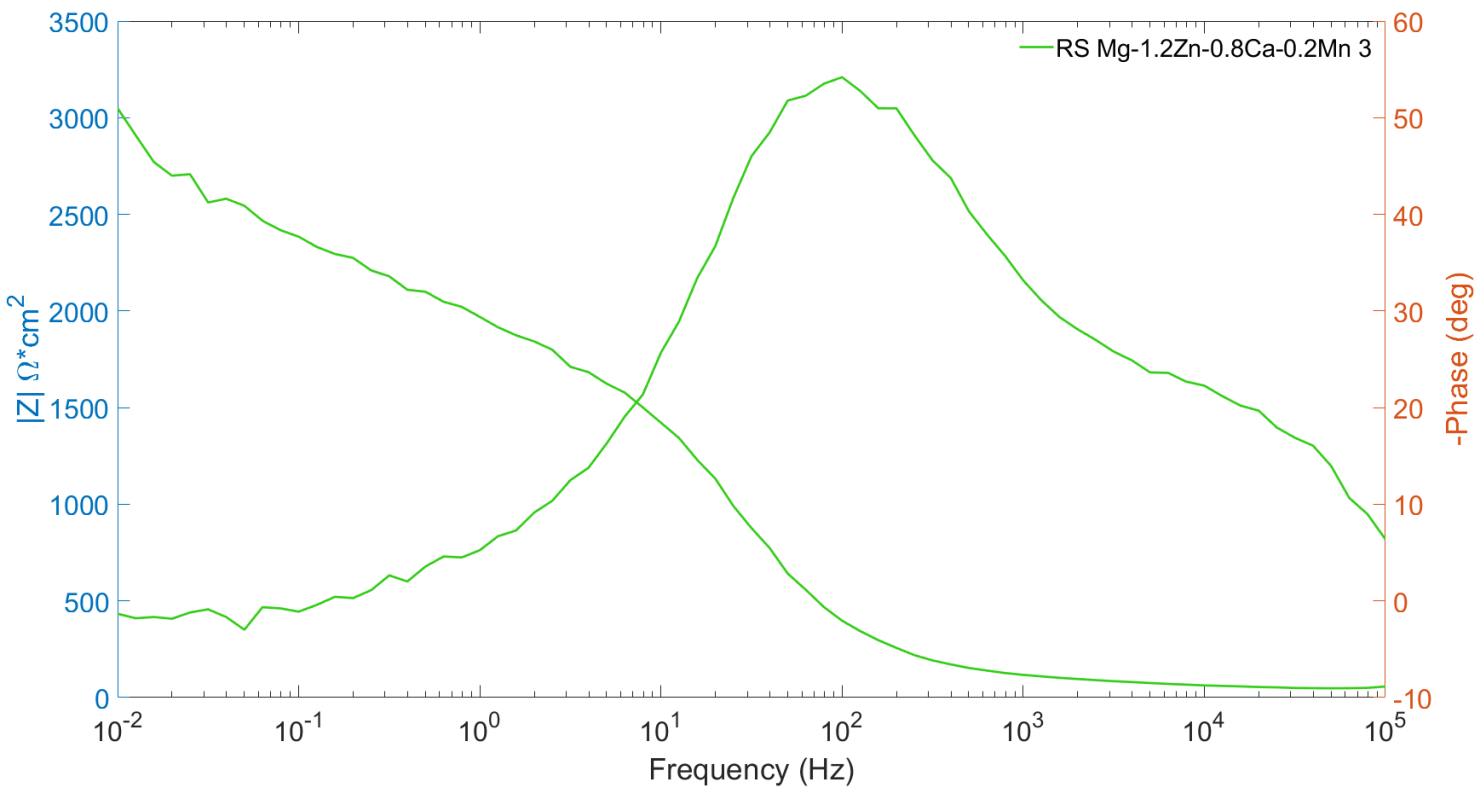

Figure 9.9. Bode plot of RS Mg-1.2Zn-0.8Ca-0.2Mn.

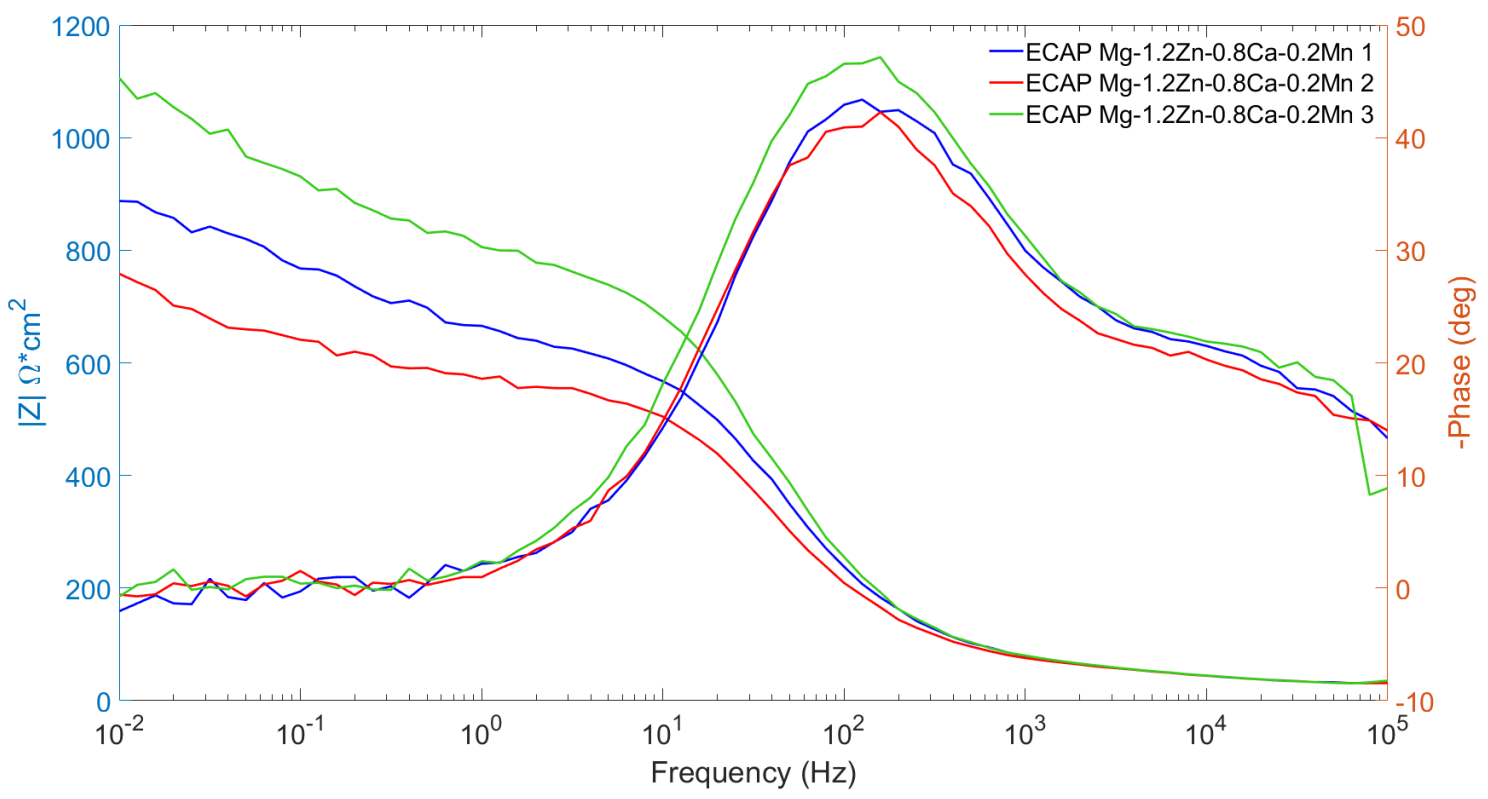

Figure 9.10. Bode plot of ECAP Mg-1.2Zn-0.8Ca-0.2Mn 


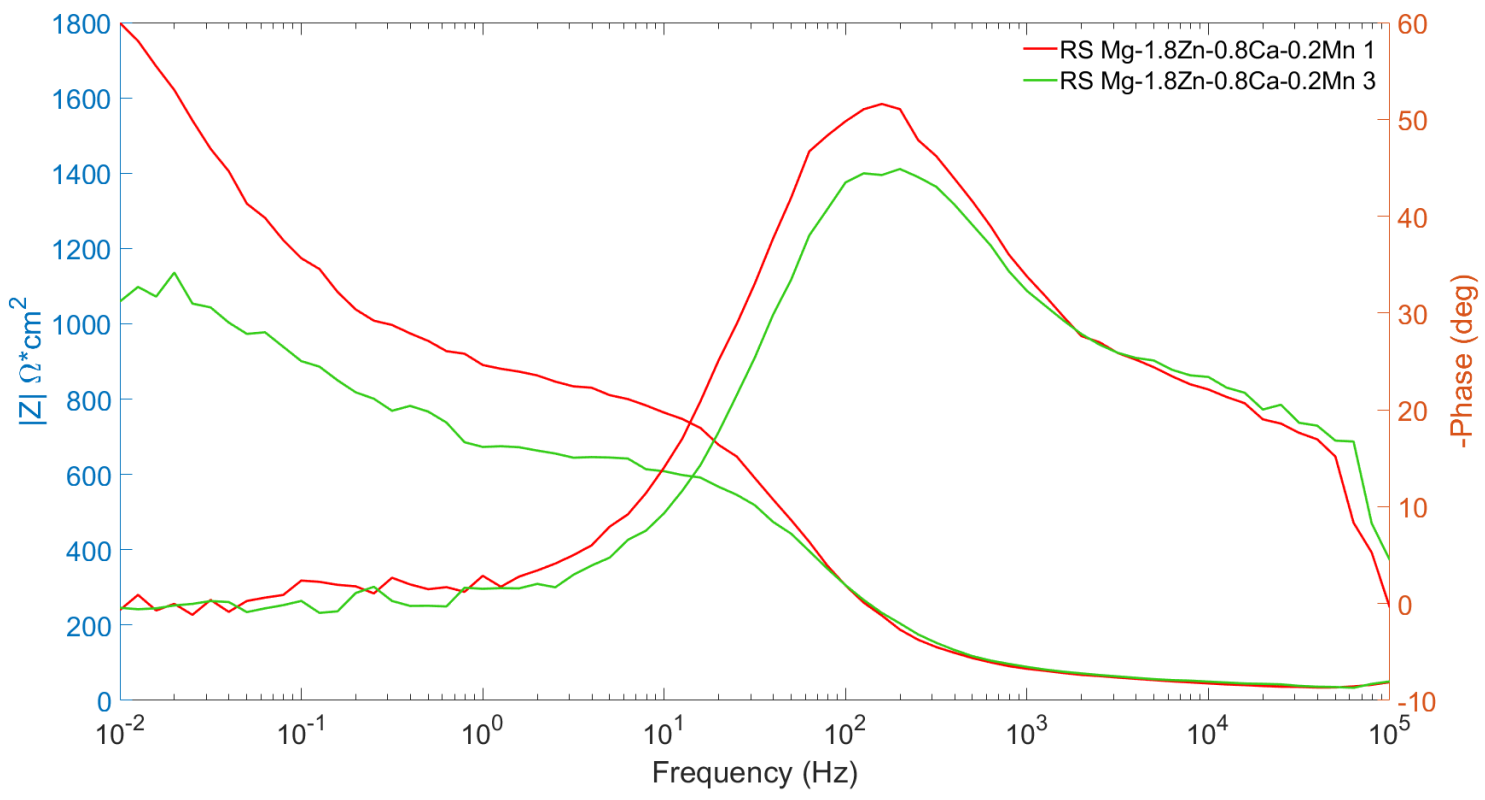

Figure 9.11. Bode plots of RS Mg-1.8Zn-0.8Ca- $0.2 \mathrm{Mn}$.

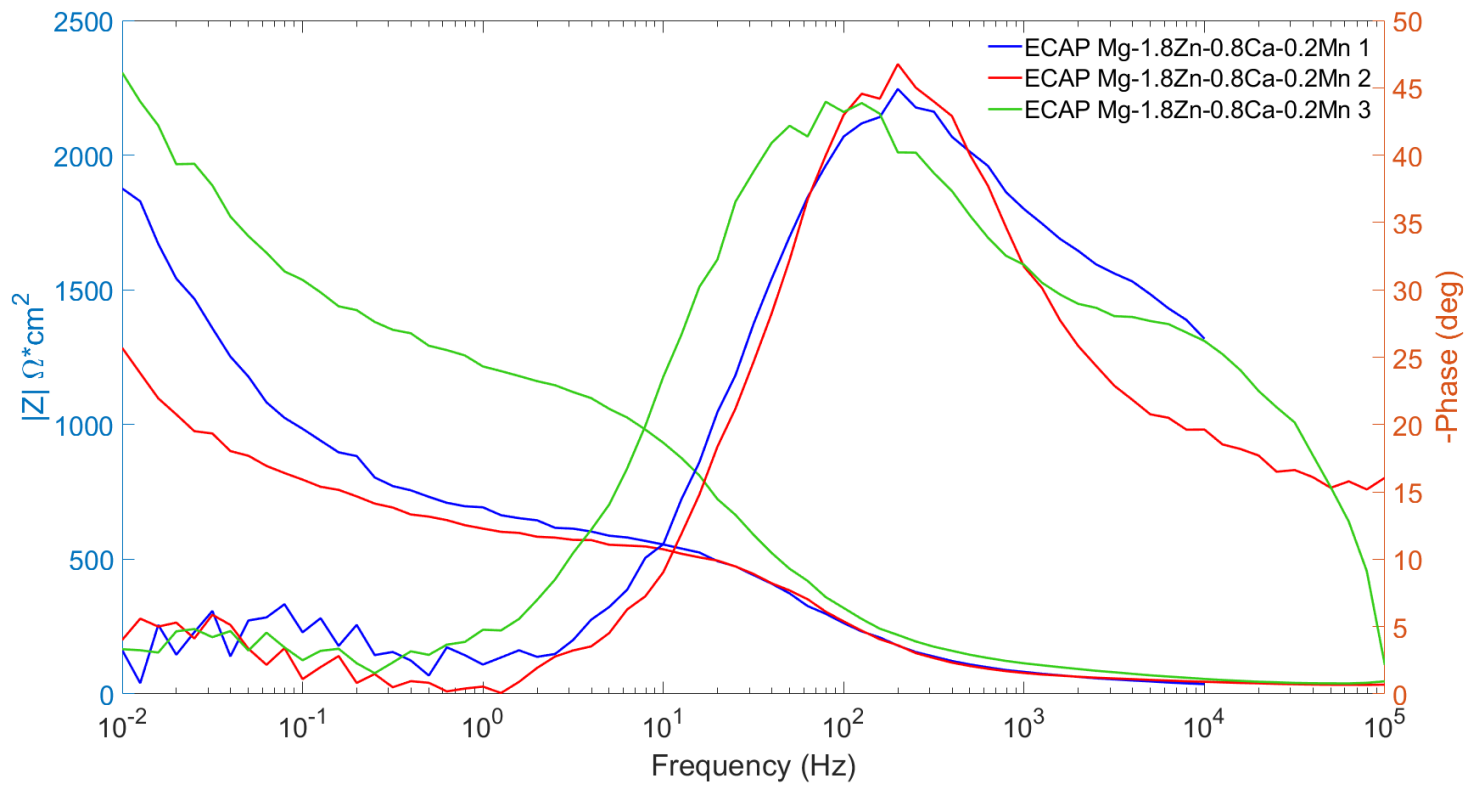

Figure 9.12. Bode plots of ECAP Mg-1.8Zn-0.8Ca-0.2Mn. 


\section{Copyright documentation}

Figure 1.1: Acquired from IStock. Tonpor Kasa.

Figure 1.2: Reprinted from Biomaterials, 112, Dewei Zhao, Frank Witte, Faqiang Lu, Jiali Wang, Junlei Li, Ling Qin Current Status on clinical applications of magnesium-based orthopaedic implants: A review from clinical translational perspective, 287-302, Copyright (2017), with permission from Elsevier."

Figure 1.6: Reprinted from Materials Science and Engineering: R: Reports, 77, Y.F. Zheng, X.N. Gu, F. Witte, Biodegradable Metals, 1-34, Copyright (2014), with permission from Elsevier" 